THREE ESSAYS ON WATER MANAGEMENT STRATEGIES

IN RESPONSE TO CLIMATE CHANGE

A Dissertation
presented to
the Faculty of the Graduate School
at the University of Missouri-Columbia
In Partial Fulfillment
of the Requirements for the Degree
Doctor of Philosophy
by
Yubing Fan
Prof. Laura McCann, Dissertation Supervisor
DECEMBER 2016


(C) Copyright by Yubing Fan 2016

All Rights Reserved 
The undersigned, appointed by the dean of the Graduate School, have examined the dissertation entitled

\section{THREE ESSAYS ON WATER MANAGEMENT STRATEGIES}

\section{IN RESPONSE TO CLIMATE CHANGE}

presented by Yubing Fan,

a candidate for the degree of doctor of philosophy,

and hereby certify that, in their opinion, it is worthy of acceptance.

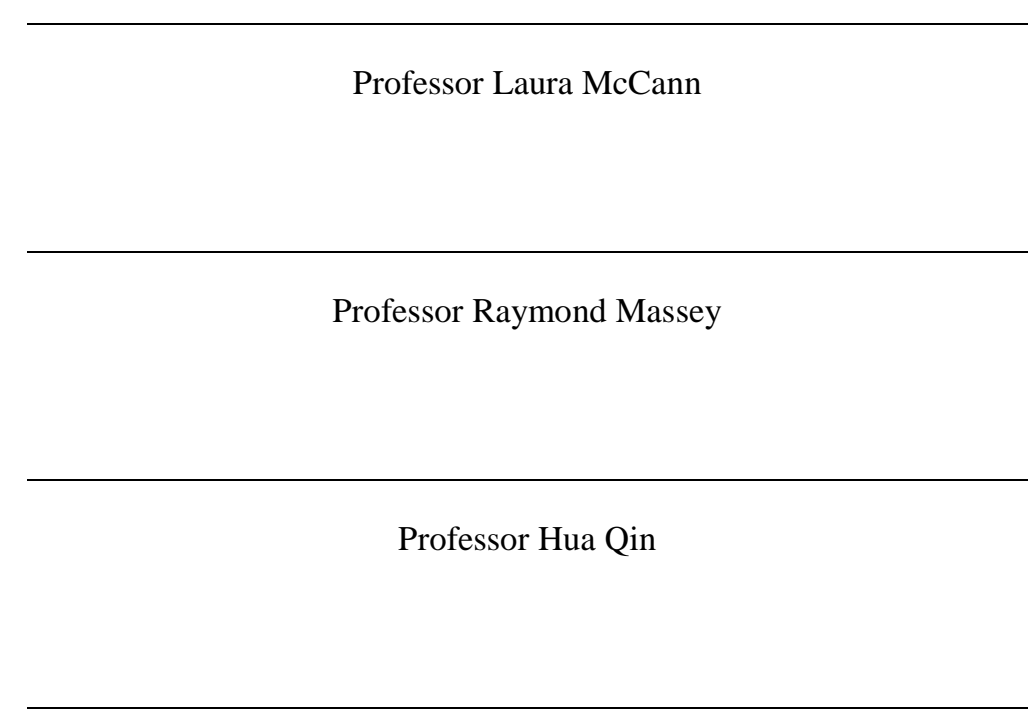

Professor Corinne Valdivia 


\section{DEDICATED TO}

My father Jinping Fan and my mother Hongjun Chen 


\section{ACKNOWLEDGEMENTS}

When I decided to study agricultural economics, I dreamed to become a good researcher and a professor some day. When I was in college, I have always been dreaming studying in the United States. With the accomplishment of the Ph.D. degree, I am much closer to my dreams. This would have been impossible, if I had not received the support from my professors, colleagues, friends, and my family.

I would like to express my sincere gratitude to my advisor Prof. Laura McCann for the continuous support of my Ph.D. study and related research, for her patience and readiness of answering my questions and discussing my research. Her guidance helped me in all the time of research and writing of this dissertation. She encouraged and supported me to present my research at conferences. She was even considerate and supportive in planning for my graduation, personal and career development. I could not have imagined having a better advisor and mentor for my Ph.D study, and I could not thank her more for all the support.

I also want to thank my committee members. I want to thank Prof. Raymond Massey for the discussions we had for my research and for his guidance to structure my dissertation. I want to thank Prof. Corinne Valdivia for her contribution in structuring the dissertation. I want to thank Prof. Hua Qin for the discussions we had on my dissertation and other research. I learned a lot in his class of natural resource management and sustainability which provided me with a better idea of conducting interdisciplinary research. 
I want to thank my colleague Dong Won Shin for designing and conducting the household survey and initially coding the data. I also learned a lot from the discussions we had on research, modeling, and job issues.

I want to thank Mr. Brad Parks for his support when I analyzed data in the USDA NASS data lab in St. Louis, Missouri. His assistance helped me better understand the complex dataset from the 2013 Farm and Ranch Irrigation Survey, analyze the data and report the results appropriately.

I would like to thank Prof. Joe Parcell and Prof. Harvey James for making it possible for me to study at Mizzou, and Ms. Jody Pestle and Ms. Johnette Blair for their assistance in the Department of Agricultural and Applied Economics. I also want to thank my other colleagues in the Department for all the assistance and discussions on research, Jasper Grashuis, Stanley Dary, Jong Yeol Yoon, Jingjing Wang, Ye Su, Lijun Chen.

I would like to thank Prof. Zhibiao Nan for all the encouragement and support for my Ph.D. study. I benefited a lot from the correspondences from Prof. Nan about research and career development. I also want to thank Prof. Chenggang Wang, Prof. Zeng Tang and other colleagues at Lanzhou University for the support and discussions on research.

My special thanks to my wife Lin Du for her great support, encouragement and sacrifices. It is very hard for her to come to a small town while not studying in any program. She was taking care of our daughter while I was very busy in my third year 
of the $\mathrm{Ph} . \mathrm{D}$. program. I also want to thank my wife's parents for taking care of my daughter since she was born. With all of the supports and sacrifices from them, it is possible for me to concentrate on my course work and research.

Special thanks also to my parents and my brother. My parents are very supportive when I am working on my Ph.D. My brother takes care of them well, so I can concentrate on my study in US.

The research was supported by the USDA National Integrated Water Quality Grant Program number 110.C (Award 2012-03652) and by USDA Multi-state Grant W-3190 Management and Policy Challenges in a Water-Scarce World. 


\section{TABLE OF CONTENTS}

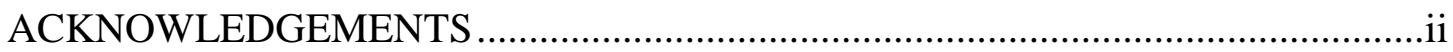

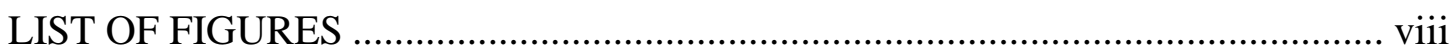

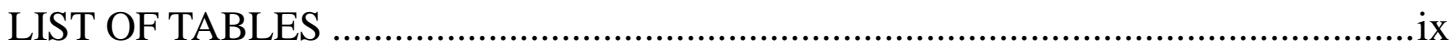

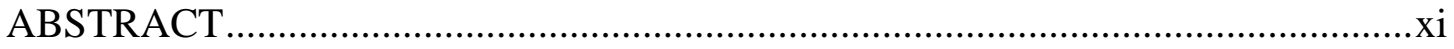

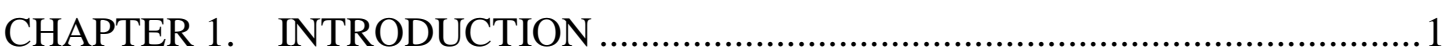

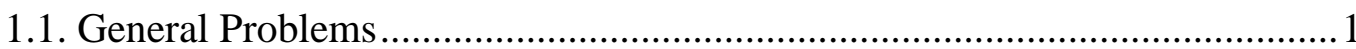

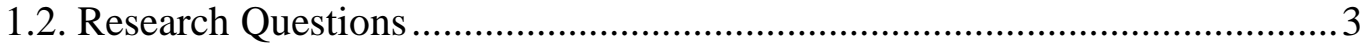

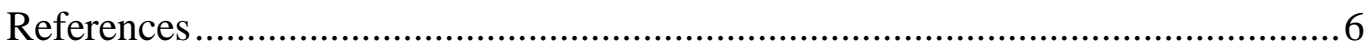

CHAPTER 2. HOUSEHOLDS'ADOPTION OF DROUGHT TOLERANT PLANTS: AN ADAPTATION TO CLIMATE CHANGE? ..........................................

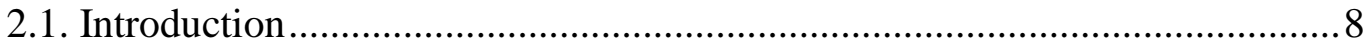

2.2. Adaptation and Households' Water Conservation Practices ......................... 10

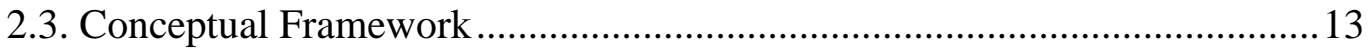

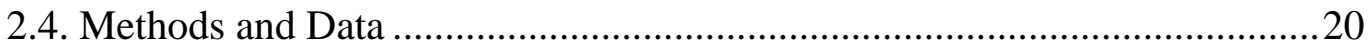

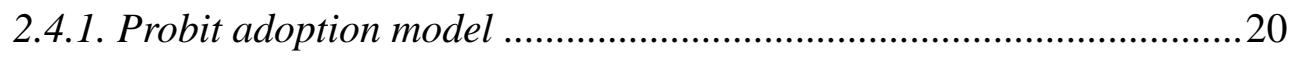

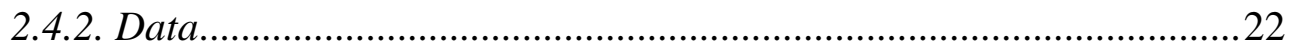

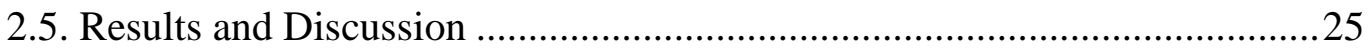

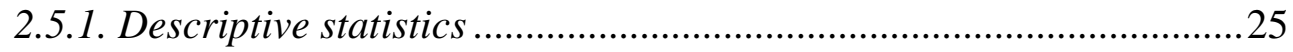

2.5.2. Comparison of adopters and non-adopters ....................................29

2.5.3. Regression results and discussion ....................................................2 29

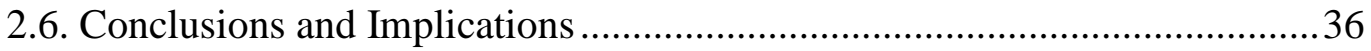

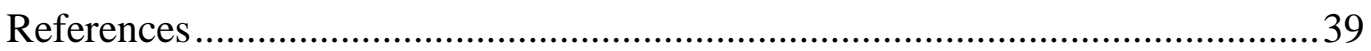

CHAPTER 3. FARMERS' IRRIGATION DECISIONS AND ADOPTION OF PRESSURE IRRIGATION AND SCIENTIFIC SHEDULING PRACTICES ...........45

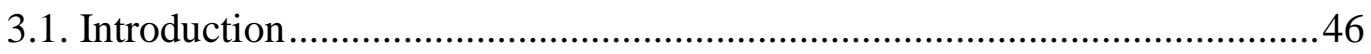

3.2. Literature Review on Farmers' Water Conservation Practices .....................48 


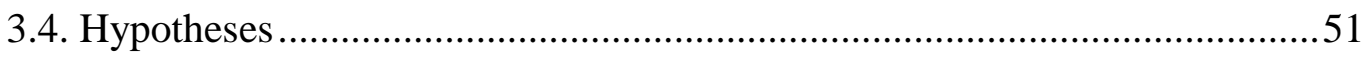

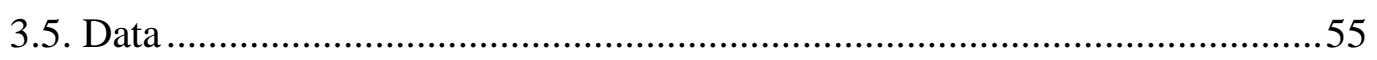

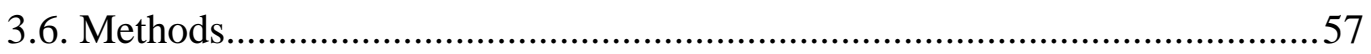

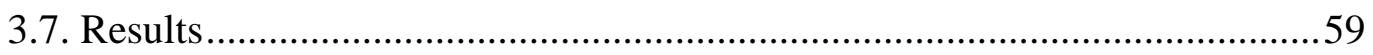

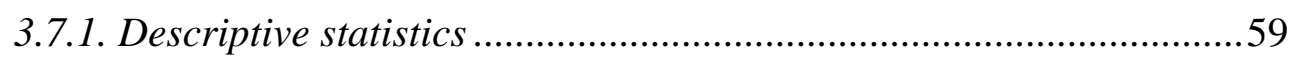

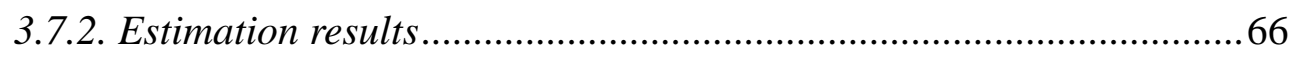

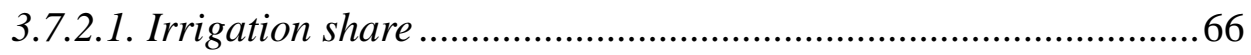

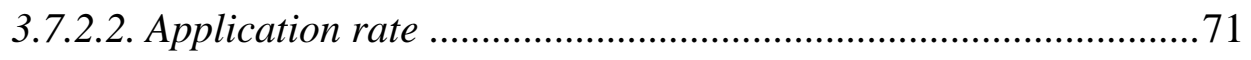

3.7.2.3. Crop-specific adoption of pressure irrigation systems and scientific scheduling practices ........................................................... 75

3.7.2.3.1. Pressure irrigation systems ............................................... 76

3.7.2.3.2. Adoption of scientific irrigation scheduling practices......... 82

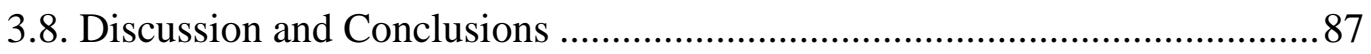

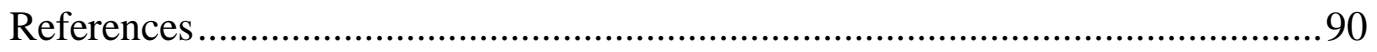

CHAPTER 4. MULTICROP PRODUCTION DECISIONS AND CROP IRRIGATION WATER USE EFFICIENCY: EFFECTS OF WATER PRICE, PRESSURE IRRIGATION ADOPTION AND CLIMATIC DETERMINANTS .......96

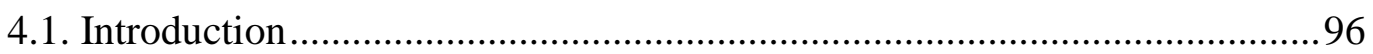

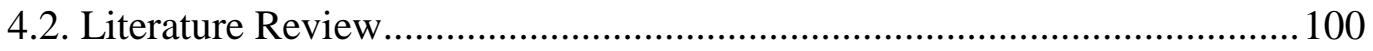

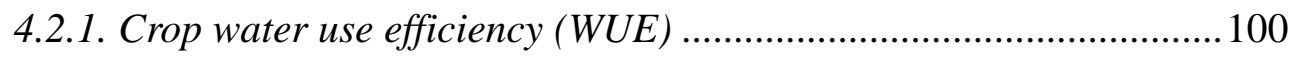

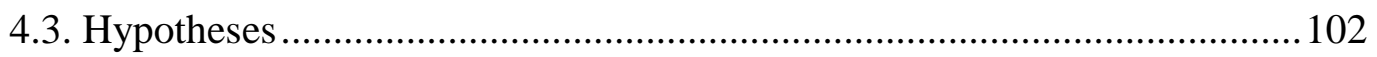

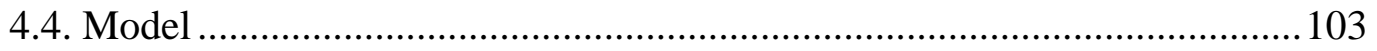

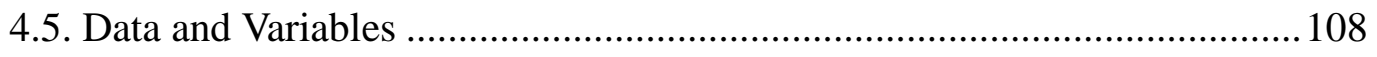

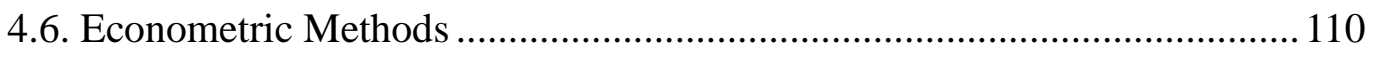

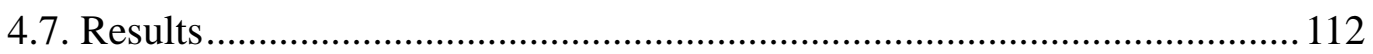

4.7.1. Decomposition of farm-level water demand ................................... 112

4.7.2. Intraclass correlation coefficients from MLMs.............................. 113

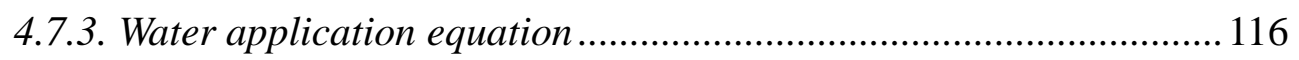

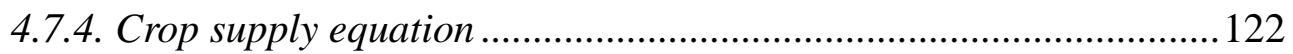




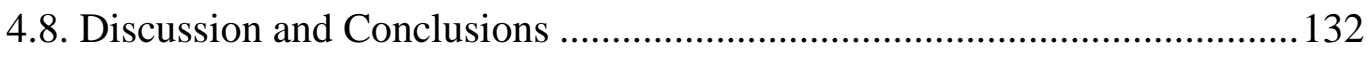

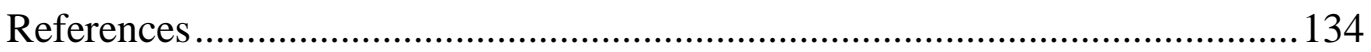

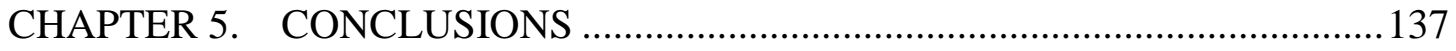

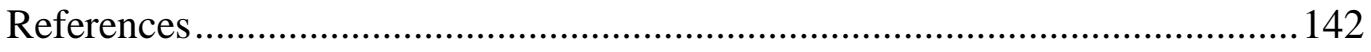

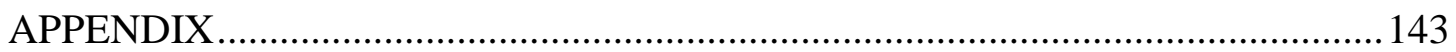

A. Additional tables on summary statistics and results for chapter 3 and 4 ..... 143

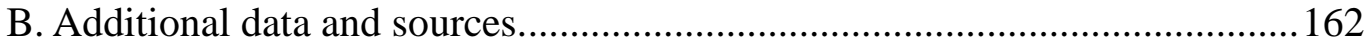

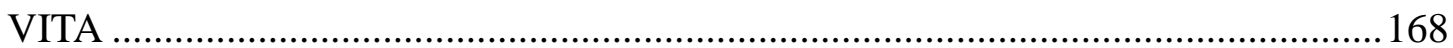




\section{LIST OF FIGURES}

Figure

Page

1.1. Climate change and responses by households and farmers..................2

2.1. Expected utility model and households' adoption of drought tolerant plants...14

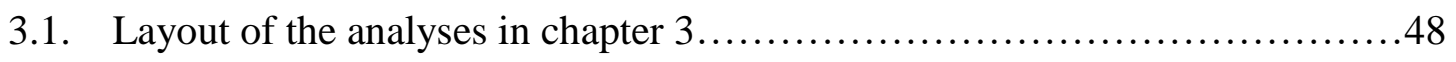

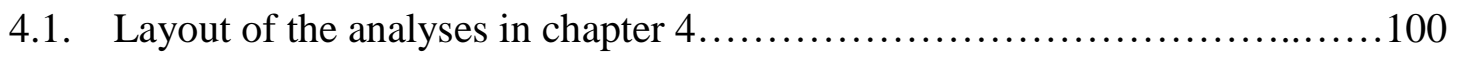




\section{LIST OF TABLES}

Table

Page

2.1. Independent variables and definitions................................. 19

2.2. Comparison of sample to Census data.................................26

2.3. Summary statistics and characteristics of adopters and non-adopters of DTPs (N

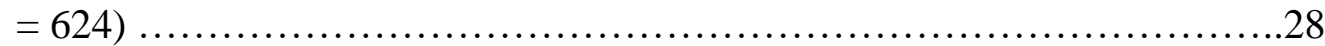

2.4. Results of probit regression for the adoption of drought tolerant plants.........33

3.1. Summary statistics of farm-level independent variables $(\mathrm{N}=19,272)$..........61

3.2. Summary statistics of farm-level and crop-specific dependent variables and state-level independent variables ....................................65

3.3. Results for irrigation share equation................................68

3.4. Results for water application rate equation............................ 73

3.5. Results of multilevel models for the adoption of pressure irrigation systems by

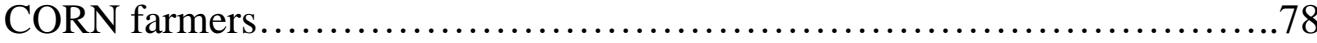

3.6. Results of multilevel models for the adoption of pressure irrigation systems by SOYBEAN farmers.

3.7. Results of multilevel models for the adoption of scientific irrigation scheduling practices by CORN farmers...........................................83

3.8. Results of multilevel models for the adoption of scientific irrigation scheduling practices by SOYBEAN farmers

4.1. Summary statistics of dependent variables: irrigated farms, mean farming area, mean water use, mean yield and water use efficiency. 109

4.2. Crop-specific extensive and intensive margins to water cost. .115

4.3. Intraclass correlation coefficients (ICC) for null models of each crop-specific multilevel model.

4.4. Results of multilevel models for mean water application for CORN farms...118

4.5. Results of multilevel models for mean water applied on SOYBEAN farms...120 
4.6. Results of multilevel models for mean yield of CORN farms..............123

4.7. Results of multilevel models for mean yield of SOYBEAN farms...........125

4.8. Results of multilevel models for economics irrigation water use efficiency (EIWUE) of CORN farms........................................... 128

4.9. Results of multilevel models for economics irrigation water use efficiency (EIWUE) of SOYBEAN farms.....................................130 


\title{
THREE ESSAYS ON WATER MANAGEMENT STRATEGIES IN RESPONSE TO CLIMATE CHANGE
}

Yubing Fan

Prof. Laura McCann, Dissertation Supervisor

\begin{abstract}
Due to climate change, the amount of rainfall, and its uneven temporal and spatial distribution, affect water availability. As a result, both households and farmers need to adapt to climate change by taking appropriate actions. This dissertation incorporates insights from scholarship on both adaptation to climate change and innovation adoption. For residents, adopting drought tolerant plants (DTPs) to conserve water use is a potential adaptation to the predicted effects of climate change. Survey responses from 624 households in Missouri are analyzed using a univariate probit model. DTPs adoption is positively correlated with both low and high household incomes, homeownership, living in rural subdivisions, mowing lawns high, time spent on yardwork, pro-environmental attitudes, and concerns about droughts. Policy interventions might include subsidizing the purchase of DTPs, requirements for use of DTPs in new housing developments, and targeted educational efforts.

To encourage farmers to conserve water and use water more efficiently, understanding their decision-making on adoption of enhanced irrigation systems and scientific scheduling practices is essential. Using data from the national 2013 Farm and Ranch Irrigation Survey (FRIS) conducted by USDA, this dissertation employs a mixed and multilevel approach to analyze both land- and crop-specific irrigation decisions. Three land-level equations on irrigation share, irrigation application rate,
\end{abstract}


and harvest share are estimated. Results show that irrigation share, application rate and harvest share are associated with variables related to water costs, farm size, irrigation systems, barriers to improvements, information sources, etc. In addition, the adoption decisions are analyzed focusing on corn and soybean farms using multilevel models (MLMs) as they can better deal with the farm-level data embedded in states. Application of MLMs to the analysis of farmers' adoption provides new insights on the proportion of variability in each response accounted for by farm- versus state-level factors. The results suggest that, while adoption is affected by land areas, off-farm surface water, various barriers and information sources, the variability of pressure irrigation adoption is mainly accounted for by factors at the state level, while the adoption of scientific scheduling practices is mainly accounted for by farm-level variation. Controlling for farm-level factors, farmers in areas with drought conditions in 2012, i.e., lower than average rainfall and higher than average temperatures, are more likely to have adopted pressure irrigation systems and scientific scheduling practices by 2013 .

In addition, sustainability of water resources requires producers to take account of marginal user costs when making production decisions. Adoption of enhanced irrigation systems and higher water cost can achieve potential improvements in irrigation water use efficiency. In a multicrop production system with irrigation, farmers make decisions about land allocated to each crop, irrigation water application, and their decisions, along with growing conditions, determine crop supply. This dissertation also analyses water application to multiple crops at the farm level and the effects of influential factors on irrigation water use efficiency of specific crops. As MLMs permit the incorporation of state-level variables, they are further applied in analyzing the multicrop production decisions and irrigation water use efficiency. The 
results show higher water price encourages efficient water use. Moreover, adoption of pressure irrigation systems could reduce soybean water use or increase corn yield. Adoption of pressure irrigation increases the economic irrigation water use efficiency on soybean farms. The findings from MLMs show that variables representing deviations from 30 year state average climate conditions in 2012 and 2013 have fairly consistent effects. Climate risks and higher temperatures promote more efficient water use and higher yields. Higher precipitation is correlated with lower water application and higher crop yield. Federal programs and policy should not only target specific barriers and increase the effectiveness of incentives at the farm level, but also address differing priorities in each state. Implications from these analyses should benefit future policy design and improve education programs. 


\section{CHAPTER 1. INTRODUCTION}

\subsection{General Problems}

Climate change presents clear risks to natural resource systems including water resources. Potential impacts of climate change include increased frequency and magnitude of droughts and floods. The amount of rainfall and its uneven temporal and spatial distribution affect water availability (Fischer et al., 2007). Areas in the Western and Midwestern United States are facing water shortages induced by droughts as well as potentially higher evaporation due to higher temperatures in recent years (Sinha and Cherkauer, 2010; Wuebbles and Hayhoe, 2004). Homeowners have to irrigate more to prevent lawns and gardens from dying, or plant more drought-tolerant species. At the same time large losses occurred in agricultural production due to the drought in 2012, and farmers have to increasingly irrigate crops to relieve the impacts of drought (Balling and Gober, 2007). In addition to the short-term variation in water resources, climate change may also affect their long-term availability in many regions (Ma et al., 2008). Thus, both residential and agricultural irrigation are restricted by water availability, and adaptation to climate change is of fundamental significance. As defined by Adger et al. (2005): p.78), adaptation to climate change is:

"an adjustment in ecological, social or economic systems in response to observed or expected changes in climatic stimuli and their effects and impacts in order to alleviate adverse impacts of change or take advantage of new opportunities. Adaptation can involve both building adaptive capacity thereby increasing the ability of individuals, groups, or organizations to adapt to changes, and implementing adaptation decisions, i.e. transforming that capacity into action. 
Both dimensions of adaptation can be implemented in preparation for or in response to impacts generated by a changing climate."

As shown in figure 1.1, the objective of this dissertation is to study the adaptation capacity and specific actions by households and farmers in response to climate change. Facing short-term variation and long-term availability of water resources, one of major strategies for residents to improve their adaptive capacity is to reduce water use. Many practices have been proposed and some have been implemented by households in some Western states, e.g., California. Drought tolerant plants (DTPs) have been adopted to deal with regional water constraints in some urban areas. In agriculture, farmers might want to reduce the total amount of irrigation water and/or increase crop irrigation water use efficiency (WUE). Common practices adopted by U.S. farmers include micro irrigation systems (MISs), for instance, drip irrigation or sprinklers, as well as scientific irrigation scheduling practices (SISs),

Figure 1.1. Climate change and responses by households and farmers.

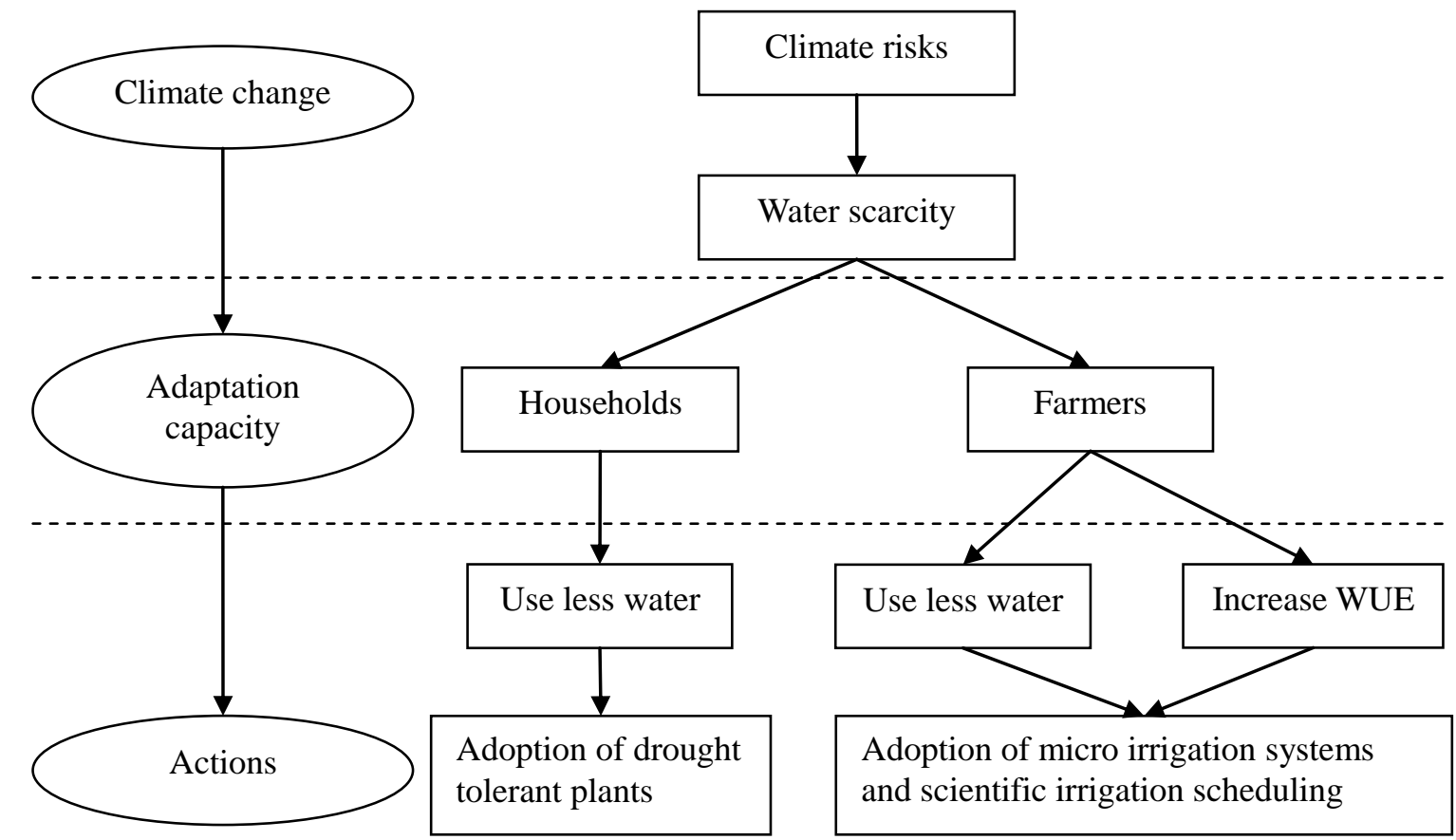


such as soil moisture-sensing devices, irrigation scheduling services, etc. Appropriate irrigation scheduling and other information technologies could improve farmers' decision-making regarding when and how much to irrigate.

\subsection{Research Questions}

Complexities and uncertainties go along with climate change, which complicates water resource sustainability and potentially necessitates adaptive actions by water users. Drought adaptation has fundamental significance for sustainable use of water resources. Adaptation to climate change requires efforts from both residents and farmers. For the resident component, I will focus on the adoption of drought tolerant plants. Residential yards take $50-90 \%$ of the total household water consumption and the majority of the water is used to irrigate turf grasses (Nautiyal et al., 2015). Residential landscapes are complex adaptive systems, which are of fundamental significance when looking at adaptation strategies in urbanizing watersheds. Reasonable landscape management could ease the limitation of water availability and better prepare homeowners to cope with potential climate risks in the future (Hurd, 2006). In addition, interacting with social and environmental systems, as well as perceptions of climate risks and water scarcity, households could adjust their behaviors in response to these interactions. Analysis of the determinants influencing the adoption behaviors can inform policy design to facilitate adaptation to climate change.

For the farmer component, I will focus on the adoption of micro irrigation systems and scientific irrigation scheduling. Adoption of these irrigation systems and scheduling technologies and services requires financial investments and professional knowledge (Frisvold and Deva, 2012; Rodriguez et al., 2009). However, to the best of my knowledge, factors affecting their adoption, including the potential role of third 
party information providers, are understudied. In addition, this study evaluates and compares the irrigation water use efficiency of two major crops: corn and soybeans. Irrigation water use efficiency is defined as the amount of grain yield per unit of irrigation water applied (George et al., 2000). Economic irrigation water use efficiency incorporates output price and is defined as the value of grain yield per unit of irrigation water applied (Dalton et al., 2001). The irrigation expenses (input costs) include expenditures for irrigation facilities and equipment, energy expense for pumping, labor payments, and water cost, if any. Enhanced irrigation methods have been applied primarily to save water and improve irrigation efficiencies according to previous studies that conducted field experiments and analysis using field level data. Using the farm level data from the 2013 USDA Farm and Ranch Irrigation Survey (FRIS), I explore whether enhanced irrigation methods improve farm irrigation efficiencies and whether there is any association between farm characteristics and irrigation efficiencies, as well as between input use and irrigation efficiencies.

In the three essays of this dissertation, I try to answer three sets of questions:

1) How do residents respond to local climate risks; what are the factors that affect residential adoption of drought tolerant plants; and what are the effects of the factors?

2) What are the major barriers to adoption of enhanced farm irrigation technologies and scientific irrigation scheduling practices in the U.S., and what information is needed to overcome those barriers?

3) Do enhanced irrigation methods increase irrigation efficiency; do farmers of major crops use irrigation water efficiently? 
The rest of this dissertation is structured as follows:

Chapter 2 is essay I, households' adoption of drought tolerant plants, in which the influential factors are identified and their effects on the homeowners' adoption behavior are studied.

Chapter 3 is essay II, farmers' adoption of enhanced irrigation systems and scientific irrigation scheduling, in which I study use of various irrigation information sources to overcome barriers to adoption, as well as the effects of perceived barriers and information sources on farmers' adoption behaviors.

Chapter 4 is essay III, evaluation of crop irrigation efficiency, in which I study the farm-level water use efficiency for irrigated crops, as well as the effects of water use, climate risks, etc. on efficiency.

Chapter 5 concludes the dissertation. 


\section{References}

Adger, W.N., Arnell, N.W., Tompkins, E.L., 2005. Successful adaptation to climate change across scales. Global Environmental Change. 15, 77-86.

Balling, R.C., Gober, P., 2007. Climate variability and residential water use in the city of Phoenix, Arizona. Journal of Applied Meteorology and Climatology. 46, 1130-1137.

Dalton, P., Raine, S., Broadfoot, K., 2001. Best management practice for maximising whole farm irrigation efficiency in the Australian cotton industry. Final Report for CRDC Project NEC2C, Retrieved from: http://www.insidecotton.com/xmlui/handle/1/3535.

Fischer, G., Tubiello, F.N., van Velthuizen, H., Wiberg, D.A., 2007. Climate change impacts on irrigation water requirements: Effects of mitigation, 1990-2080. Technological Forecasting and Social Change. 74, 1083-1107.

Frisvold, G.B., Deva, S., 2012. Farm size, irrigation practices, and conservation program participation in the US Southwest. Irrigation and Drainage. 61, $569-582$.

George, B.A., Shende, S.A., Raghuwanshi, N.S., 2000. Development and testing of an irrigation scheduling model. Agricultural Water Management. 46, 121-136.

Hurd, B.H., 2006. Water conservation and residential landscapes: Household preferences, household choices. Journal of Agricultural and Resource Economics. 31, 173-192.

Ma, Z., Kang, S., Zhang, L., Tong, L., Su, X., 2008. Analysis of impacts of climate variability and human activity on streamflow for a river basin in arid region of northwest China. Journal of Hydrology. 352, 239-249.

Nautiyal, M., Grabow, G., Huffman, R., Miller, G., Bowman, D., 2015. Residential irrigation water use in the Central Piedmont of North Carolina. II: Evaluation of smart irrigation technologies. Journal of Irrigation and Drainage Engineering. 141, 04014062.

Rodriguez, J.M., Molnar, J.J., Fazio, R.A., Sydnor, E., Lowe, M.J., 2009. Barriers to adoption of sustainable agriculture practices: Change agent perspectives. Renewable Agriculture and Food Systems. 24, 60-71.

Sinha, T., Cherkauer, K.A., 2010. Impacts of future climate change on soil frost in the midwestern United States. Journal of Geophysical Research: Atmospheres (1984-2012). 115. 
Wuebbles, D.J., Hayhoe, K., 2004. Climate change projections for the United States Midwest. Mitigation and Adaptation Strategies for Global Change. 9, 335-363. 


\section{CHAPTER 2. HOUSEHOLDS' ADOPTION OF DROUGHT TOLERANT PLANTS: AN ADAPTATION TO CLIMATE CHANGE?}

Households in the Midwest will face increased variation in rainfall, including more frequent droughts. Adopting drought tolerant plants (DTPs) to conserve water use is a potential adaptation to the predicted effects of climate change. Survey responses from 624 households in Missouri were analyzed with a univariate probit model. DTPs adoption was positively correlated with both low and high household incomes, homeownership, living in rural subdivisions, mowing lawns high, time spent on yardwork, pro-environmental attitudes, and concerns about droughts. Policy interventions might include subsidizing the purchase of DTPs, requirements for use of DTPs in new housing developments, and targeted educational efforts.

\subsection{Introduction}

In many regions, climate change will not only manifest itself as gradual changes in average conditions, but changes will likely occur in the frequency and intensity of extreme events (Angel and Huff, 1997; Arnell, 1999; IPCC, 2014; Sinha and Cherkauer, 2010). Typically, the Midwest received enough rainfall for both crops and urban landscapes, but it is increasingly threatened by droughts along with most other regions of the U.S. Studies at various scales have reported that hotter summers with longer dry periods and milder, wetter winters will be more likely to occur in the Midwest (Arnell, 1999; EPA, 2014; Murray, Foster, and Prentice, 2012; Sinha and Cherkauer, 2010). For example, a severe drought occurred in the Midwest in 2012; Missouri received 31 inches of rainfall versus the average 43 inches. The potential impacts of these changes on water resources are likely to increase in magnitude, diversity and severity in future decades (IPCC, 2014). 
Household-level adaptation to climatic threats can contribute to increasing the resilience and flexibility of interacting physical and social systems (Qin et al., 2015; Wamsler and Brink, 2014). More specifically, adaptation to drought enables sustainable use of water resources and reduced irrigation costs, so analysis of its determinants can inform policy design to facilitate this process.

Households can adopt different strategies to respond to limited or costly water resources, one of which is to appropriately manage residential landscapes (Martin,

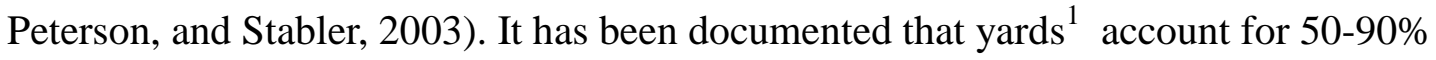
of household water consumption and the majority of the water is used to irrigate lawns (Hurd, Hilaire, and White, 2006; Sovocool, Morgan, and Bennett, 2006). Adoption of drought tolerant plants (DTPs) is thus expected to be a promising strategy to deal with changing water availability induced by climate change. Residential landscapes with more DTPs can reduce the costs of yard irrigation, maintenance, etc. and thus assessment of households' adoption of DTPs is of great significance. Homeowners are already adopting DTPs to cope with water scarcity resulting from climate change, especially in some drought-stricken and urban areas of Florida (Shober, Denny, and Broschat, 2010), as well as New Mexico (Hurd, 2006), Nevada (Curtis and Cowee, 2010) and other western states. Landscape choices by homeowners have been examined in the literature (e.g., Hurd, 2006), focusing on the effects of water cost, number of children, education, responsibility for conserving water, and location.

However, to the best of our knowledge, there have been few systematic studies of the determinants of residential adoption of DTPs, or the role of households'

\footnotetext{
${ }^{1}$ In this article, yard refers to lawn as well as both vegetable and flower gardens. It is used interchangeably with residential landscape.
} 
perceptions of climate change in the decision-making process. These perceptions may be particularly important in areas that have not typically been drought-prone. Therefore, to help reduce residential water consumption and improve residents' capacity to deal with future climate risks, we studied households' adoption of DTPs in an urbanizing watershed in the Midwest. A deeper understanding of the important behavioral factors affecting households' adoption of DTPs can provide useful implications for policy development and educational efforts.

\subsection{Adaptation and Households' Water Conservation Practices}

As shown in figure 2.1, the individual's DTPs adoption decision is made in the risk context of climate change. Climate change, specifically more frequent droughts, will increase the costs of irrigating and maintaining residential landscapes (Balling and Gober, 2007; Cook, Hall, and Larson, 2012). As a consequence of predicted effects of climate risks, and people's perceptions of those risks, appropriate adjustments or changes can be made to their lifestyles (Qin et al., 2015). Specific adaptations will substantially affect the benefits or costs associated with those impacts (Larson et al., 2013; Mankad and Tapsuwan, 2011). Households' responses are influenced by their susceptibility to risks, perceived exposure to risks, and opportunities to make changes (Larson et al., 2013; Qin et al., 2015; Wamsler and Brink, 2014). At the residential level, homeowners are mainly affected by personal awareness of climate change effects, information availability on adaptive options, undervaluation of potential losses and individual financial feasibility, among other factors (Adger, Arnell, and Tompkins, 2005; Adger et al., 2009; Kusangaya et al., 2014; Qin et al., 2015; West et al., 2009). To examine this issue, we need to understand residential irrigation and landscape management, which are investigated in the following paragraphs. 
Residential landscapes provide fundamental community amenities and cultural values, for example, a sense of place for residents of the neighborhood (Cook, Hall, and Larson, 2012; Martin, Peterson, and Stabler, 2003), which can be one of the reasons why homeowners prefer green space (Bark et al., 2011). However, irrigation of these yards takes a substantial amount of water to maintain various social and cultural values. For instance, in Las Vegas, the residential irrigation system uses approximately $60 \%$ of all water (e.g., Devitt, Carstensen, and Morris, 2008), so efficient outdoor water use could potentially reduce household water consumption (Hurd, 2006; Shober, Denny, and Broschat, 2010).

In the scholarship of water conservation by homeowners, water management practices can be divided into irrigation practices and landscape maintenance (Scheiber and Beeson, 2006; Volo, Vivoni, and Ruddell, 2015). Water conservation techniques include "smart irrigation" controllers (McCready and Dukes, 2011; Nautiyal et al., 2015) and residential micro-irrigation systems (e.g., sprinkler, drip systems) (Haley, Dukes, and Miller, 2007; Volo, Vivoni, and Ruddell, 2015). However, installation of these automatic residential irrigation systems is costly and they can result in over irrigation (Haley, Dukes, and Miller, 2007; McCready and Dukes, 2011; Scheiber and Beeson, 2006; Shober, Denny, and Broschat, 2010).

An effective way to conserve water and prepare for uncertain water availability is to develop low-water-consuming landscapes (Sovocool, Morgan, and Bennett, 2006), specifically, planting water-efficient species such as native landscape ornamentals (Hurd, Hilaire, and White, 2006; Shober, Denny, and Broschat, 2010), and xeriscape conversion (Chow and Brazel, 2012; Sovocool, Authority, and Morgan, 2005; Sovocool, Morgan, and Bennett, 2006). Xeriscaping is viewed as a good way to 
reduce residential water use and has been used in some southwestern states (Sovocool, Morgan, and Bennett, 2006). Some fundamental principles of xeriscaping include rational planning, low irrigation, and planting low water-consuming plants (Hurd, Hilaire, and White, 2006).

In most residential landscapes, the planting of drought tolerant plant species is one of the essential components (Hurd, 2006; Lockett et al., 2002). In horticulture, these species are also frequently referred as "drought resistant plants", "desert plants", or "xeriscape plants." Though there is no unified definition for drought tolerant plants, most of them are found to be native plants, consuming less water once established, tolerating some dry conditions better than other plants, exhibiting high water use efficiency, making yard maintenance easier in the long term, and presenting as much comfort and aesthetic value as other plants and lawns (Hilaire, VanLeeuwen, and Torres, 2010; Howley, 2011; Shober, Denny, and Broschat, 2010).

Regarding the studies of residential landscapes and adoption of DTPs, attention has been given to three aspects: 1) adoption of environmental and water-conserving practices, focusing on residential landscape choices and factors influencing those choices including behavioral, demographic and environmental aspects (e.g., Brehm, Pasko, and Eisenhauer, 2013; Howley, 2011), 2) effects of respondents' attitudes towards landscapes, perceptions of climate conditions and landscapes' water needs (Balling and Gober, 2007; Yabiku, Casagrande, and Farley-Metzger, 2008), and 3) effects of information providers, educational programs and income levels on the adoption of DTPs (Helfand et al., 2006; Hilaire, VanLeeuwen, and Torres, 2010; Lockett et al., 2002). In studying adoption by households, most research studies were restricted to effects of similar combinations of variables. However, one key limitation 
of existing analyses of DTPs adoption is that most studies ignored the potential influence of people's perceptions about climate change, attitudes towards the local environment, and trust in information providers, which may influence yard management choices and water consumption behaviors. Though most of the studies were focused on residential adoption of water conservation practices in the South and West of the U.S., no research has been carried out on adoption of DTPs as a way of adapting to climate change in the Midwest. Contrary to the West, in the study area, water resources will probably be sufficient. However, the volume of water use will increase during droughts and the per unit cost of water may also increase due to the need for additional water treatment plants. A review of the literature enables us to put the adoption decision in the broader context of climate adaptation and to identify specific variables for inclusion in our empirical analysis.

\subsection{Conceptual Framework}

Households make adoption decisions to maximize their expected utility. Households' utility is a function of expected costs and benefits of adoption as well as their preferences, which are influenced by various factors (figure 2.1). In our model, the explanatory variables fall into five major categories: 1) demographic characteristics, 2) yard management practices, 3) trust in information sources about soil and water, 4) neighbors' opinions and residents' attitudes, and 5) perceptions of climate change. These categories follow conventions in adoption studies (e.g., Arbuckle, Morton, and Hobbs, 2015; Mills and Schleich, 2010; Prokopy et al., 2008; Roberts et al., 2004; Weber and McCann, 2015). 
Figure 2.1. Expected utility model and households' adoption of drought tolerant plants.

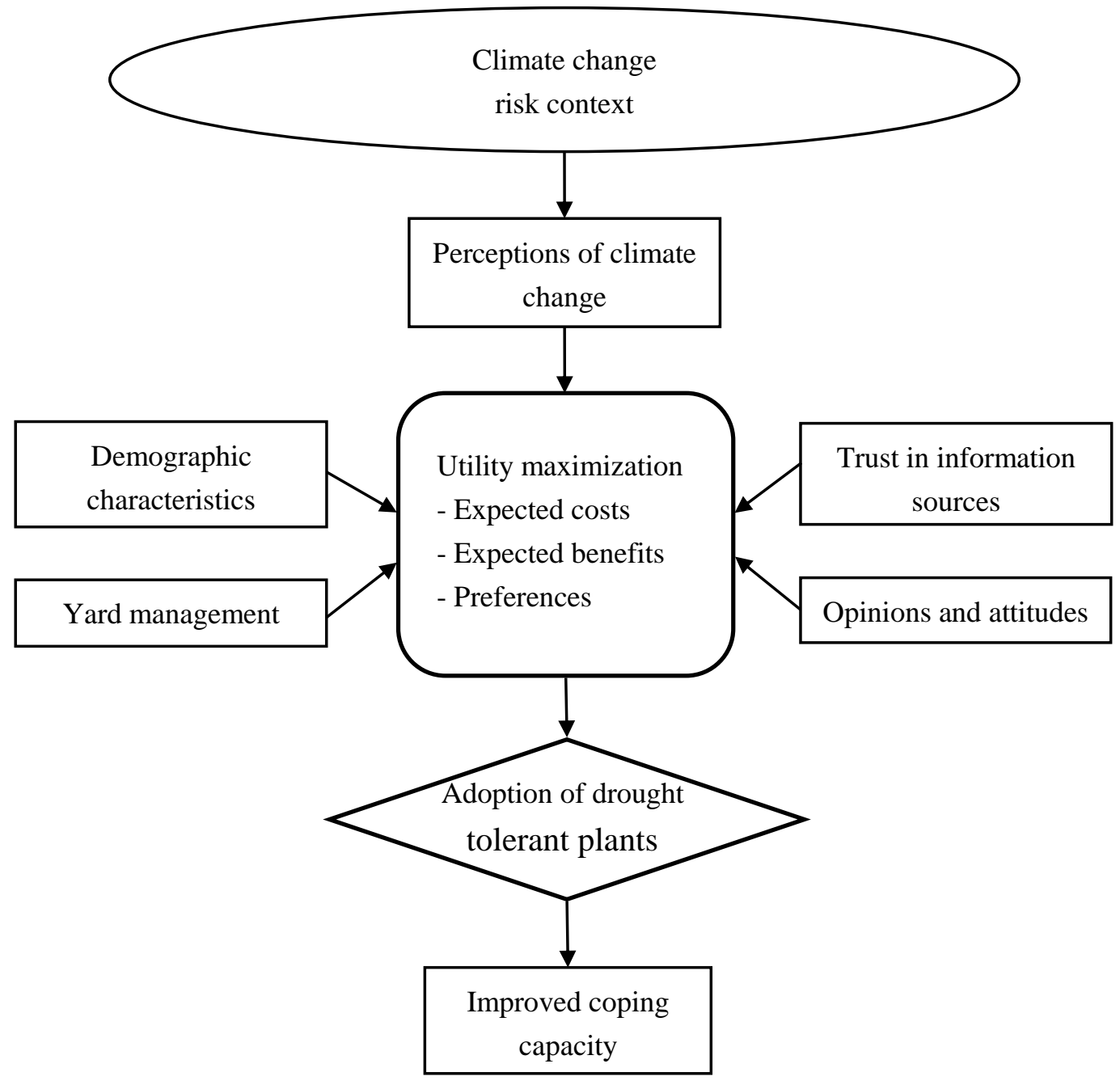

Among demographic factors, education and income variables assume a link between knowledge, ability and willingness to adapt to climate change and the current application of adaptation strategies (Alam, 2015; Alauddin and Sarker, 2014; Arbuckle, Morton, and Hobbs, 2013; Cook, Hall, and Larson, 2012; Hilaire, VanLeeuwen, and Torres, 2010; Lockett et al., 2002; Martini, Nelson, and Dahmus, 2014). Homeowners with higher levels of these attributes are not only exposed to more ideas and have more experience making decisions and effectively using information (Loss, Ruiz, and Brawn, 2009; Prokopy et al., 2008), but are motivated to 
learn about consequences of climate risks and to take appropriate measures to mitigate negative outcomes (Adger, Arnell, and Tompkins, 2005; Volo, Vivoni, and Ruddell, 2015). Thus, we hypothesize respondents with either more schooling or higher income to be more likely to adopt DTPs. Property ownership determines whether the residents can make long-term yard management plans or not. Renters may not be allowed to modify the landscape. People who own their home also receive a stream of future benefits from planting DTPs (Des Rosiers et al., 2002), so we hypothesize residents owning their home are more likely to adopt DTPs compared with those who rent. In addition, gender and having children are also included in the regression as control variables. Residential choices regarding practices on the landscape may differ due to different behaviors and preferences by men and women, and can be affected by different outdoor activities if they have children (Cook, Hall, and Larson, 2012; Martínez-Espiñeira, García-Valiñas, and Nauges, 2014). However, depending on the context, findings differ on whether male or female headed households are more likely to adopt DTPs (Bryan et al., 2009). Households with children may enjoy more time in their yard and want low maintenance compared to those without children. Households with children may be less likely to water their lawn and garden (Dupont and Renzetti, 2013), but they also play on the lawn, implying an indeterminate effect of having children on DTPs adoption. Lastly, location variables are good predictors of water consumption and area of land (Cook, Hall, and Larson, 2012; Sovocool, Authority, and Morgan, 2005). Households living far from urban areas have larger areas to irrigate and, contrary to urban homes, they may actually need to install expensive irrigation systems to water plants that are far from the house. So we hypothesize residents living in rural subdivisions and isolated rural residences to be more likely to adopt DTPs to reduce water bills and/or the likelihood of plants dying. 
Variables regarding yard management include mowing their lawns high, never watering or only watering their lawns when in severe droughts, and time spent on yardwork. The practice of mowing lawns high, referring to setting mowers at the highest setting (4 inches), can promote the development of a deeper root system, so households can use less irrigation water and lower their water bills (Smith and Fellowes, 2014). Mowing high may also indicate that residents have a better understanding of responses to drought. Thus, we hypothesize homeowners to be more likely to adopt DTPs if they mow their lawns high. For lawns' watering status, the literature shows that households' water conservation practices can determine their choices of plants in their yards (Martin, Peterson, and Stabler, 2003; Scheiber and Beeson, 2006). Less frequent watering indicates households may be doing so to reduce their water bills. We hypothesize homeowners would be more likely to adopt DTPs if they seldom or never water their lawns since drought tolerant plants and irrigation may be seen as substitutes. The amount of time spent taking care of the yard reflects homeowners' preference for yardwork and gardening (Lockett et al., 2002; Martin, Peterson, and Stabler, 2003). Therefore, we hypothesize that residents would be more likely to adopt DTPs if they spend more time on yard or lawn management activities.

Access to information and trust in information providers can be barriers/stimuli and limit/promote decision making about innovation adoption (Lockett et al., 2002). Homeowners trusting in specific information providers would believe and follow what they suggest regarding water management, lawn maintenance, landscape choices, and so on (Martini, Nelson, and Dahmus, 2014). Different providers spread varying information based on their objectives and thus their information may have diverse effects. For example, information from local water groups probably encourages less 
water-consuming and more environmentally-friendly yard management practices, e.g., mowing lawns high, watering less frequently, applying less fertilizer, planting some native plants, etc. Information from local news media could inform residents of regulations and raise people's awareness of potential environmental problems. Thus we hypothesize that homeowners who trust in local water groups and local news media are more likely to adopt DTPs. On the contrary, information from lawn care companies who mow, and apply fertilizers and pesticides would not encourage the planting of DTPs and most of their advertisements promote green, weed-free lawns. From this perspective, we hypothesize that homeowners who trust in lawn care companies are less likely to adopt DTPs.

Valuing neighbors' opinions and residents' environmental knowledge have differing effects on adoption. The effects of neighbors' opinions about lawn care choices relate to whether households get private satisfaction or gain status if their neighbors appreciate the lawns’ appearance (Kiesling and Manning, 2010). Homeowners who want to obtain private satisfaction and self-identity through neighbors' compliments on their nice lawns would tend to irrigate lawns more frequently (Larsen and Harlan, 2006). Thus we hypothesize that these individuals would be less likely to adopt DTPs. Residents' knowledge about management practices relates to whether they think the way they care for their yards would influence local water quality (Clayton, 2007). Homeowners who agree that their yard care influences local water quality tend to make changes and protect local waterways for the benefit of their community and environment (Kiesling and Manning, 2010), indicating homeowners' attitude towards the impact of yard care can be a proxy for general environmental concerns regarding yards. Therefore we hypothesize those residents would choose to plant more DTPs. 
In addition, landscape choices made by homeowners can be affected by specific climatic conditions (Martin, Peterson, and Stabler, 2003). We hypothesize homeowners' adoption of DTPs to be correlated with their perceptions of climate change impacts. Specifically, if residents are more concerned about longer droughts, they are expected to plant more DTPs. Adoption of DTPs could reduce high water bills resulting from more irrigation during droughts, and/or reduce the likelihood of plant death. On the contrary, if they are more concerned about more frequent intense rains, less adoption of DTPs would be expected. Based on the reviewed literature, the hypothesized signs of the independent variables are presented in table 2.1. 
Table 2.1. Independent variables and definitions.

\begin{tabular}{|c|c|c|}
\hline Independent variables & Exp. sign & Definition \\
\hline \multicolumn{3}{|c|}{ Demographic characteristics } \\
\hline Education & & Highest grade completed by respondents \\
\hline$\leq$ high school & - & \\
\hline 2 year college & Base & \\
\hline$\geq 4$ year college & + & \\
\hline Household income & & Household income in 2013 \\
\hline$<\$ 25,000$ & - & \\
\hline$\$ 25,000-\$ 49,999$ & Base & \\
\hline$\$ 50,000-\$ 74,999$ & + & \\
\hline$\$ 75,000-\$ 99,999$ & + & \\
\hline$>\$ 100,000$ & + & \\
\hline Own home & + & $\begin{array}{l}\text { Own the home or have mortgage (yes }=1 \text {; } \\
\text { otherwise }=0 \text { ) }\end{array}$ \\
\hline Male & $+/-$ & Family head is male $($ yes $=1$; female $=0$ ) \\
\hline Children & $+/-$ & Have children under the age of $12($ yes $=1 ;$ no $=0)$ \\
\hline Location & & Where the respondent's home is located \\
\hline City & - & City of Columbia, Missouri $(y e s=1 ;$ no $=0)$ \\
\hline Suburban & - & Suburban area in or near the city $($ yes $=1 ;$ no $=0$ ) \\
\hline Rural subdivision & Base & Rural subdivision $($ yes $=1 ;$ no= $=0$ ) \\
\hline Isolated rural area & + & Isolated, non-farm or farm area $(y e s=1 ;$ no $=0)$ \\
\hline \multicolumn{3}{|l|}{ Yard management } \\
\hline Mowing high & + & $\begin{array}{l}\text { Set mower at highest setting (i.e., } 4 \text { inches) (use }=1 \text {; } \\
\text { otherwise }=0 \text { ) }\end{array}$ \\
\hline Watering in drought & + & $\begin{array}{l}\text { Never water or only water lawn when in severe } \\
\text { drought (yes }=1 \text {; otherwise }=0 \text { ) }\end{array}$ \\
\hline Time & & $\begin{array}{l}\text { Hours per month spent on yardwork during the } \\
\text { growing season }\end{array}$ \\
\hline $0-5$ hours & - & \\
\hline $6-15$ hours & Base & \\
\hline$>15$ hours & + & \\
\hline \multicolumn{3}{|c|}{ Trust in information sources about soil and water } \\
\hline Water group & + & $\begin{array}{l}\text { Local watershed group/project (moderately or very } \\
\text { much }=1 ; \text { otherwise }=0 \text { ) }\end{array}$ \\
\hline Media & + & $\begin{array}{l}\text { Local news media (moderately or very much }=1 \text {; } \\
\text { otherwise }=0 \text { ) }\end{array}$ \\
\hline Lawn care company & - & $\begin{array}{l}\text { Lawn care company (moderately or very much }=1 \text {; } \\
\text { otherwise }=0 \text { ) }\end{array}$ \\
\hline \multicolumn{3}{|c|}{ Neighbors' opinions and residents' attitudes } \\
\hline Nice lawn & - & $\begin{array}{l}\text { It is important to me that my neighbors think I have a } \\
\text { nice lawn (agree or strongly agree }=1 \text {; otherwise }=0 \text { ) }\end{array}$ \\
\hline Water quality & + & $\begin{array}{l}\text { The way I care for my yard can influence water } \\
\text { quality in local streams and lakes (agree or strongly } \\
\text { agree }=1 \text {; otherwise }=0 \text { ) }\end{array}$ \\
\hline \multicolumn{3}{|c|}{ Perceptions of climate change } \\
\hline Drought & + & $\begin{array}{l}\text { I am concerned about longer dry periods or drought } \\
\text { (agree or strongly agree }=1 \text {; otherwise }=0 \text { ) }\end{array}$ \\
\hline Rain & - & $\begin{array}{l}\text { I am concerned about more frequent intense rain } \\
\text { (agree or strongly agree }=1 \text {; otherwise }=0 \text { ) }\end{array}$ \\
\hline
\end{tabular}




\subsection{Methods and Data}

\subsubsection{Probit adoption model}

To analyze the factors influencing adoption of DTPs, we can construct an adoption decision model specifying the explanatory variables. Residents weigh the expected utilities from adoption vs. non-adoption. Following Rahm and Huffman (1984), the expected utility can be given by $U\left(C_{i j}, B_{i j}, P_{i j}\right)$ for household $i$ if he/she adopts DTPs $(j=1)$ or does not adopt $(j=2)$, where $C_{i j}$ represents the expected costs of planting DTPs, including the price of plants, the time spent planting them, maintenance until they are fully established, etc.; $B_{i j}$ represents the expected benefits from enjoying the beauty of the garden and the ease of future maintenance, including reduced irrigation costs; and $P_{i j}$ represents residents' preferences for lawn and gardening, attitudes toward local water quality, etc. The household would choose to adopt if the expected utility of adoption is greater than that of non-adoption, i.e., if $U_{i 1}>U_{i 2}$. As the parameters of the household's choice are unobservable, it is usually defined by a latent variable $U_{i j}^{*}$. The latent variable is associated with a set of explanatory variables $\left(\mathrm{X}_{i}\right)$ :

$$
U_{i j}^{*}=X_{i} \alpha_{j}+e_{i j} \quad i=1,2, \ldots, N ; j=1,2
$$

where $\alpha_{j}$ is a vector of adoption parameters and $e_{i j}$ is a random error term. After knowing the household's decision, the observed pattern of DTPs adoption can be represented by the binary variable $\left(y_{i}\right)$ and these observed values of $y_{i}$ are related to $U_{i j}^{*}$ :

$$
y_{i}= \begin{cases}1 & \text { if } U_{i 1}^{*}>U_{i 2}^{*} \\ 0 & \text { otherwise }\end{cases}
$$


Accordingly, the probability of adoption can be denoted as:

$$
\begin{aligned}
& P_{r}\left[y_{i}=1\right]=\operatorname{Pr}\left(X_{i} \alpha_{1}+e_{i 1}>X_{i} \alpha_{2}+e_{i 2}\right) \\
& =P_{r}\left(u_{i}>-\boldsymbol{X}_{i} \beta\right) \\
& =1-F\left(-\boldsymbol{X}_{i} \beta\right) \\
& =F\left(\boldsymbol{X}_{i} \beta\right)
\end{aligned}
$$

where $F$ is the cumulative distribution function (CDF), $u_{i}=e_{i 1}-e_{i 2}$ and $\beta=\alpha_{1}-\alpha_{2}$. The parameters $\beta$ can be estimated using maximum likelihood estimation. Binary choice models differ only in the assumption about the functional form of $F$.

A probit or logit model is commonly used in studies of adoption and the factors influencing adoption likelihood (Hahn and Soyer, 2005). In our adoption model, all the variables were binary, where 1 represents agree or yes, and 0 represents no or otherwise. Probit models have been preferred primarily due to the relative ease of computation. For probit models, we assume $p_{i}$ is given by the standard normal distribution function $\Phi\left(x^{\prime} \beta\right)$ (Greene, 2005). Thus given the dichotomous nature of the dependent variable, the following univariate probit model is used:

$$
P_{r}\left(y=1 \mid x_{1}, x_{2}, \ldots, x_{k}\right)=\Phi\left(x^{\prime} \boldsymbol{\beta}\right)
$$

where $\boldsymbol{x}=x_{1}, x_{2}, \ldots, x_{k}$ are independent variables, and $\boldsymbol{\beta}=\beta_{1}, \beta_{2}, \ldots, \beta_{k}$ are parameters, which can be estimated for each corresponding $x$ variable.

All the analyses are conducted using the data analysis package STATA version 13.1. For probit models, the coefficients cannot be directly explained as marginal 
effects, and marginal effects for discrete (i.e., binary or dummy) variables used in our model have to be computed separately.

For a categorical variable $x_{k}$,

$$
\text { Marginal effect of } x_{k}=\operatorname{Pr}\left(y=1 \mid x, x_{k}=1\right)-\operatorname{Pr}\left(y=1 \mid x, x_{k}=0\right)
$$

\subsubsection{Data}

We use data from a mail survey of randomly selected Columbia, Missouri households in single-family homes ${ }^{2}$. The survey was conducted from February to May of 2014. The survey covered specific practices adopted by residents regarding water management and nutrient use related to their lawn and garden as well as their attitudes towards these issues. Some of the questions were designed to learn whether households had adopted drought tolerant plants as a residential water conservation practice and how the household's and yard's characteristics had affected the adoption decision. In designing the questionnaire, the Dillman survey method (Dillman, 2000) was followed. A focus group pretesting method was utilized and minor modifications were made based on comments of participants. In the spring of 2014, 2000 questionnaires were initially mailed out to a random sample of households, followed by a reminder postcard after two weeks. A second questionnaire was sent out two weeks later to those who had not responded to the first. The person who was responsible for yard care in each household was asked to fill out the survey. The effective response rate (adjusted for those who had moved or died) was $44 \%$, which is quite good.

\footnotetext{
2 The source of our sample was Survey Sampling Incorporated. The survey covers an area of three zip codes (65201, 65202 and 65023), which is roughly the Columbia metropolitan area.
} 
There were 751 households providing responses on the DTPs adoption question ${ }^{3}$ and among those respondents, the adoption rate was $32.89 \%$. A total of 127 observations were excluded due to one or more missing values, in particular, on income, education, and information sources. Among the remaining 624 observations, 200 households had adopted drought tolerant plants in their gardens so the adoption rate was $32.05 \%$.

The variables shown in table 2.1 reflect the combining of some response categories in the original survey. These transformations were made primarily for Likert scale variables to preserve degrees of freedom and to develop a more parsimonious model. Because of the nature of Likert scale variables, they cannot be treated as continuous variables as the intervals are not equal. The dependent variable was adoption of drought tolerant plants $(1=$ currently use it, and $0=$ otherwise, including responses of: know how to use it, but not using it, somewhat familiar with it, but not using it, never heard of it, and not applicable).

The explanatory variable of education included three subcategories, specifically, some schooling or high school diploma, some college or 2 year college degree (base category), and 4 year college or post-graduate degree. Annual household income was divided into five subcategories in the survey - less than $\$ 25,000, \$ 25,000-\$ 49,999$ (base category), $\$ 50,000-\$ 74,999, \$ 75,000-\$ 99,999$ and more than $\$ 100,000$. Dummy variables were also used for variables of male (vs. female), owning home (vs. renting) and having children under the age of 12 (vs. none). Location variables

\footnotetext{
3 The survey examined practices in addition to DTPs. The specific question and responses were: Please indicate which statement most accurately describes your level of experience with each practice listed below.

e. Plant drought tolerant plants in my garden.

Response options: Not applicable; never heard of it; somewhat familiar with it, but not using it; know how to use it, but not using it; currently use it.
} 
included living in the City of Columbia, its suburbs, rural subdivision (base category) and isolated rural residence ${ }^{4}$.

The adoption of the practice of mowing high was treated in the same way as adoption of DTPs. Four categories of frequency of watering lawns were provided to respondents: watering on an as-needed basis to keep it green, only in summer, only in severe droughts and never watering. We combined the last two as the low watering variable and the rest as the base in the regression. Variables for time spent on yardwork were recoded to reflect three subcategories, i.e., $0-5$ hours, 6-15 hours (base category) and more than 15 hours. Response options for the degree of trust in various information providers included not at all, slightly, moderately, very much and not familiar. For each information provider, the moderate and very much categories were combined to a dummy variable and the others were combined into a base category. Variables regarding neighbors' opinions about their lawn, and the effects of yard management on local water quality, as well as perceptions of climate change were obtained by asking respondents to rate their views on these statements using a Likert scale ( $1=$ strongly disagree, $2=$ disagree, $3=$ neither agree nor disagree, $4=$ agree, and $5=$ strongly agree). Responses of 4 and 5 were combined into an agree category and responses of 1,2 and 3 were combined into the base category in the regression.

\footnotetext{
${ }^{4}$ In the Columbia area, one does not find a continuum from small urban/city yards to larger suburban yards, followed by even larger yards at the rural/urban interface (or the peri-urban region). Some rural subdivisions may have yards similar in size to suburban ones, but they are separated from the suburban areas by several miles, with an area of farms in between.
} 


\subsection{Results and Discussion}

\subsubsection{Descriptive statistics}

Table 2.2 compares the survey respondents to the population in both the City of Columbia and the Columbia metropolitan area. While our survey covered an area very similar to the metropolitan area, the survey timing was closer to when the latest Census data for the city were available. It is important to note that the Census data are for all residents while the surveyed population was only those with single-family homes. Compared with the U.S. Census data for both the City of Columbia and the metropolitan area, the sample had a higher proportion of respondent households with a Bachelor's degree or higher. Survey respondents also had higher household income levels than the populations in both the city and metropolitan area, i.e., for categories $\$ 50,000-\$ 74,999, \$ 75,000-\$ 99,999$ and greater than $\$ 100,000$. More than half of the population of both the city and metropolitan area had incomes less than $\$ 50,000$. The education and income levels of respondents may be fairly representative of the surveyed population living in single-family homes because those living in houses versus apartments would tend to be more educated and have higher incomes (Bourassa, Cantoni, and Hoesli, 2007; Mary Ann Groves, personal communication ${ }^{5}$ ).

\footnotetext{
${ }^{5}$ Groves pointed out that Columbia, Missouri is a college town with two universities and three colleges and also a medical town with five medical centers. Both facts would increase the education level of local residents compared to similar-sized cities elsewhere.
} 
Table 2.2. Comparison of sample to Census data.

\begin{tabular}{|c|c|c|c|}
\hline & $\begin{array}{c}\text { Survey } \\
\text { respondents } \\
(2014) \\
\end{array}$ & $\begin{array}{c}\text { City of } \\
\text { Columbia } \\
(2010-2014)^{\mathrm{a}} \\
\end{array}$ & $\begin{array}{c}\text { Metropolitan } \\
\text { area } \\
(2005-2007)^{\mathrm{a}}\end{array}$ \\
\hline \multicolumn{4}{|l|}{ Education } \\
\hline Less than Bachelor's degree & $29 \%$ & $44 \%$ & $55 \%$ \\
\hline Bachelor's degree or higher & $71 \%$ & $56 \%$ & $45 \%$ \\
\hline \multicolumn{4}{|l|}{ Household income } \\
\hline$<\$ 25,000$ & $7 \%$ & $55 \%$ & $30 \%$ \\
\hline$\$ 25,000-\$ 49,999$ & $19 \%$ & $55 \%$ & $27 \%$ \\
\hline$\$ 50,000-\$ 74,999$ & $27 \%$ & $15 \%$ & $18 \%$ \\
\hline$\$ 75,000-\$ 99,999$ & $18 \%$ & $10 \%$ & $11 \%$ \\
\hline$>\$ 100,000$ & $29 \%$ & $20 \%$ & $15 \%$ \\
\hline
\end{tabular}

Notes: Census data included those living in both apartments and detached homes.

${ }^{a}$ Source: US Census Bureau (2010, 2015).

Summary statistics for the survey data used in the regression are presented in table 2.3. Approximately $32 \%$ of the respondents reported adopting drought tolerant plants. For other detailed demographic characteristics, the most common educational category according to the survey was completion of 4 year college or post-graduate degree $(71 \%)$. Residents with education levels of some formal school or high school diploma or GED and some college or 2 year college degree were $10 \%$ and $20 \%$, respectively. A majority of the respondents were male (62\%) and almost all respondents owned their home or had a mortgage (91\%) rather than renting. Around $13 \%$ of the surveyed households had one or more children under the age of 12 . Most of the people were living in the City of Columbia (61\%), with fewer living in suburbs (25\%), rural subdivisions (8\%) and isolated rural areas (6\%).

Regarding residential yard management practices, $66 \%$ of people set their mowers at the highest level. About $62 \%$ of the respondents never watered or only watered their lawns when in severe droughts. More than half of the households (56\%) 
spent $6-15$ hours per month on lawn maintenance, and the residents spending $0-5$ hours and more than 15 hours per month were $20 \%$ and $23 \%$, respectively. Generally, more than half of the residents trusted information regarding soil and water from local watershed groups and projects $(61 \%)$. Fewer people trusted local news media and lawn care companies (35\% and 37\%, respectively).

About $37 \%$ of the homeowners valued their neighbors' attitude towards the appearance of their lawns. Most people (87\%) agreed that the way they cared for their yards could influence water quality in local streams and rivers. More people were concerned with long dry periods or droughts (77\%) than frequent intense rains $(36 \%)$ which may relate to the drought in 2012. 


\subsubsection{Comparison of adopters and non-adopters}

A comparison was conducted to better understand characteristics of adopters versus non-adopters (table 2.3). Compared with non-adopters, more adopters owned their home, while a significantly lower proportion of male respondents were found to be adopters. More adopters lived in rural subdivisions compared to non-adopters, while there were no significant differences for other locations. More adopters mowed lawns high than non-adopters, implying a correlation between DTPs adoption and mowing high. Among those spending less than 5 hours per month on yardwork, there were fewer adopters than non-adopters, but among those spending more than 15 hours, this was reversed, indicating adopters spent more time gardening. There were a higher number of adopters trusting information from local water groups/projects, while fewer adopters trusted information from lawn care companies. More adopters agreed that the way they cared for the yard could influence local water quality. Over three-fourths of both adopters and non-adopters were concerned about future droughts. Fewer adopters were concerned with intense rainfall. While these comparisons are useful, regression allows us to examine the combined effects of these factors in determining DTPs adoption as well as magnitudes of the effects.

\subsubsection{Regression results and discussion}

Because the five variable categories included a wide variety of independent variables, we examined correlation coefficients for each pair of the variables and tested for multicollinearity in the regression as a whole. For all pairs, the correlation coefficients had absolute values smaller than 0.40 . We found no evidence of 
multicollinearity, as indicated by the values of variance inflation factor (VIF) ${ }^{6}$. The pseudo- $\mathrm{R}^{2}$ value for the probit regression was 0.15 (table 2.4$)^{7}$. The likelihood ratio (LR) Chi-square indicated the model as a whole was significant, with a $p$ value less than 0.001 .

Probit regression results are shown in table 2.4. For this model, the values for marginal effects measure the conditional probability changes in adoption, given the level of the other independent variables. For the variables regarding demographic characteristics, diverse effects were found in the model. Unexpectedly, education levels were nonsignificant. Very high annual household income $(>\$ 100,000)$ had a positive effect on adoption $(p<0.10)$, which is consistent with the research by Brehm, Pasko, and Eisenhauer (2013), Helfand et al. (2006), and Loss, Ruiz, and Brawn (2009) that wealthier people were more willing to pay for residential plant species. Meanwhile, respondents with very low incomes $(<\$ 25,000)$ were also significantly more likely to adopt $(p<0.01)$, which is contrary to our expectation. However, this finding could be true because low income limits household expenditure on yard care (Balling and Gober, 2007; Cook, Hall, and Larson, 2012), including irrigation. Contrary to western states where residents replaced lawns with DTPs, in the Midwest adoption of DTPs would typically mean choosing to plant drought tolerant species of

\footnotetext{
${ }^{6}$ The VIF values for all variables were less than 2.40, with an average of 1.40 , whereas a VIF of greater than 8 indicates that a variable may be deemed a linear combination of other independent variables in the model. For the original model, we also included dummy variables on respondents' age, age of house, and money spent on yard care. However, there was a strong correlation between age and income, as well as age of house and homeownership. For the money spent gardening variable, one third of the observations had missing values. Exclusion of these variables improved the overall goodness of fit of the model.

${ }^{7}$ For models with binary dependent variables, the traditional ordinary least squares measure of fit, $\mathrm{R}^{2}$, cannot be applied. Moreover, the regression had binary independent variables, so the appropriate measure reported in the probit regression results was a pseudo- $\mathrm{R}^{2}$ value, which is a likelihood-based measure. It ranges from 0 to 1 , with higher values indicating better fit of the model. The pseudo- $\mathrm{R}^{2}$ value was low but acceptable for adoption studies (Alcon et al., 2014; Sharp, Daley, and Lynch, 2011). This indicated that other variables not included in this regression probably affected the adoption of drought tolerant plants.
} 
trees and bushes rather than water-consuming species, which would reduce costs relative to lawn replacement. DTPs generally cost less over time compared to planting water-consuming plants and lawns ${ }^{8}$, in terms of expenditure on irrigation water, irrigation systems, fertilizer, maintenance equipment and professional services (Martin, Peterson, and Stabler, 2003; Shober, Denny, and Broschat, 2010).

Regarding other demographic variables, being male was negatively correlated with the adoption of DTPs $(p<0.01)$. A male-headed household would be $11.5 \%$ less likely to use DTPs. Literature has shown that gender may have mixed effects depending on the context (Bryan et al., 2009; Cook, Hall, and Larson, 2012). Our result was in line with that of Larson et al. (2009), Martin, Peterson, and Stabler (2003) and Yabiku, Casagrande, and Farley-Metzger (2008). Men may express lower environmental concerns than women (Hunter, Hatch, and Johnson, 2004;

Martínez-Espiñeira, García-Valiñas, and Nauges, 2014). Residents owning their home were significantly more likely to adopt DTPs compared to those who rented. This was consistent with our prediction since people who own their property could obtain benefits over time from the lower costs associated with DTPs, and also from any improvements at the time of sale. The effect of having children was not significant. Residents living in city, suburban or isolated rural residences, versus those living in rural subdivisions, were significantly less likely to adopt DTPs. Rural residential lots are usually somewhat larger and households might choose to plant DTPs due to the difficulty of watering large areas and to save time and money on yard care and maintenance. Isolated rural residences or farms would have much larger areas to

\footnotetext{
${ }^{8}$ For many technologies, a higher up-front cost can be dwarfed by the benefit of reduced future expenditures (Mills and Schleich, 2010).
} 
irrigate so these respondents may think that preventing the consequences of droughts would be infeasible, even with DTPs. 
Table 2.4. Results of probit regression for the adoption of drought tolerant plants.

\begin{tabular}{|c|c|c|c|c|}
\hline \multirow[b]{2}{*}{ Independent variables } & \multicolumn{2}{|c|}{ Parameter estimate } & \multicolumn{2}{|c|}{ Marginal effect } \\
\hline & Coefficient & $\begin{array}{l}\text { Robust } \\
\text { Std. Err. }\end{array}$ & $\mathrm{dy} / \mathrm{dx}$ & $\begin{array}{l}\text { Delta-method } \\
\text { Std. Err. }\end{array}$ \\
\hline Intercept & $-1.145^{* * * *}$ & 0.410 & & \\
\hline \multicolumn{5}{|l|}{ Demographic characteristics } \\
\hline \multicolumn{5}{|l|}{ Education (Base $=2$ year college $)$} \\
\hline$\leq$ high school & -0.302 & 0.224 & -0.091 & 0.067 \\
\hline$\geq 4$ year college & -0.122 & 0.142 & -0.037 & 0.043 \\
\hline \multicolumn{5}{|c|}{ Household income (Base $=\$ 25,000-\$ 49,999)$} \\
\hline$<\$ 25,000$ & $0.590^{* *}$ & 0.261 & $0.178^{* *}$ & 0.077 \\
\hline$\$ 50,000-\$ 74,999$ & 0.088 & 0.177 & 0.027 & 0.053 \\
\hline$\$ 75,000-\$ 99,999$ & 0.240 & 0.197 & 0.072 & 0.059 \\
\hline$>\$ 100,000$ & $0.309^{*}$ & 0.186 & $0.093^{*}$ & 0.056 \\
\hline Own home & $0.384^{*}$ & 0.225 & $0.116^{*}$ & 0.067 \\
\hline Male & $-0.381^{* * *}$ & 0.119 & $-0.115^{* * *}$ & 0.035 \\
\hline Children & -0.175 & 0.178 & -0.053 & 0.054 \\
\hline \multicolumn{5}{|l|}{ Location (Base $=$ Rural subdivision) } \\
\hline City & $-0.591^{* * *}$ & 0.214 & $-0.178^{* * *}$ & 0.064 \\
\hline Suburban & $-0.637^{* * *}$ & 0.234 & $-0.192^{* * *}$ & 0.069 \\
\hline Isolated rural area & $-0.654^{* *}$ & 0.293 & $-0.197^{* *}$ & 0.087 \\
\hline \multicolumn{5}{|l|}{ Yard management } \\
\hline Mowing high & $0.626^{* * *}$ & 0.130 & $0.189^{* * *}$ & 0.037 \\
\hline Watering in drought & 0.114 & 0.131 & 0.034 & 0.039 \\
\hline \multicolumn{5}{|l|}{ Time (Base $=6-15$ hours $)$} \\
\hline $0-5$ hours & $-0.406^{* *}$ & 0.168 & $-0.122^{* *}$ & 0.050 \\
\hline$>15$ hours & $0.429^{* * *}$ & 0.135 & $0.129^{* * *}$ & 0.040 \\
\hline \multicolumn{5}{|c|}{ Trust in information sources about soil and water } \\
\hline Water group & $0.409^{* * *}$ & 0.125 & $0.123^{* * *}$ & 0.037 \\
\hline Media & -0.067 & 0.121 & -0.020 & 0.036 \\
\hline Lawn care company & $-0.279^{* *}$ & 0.122 & $-0.084^{* *}$ & 0.036 \\
\hline \multicolumn{5}{|c|}{ Neighbors' opinions and residents' attitudes } \\
\hline Nice lawn & 0.140 & .125 & 0.042 & 0.038 \\
\hline Water quality & $0.475^{* *}$ & 0.187 & $0.143^{* *}$ & 0.056 \\
\hline \multicolumn{5}{|l|}{ Perceptions of climate change } \\
\hline Drought & $0.253^{*}$ & 0.148 & $0.076^{*}$ & 0.044 \\
\hline Rain & $-0.230^{*}$ & 0.127 & $-0.069^{*}$ & 0.038 \\
\hline \multicolumn{5}{|l|}{ Goodness of fit } \\
\hline Observations & 624 & & & \\
\hline Wald Chi-square & 101.08 & & & \\
\hline Prob $>$ Chi-square & $<0.001$ & & & \\
\hline Log likelihood & -332.09 & & & \\
\hline Pseudo $\mathrm{R}^{2}$ & 0.15 & & & \\
\hline Variance inflation factor (VIF) & Mean: 1 & 40 (min-ma & $1.04-2.40)$ & \\
\hline
\end{tabular}

Notes: ${ }^{*} p<0.10,{ }^{* *} p<0.05,{ }^{* * *} p<0.01$. 
For yard management, the practice of mowing lawns high showed a positive effect on adoption $(p<0.01)$, as expected, since both are adaptive responses to drought. Using the time category of 6-15 hours of yardwork as the base in the regression, the effect of spending $0-5$ hours was negatively correlated with adoption $(p<0.05)$ and the category more than 15 hours was positively correlated with the adoption $(p<0.01)$. The results were consistent with our hypothesis. The respondents who spend more than 15 hours probably like to garden and are curious about plants. The lowest time category would correspond to the time required to just mow the lawn. Interestingly, the low watering variable reflecting never watering or only watering lawn in severe droughts was not significant ceteris paribus.

The trust in various information sources had mixed effects on adoption. Trust in information from local watershed groups/projects had a positive effect on adoption $(p<0.01)$ and it could lead to being $12.3 \%$ more likely to adopt compared to the case of no trust. On the contrary, trust in information from lawn care companies had a negative effect on adoption $(p<0.05)$ compared to that of no trust. These findings were in line with our expectations based on the literature (Martini, Nelson, and Dahmus, 2014).

The effect of valuing neighbors' opinions on lawn care choices was not significant which indicates social norms are probably not a barrier to the adoption of DTPs in this area. On the other hand, our regression results indicated households who agreed that the way they cared for yards could influence local water quality were more likely to adopt DTPs $(p<0.05)$, which was consistent with the literature. To be environmentally-friendly and benefit their community, residents are more willing to 
use plant species and reduce water pollution induced by yard fertilization and irrigation (Kiesling and Manning, 2010).

According to the results, concern about droughts was positively associated with adoption $(p<0.10)$, while concern about intense rains was negatively associated with adoption $(p<0.10)$. These results were in line with our hypothesis that respondents who were concerned about longer droughts were more likely to adopt DTPs, and those concerned with more frequent intense rains were less likely to adopt (Hilaire, VanLeeuwen, and Torres, 2010; Martin, Peterson, and Stabler, 2003). While there was no significant difference between adopters and non-adopters in the level of concern about droughts ${ }^{9}$, in the regression this variable was significant, which shows the importance of statistically controlling for other factors.

Robustness checks were conducted in multiple ways. Before choosing the final parsimonious model, we estimated two models with more variables: 1) using dummies of the original five-point Likert scale variables, and 2) using dummies combining some minor scales ${ }^{10}$. Other models were tested, including bivariate probit regression, seemingly unrelated bivariate probit, two-stage bivariate probit, and the Heckman selection model ${ }^{11}$. Comparisons across the results from these models

\footnotetext{
9 The non-significant difference may be a result of combining response categories "agree" with "strongly agree". More adopters strongly agreed with the drought concern, while more non-adopters were found to just agree.

${ }^{10}$ We tried the combinations of "strongly disagree" and "disagree" as well as of "strongly agree" and "agree" (with "neither" as the base). For the variables regarding trust in information sources, we tried dummies of the original categories as well as some combinations of similar categories. In addition, we tried the original categories for the variables of watering lawn and of education levels.

${ }^{11}$ The rho in the bivariate probit regression with adoption of drought tolerant plants and mowing high was not significant ( $>00.10$ ), indicating no evidence of endogeneity (Knapp and Seaks, 1998), which was confirmed by the later models, for instance, the nonsignificant rho in seemingly unrelated biprobit models (Cameron and Trivedi, 2009) and nonsignificant inverse Mills ratio in the two stage models (Wooldridge, 2015). The results of the models for robustness checks are available upon request.
} 
showed the signs and significance levels of most variables were robust (Knapp and Seaks, 1998) $)^{12}$.

\subsection{Conclusions and Implications}

One dimension of climate change is that rainfall will become more unevenly distributed in time, which could affect the availability and use of local water resources (Wanders and Wada, 2015). Midwestern states are not typically drought-stricken, so local infrastructure and landscape design give little consideration to possible climate risks. That is part of the reason why the 2012 drought in the Midwest not only devastated agricultural production, but also brought damage to residential properties (USDA, 2012). At the residential level, homeowners' adaptation to climate risks can be enhanced through adopting various practices to conserve water use. The adoption of drought tolerant plants for the landscape is considered to be a fundamental adaptation strategy (e.g., Bryan et al., 2009). By analyzing survey data from an urbanizing watershed in the Midwest, we obtained unique findings that could contribute to the literature and to future policy design on adaptation to climate change and water shortages.

Household income and location were found to be fundamental factors impacting adoption decisions. High income facilitates higher adoption due to the ability to purchase new plants, while low income may motivate households to limit irrigation costs. At the same time, households in rural subdivisions have larger areas to irrigate and DTPs adoption could potentially save costs on irrigation water and equipment. An

\footnotetext{
${ }^{12}$ For the climate change concern variables, non-significant results were obtained using two or four dummy variables, but the $p$ values were $0.12-0.18$. We found the combined category "strongly disagree \& disagree" and "neither" have the same effect on DTPs adoption, and the effect was opposite to that of "strongly agree \& agree." Thus combining "strongly disagree", "disagree" and "neither" as a base used in the regression yielded a significant effect of "strongly agree \& agree" for both drought and rain variables.
} 
interest in gardening (with time spent as a proxy) and understanding of responses to drought (e.g., mowing lawns high) enable a higher resilience and lower vulnerability to droughts. Environmental attitudes, as revealed by trust in local water groups and awareness of the effect of their yard actions on local water quality, are associated with more environmentally-friendly yard management.

Our findings suggest that educational programs can be designed to address the concerns of different types of residents. Presentations to gardening clubs would reach serious gardeners who may be concerned with water use but also want attractive plants. For lower income people, the benefit of reduced irrigation costs should be highlighted in educational materials and economic incentives such as subsidies could reduce the up-front costs. The City of Columbia is also considering subsidizing moisture sensors for people installing automatic irrigation systems (Connie Kacprowicz, personal communication). Columbia already has an increasing block rate structure, but households with higher than average water use could be sent fliers on water conservation strategies along with their utility bill. In addition, residential water use efficiency evaluations which increase homeowners' awareness of their water use and the potential for conservation could motivate the adoption of low water-consuming plants. For new housing developments, incentives or regulations could promote installation of more drought-tolerant landscaping as the default situation for new homeowners. For isolated rural residences and farms, local farm and home stores might collaborate with Extension specialists on point of purchase information on DTPs and their long-term private benefits. Extension specialists and local government personnel should have programs on water conservation strategies that can be quickly mobilized when droughts do occur to take advantage of a 
teachable moment. Environmental groups and programs associated with water quality and water resources can explain the broader environmental benefits of DTPs.

Our findings also suggest some interesting areas for future research. Contrary to expectations, both income and property size seem to have non-linear impacts on DTPs adoption and these phenomena need to be examined more carefully. The impact of climate change perceptions on adaptation is another area that merits further research. For example, as memories of the 2012 drought recede, will perceptions and behaviors change? Comparative research on regions that are and are not prone to droughts and water shortages would be another interesting extension of this research. More generally, improved understanding of factors affecting adaptation to increased rainfall variability by households can reduce the negative consequences of climate change and allow the development of effective policies and educational programs. 


\section{References}

Adger W. N., Arnell N. W., Tompkins E. L. "Successful Adaptation to Climate Change across Scales." Global Environmental Change 15(2005):77-86. doi:10.1016/j.gloenvcha.2004.12.005.

Adger W. N., Dessai S., Goulden M., Hulme M., Lorenzoni I., Nelson D. R., Naess L. O., Wolf J., Wreford A. "Are There Social Limits to Adaptation to Climate Change?" Climatic Change 93(2009):335-354. doi:10.1007/s10584-008-9520-z.

Alam K. "Farmers' Adaptation to Water Scarcity in Drought-Prone Environments: A Case Study of Rajshahi District, Bangladesh." Agricultural Water Management 148(2015):196-206. doi:10.1016/j.agwat.2014.10.011.

Alauddin M., Sarker M. A. R. "Climate Change and Farm-Level Adaptation Decisions and Strategies in Drought-Prone and Groundwater-Depleted Areas of Bangladesh: An Empirical Investigation." Ecological Economics 106(2014):204-213. doi:10.1016/j.ecolecon.2014.07.025.

Alcon F., Tapsuwan S., Brouwer R., de Miguel M. D. "Adoption of Irrigation Water Policies to Guarantee Water Supply: A Choice Experiment.” Environmental Science \& Policy 44(2014):226-236. doi:10.1016/j.envsci.2014.08.012.

Angel J. R., Huff F. A. "Changes in Heavy Rainfall in Midwestern United States." Journal of Water Resources Planning and Management 123(1997):246-249. doi:10.1061/(ASCE)0733-9496(1997)123:4(246).

Arbuckle J. G., Morton L. W., Hobbs J. "Farmer Beliefs and Concerns About Climate Change and Attitudes toward Adaptation and Mitigation: Evidence from Iowa." Climatic Change 118(2013):551-563. doi:10.1007/s10584-013-0700-0.

Arbuckle J. G., Morton L. W., Hobbs J. "Understanding Farmer Perspectives on Climate Change Adaptation and Mitigation: The Roles of Trust in Sources of Climate Information, Climate Change Beliefs, and Perceived Risk." Environment and Behavior 47(2015):205-234. doi:10.1177/0013916513503832.

Arnell N. W. "Climate Change and Global Water Resources." Global Environmental Change 9(1999):S31-S49. doi:10.1016/S0959-3780(99)00017-5.

Balling R. C., Gober P. "Climate Variability and Residential Water Use in the City of Phoenix, Arizona.” Journal of Applied Meteorology and Climatology 46(2007):1130-1137. doi:10.1175/JAM2518.1.

Bark R. H., Osgood D. E., Colby B. G., Halper E. B. "How Do Homebuyers Value Different Types of Green Space?" Journal of Agricultural and Resource Economics 31(2011):395-415. 
Bourassa S. C., Cantoni E., Hoesli M. "Spatial Dependence, Housing Submarkets, and House Price Prediction." The Journal of Real Estate Finance and Economics 35(2007):143-160.

Brehm J. M., Pasko D. K., Eisenhauer B. W. "Identifying Key Factors in Homeowner's Adoption of Water Quality Best Management Practices." Environmental Management 52(2013):113-122. doi:10.1007/s00267-013-0056-2.

Bryan E., Deressa T. T., Gbetibouo G. A., Ringler C. "Adaptation to Climate Change in Ethiopia and South Africa: Options and Constraints." Environmental Science \& Policy 12(2009):413-426. doi:10.1016/j.envsci.2008.11.002.

Cameron A. C., Trivedi P. K. Microeconometrics Using Stata Vol 5. College Station, TX: Stata Press, 2009.

Chow W. T. L., Brazel A. J. "Assessing Xeriscaping as a Sustainable Heat Island Mitigation Approach for a Desert City." Building and Environment 47(2012):170-181. doi:10.1016/j.buildenv.2011.07.027.

Clayton S. "Domesticated Nature: Motivations for Gardening and Perceptions of Environmental Impact." Journal of Environmental Psychology 27(2007):215-224. doi:10.1016/j.jenvp.2007.06.001.

Cook E. M., Hall S. J., Larson K. L. "Residential Landscapes as Social-Ecological Systems: A Synthesis of Multi-Scalar Interactions between People and Their Home Environment." Urban Ecosystems 15(2012):19-52. doi:10.1007/s11252-011-0197-0.

Curtis K. R., Cowee M. W. "Are Homeowners Willing to Pay for "Origin-Certified" Plants in Water-Conserving Residential Landscaping?” Journal of Agricultural and Resource Economics 35(2010):118-132. doi:10.2307/23243040.

Des Rosiers F., Thériault M., Kestens Y., Villeneuve P. "Landscaping and House Values: An Empirical Investigation." The Journal of Real Estate Research 23(2002):139-162.

Devitt D. A., Carstensen K., Morris R. L. "Residential Water Savings Associated with Satellite-Based Et Irrigation Controllers." Journal of Irrigation and Drainage Engineering 134(2008):74-82. doi:10.1061/(ASCE)0733-9437(2008)134:1(74).

Dillman D. A. Mail and Internet Surveys: The Tailored Design Method Vol 2. New York: Wiley 2000.

Dupont D. P., Renzetti S. "Household Behavior Related to Water Conservation." Water Resources and Economics 4(2013):22-37. doi:10.1016/j.wre.2013.12.003. 
EPA (United States Environmental Protection Agency). Climate Change Indicators in the United States - Weather and Climate. 2014. Available online at https://www3.epa.gov/climatechange/pdfs/climateindicators-full-2014.pdf.

Greene W. H. Econometric Analysis. 5th Ed. New York: Prentice Hall, 2005.

Hahn E. D., Soyer R. Probit and Logit Models: Differences in the Multivariate Realm. (2005) Available online at http://homegwuedu/ soyer/mv1hpdf.

Haley M. B., Dukes M. D., Miller G. L. "Residential Irrigation Water Use in Central Florida." Journal of Irrigation and Drainage Engineering 133(2007):427-434. doi:10.1061/(ASCE)0733-9437(2007)133:5(427).

Helfand G. E., Park J. S., Nassauer J. I., Kosek S. "The Economics of Native Plants in Residential Landscape Designs." Landscape and Urban Planning 78(2006):229-240. doi:10.1016/j.landurbplan.2005.08.001.

Hilaire R. S., VanLeeuwen D. M., Torres P. "Landscape Preferences and Water Conservation Choices of Residents in a High Desert Environment." HortTechnology 20(2010):308-314.

Howley P. "Landscape Aesthetics: Assessing the General Publics' Preferences Towards Rural Landscapes.” Ecological Economics 72(2011):161-169. doi:10.1016/j.ecolecon.2011.09.026.

Hunter L. M., Hatch A., Johnson A. "Cross-National Gender Variation in Environmental Behaviors.” Social Science Quarterly 85(2004):677-694. doi:10.1111/j.0038-4941.2004.00239.x.

Hurd B. H. "Water Conservation and Residential Landscapes: Household Preferences, Household Choices." Journal of Agricultural and Resource Economics 31(2006):173-192.

Hurd B. H., Hilaire R. S., White J. M. "Residential Landscapes, Homeowner Attitudes, and Water-Wise Choices in New Mexico." HortTechnology 16(2006):241-246.

IPCC (Intergovernmental Panel on Climate Change). Climate Change 2014: Impacts, Adaptation and Vulnerability - Summary for Policymakers. 2014. Available online at http://www.globalchange.gov/browse/reports/ipcc-climate-change-2014-impac ts-adaptation-vulnerability-summary-policymakers.

Kiesling F. M., Manning C. M. "How Green Is Your Thumb? Environmental Gardening Identity and Ecological Gardening Practices.” Journal of Environmental Psychology 30(2010):315-327. doi:10.1016/j.jenvp.2010.02.004.

Knapp L. G., Seaks T. G. “A Hausman Test for a Dummy Variable in Probit.” Applied Economics Letters 5(1998):321-323. doi:10.1080/758524410. 
Kusangaya S., Warburton M. L., Archer van Garderen E., Jewitt G. P. "Impacts of Climate Change on Water Resources in Southern Africa: A Review." Physics and Chemistry of the Earth, Parts A/B/C 67-69(2014):47-54. doi:10.1016/j.pce.2013.09.014.

Larsen L., Harlan S. L. "Desert Dreamscapes: Residential Landscape Preference and Behavior." Landscape and Urban Planning 78(2006):85-100. doi:10.1016/j.landurbplan.2005.06.002.

Larson K. L., Casagrande D., Harlan S. L., Yabiku S. T. "Residents' Yard Choices and Rationales in a Desert City: Social Priorities, Ecological Impacts, and Decision Tradeoffs." Environmental Management 44(2009):921-937. doi:10.1007/s00267-009-9353-1.

Larson K. L., Polsky C., Gober P., Chang H., Shandas V. "Vulnerability of Water Systems to the Effects of Climate Change and Urbanization: A Comparison of Phoenix, Arizona and Portland, Oregon (USA)." Environmental Management 52(2013):179-195. doi:10.1007/s00267-013-0072-2.

Lockett L., Montague T., McKenney C., Auld D. “Assessing Public Opinion on Water Conservation and Water Conserving Landscapes in the Semiarid Southwestern United States.” HortTechnology 12(2002):392-396.

Loss S. R., Ruiz M. O., Brawn J. D. "Relationships between Avian Diversity, Neighborhood Age, Income, and Environmental Characteristics of an Urban Landscape." Biological Conservation 142(2009):2578-2585. doi:10.1016/j.biocon.2009.06.004.

Mankad A., Tapsuwan S. "Review of Socio-Economic Drivers of Community Acceptance and Adoption of Decentralised Water Systems." Journal of Environmental Management 92(2011):380-391. doi:10.1016/j.jenvman.2010.10.037.

Martínez-Espiñeira R., García-Valiñas M. A., Nauges C. "Households' Pro-Environmental Habits and Investments in Water and Energy Consumption: Determinants and Relationships." Journal of Environmental Management 133(2014):174-183. doi:10.1016/j.jenvman.2013.12.002.

Martin C. A., Peterson K. A., Stabler L. B. "Residential Landscaping in Phoenix, Arizona, US: Practices and Preferences Relative to Covenants, Codes, and Restrictions." Journal of Arboriculture 29(2003):9-17. doi:10.1145/782941.782945.

Martini N. F., Nelson K. C., Dahmus M. E. "Exploring Homeowner Diffusion of Yard Care Knowledge as One Step toward Improving Urban Ecosystems." Environmental Management 54(2014):1223-1236. doi:10.1007/s00267-014-0368-x. 
McCready M. S., Dukes M. D. "Landscape Irrigation Scheduling Efficiency and Adequacy by Various Control Technologies." Agricultural Water Management 98(2011):697-704. doi:10.1016/j.agwat.2010.11.007.

Mills B. F., Schleich J. "Why Don't Households See the Light?: Explaining the Diffusion of Compact Fluorescent Lamps." Resource and Energy Economics 32(2010):363-378. doi:10.1016/j.reseneeco.2009.10.002.

Murray S. J., Foster P. N., Prentice I. C. "Future Global Water Resources with Respect to Climate Change and Water Withdrawals as Estimated by a Dynamic Global Vegetation Model." Journal of Hydrology 448-449(2012):14-29. doi:10.1016/j.jhydrol.2012.02.044.

Nautiyal M., Grabow G., Huffman R., Miller G., Bowman D. "Residential Irrigation Water Use in the Central Piedmont of North Carolina. Ii: Evaluation of Smart Irrigation Technologies." Journal of Irrigation and Drainage Engineering 141(2015):04014062. doi:10.1061/(ASCE)IR.1943-4774.0000820.

Prokopy L., Floress K., Klotthor-Weinkauf D., Baumgart-Getz A. "Determinants of Agricultural Best Management Practice Adoption: Evidence from the Literature." Journal of Soil and Water Conservation 63(2008):300-311. doi:10.2489/jswc.63.5.300.

Qin H., Romero-Lankao P., Hardoy J., Rosas-Huerta A. "Household Responses to Climate-Related Hazards in Four Latin American Cities: A Conceptual Framework and Exploratory Analysis." Urban Climate 14(2015):94-110. doi:10.1016/j.uclim.2015.05.003.

Rahm M. R., Huffman W. E. "The Adoption of Reduced Tillage: The Role of Human Capital and Other Variables." American Journal of Agricultural Economics 66(1984):405-413. doi:10.2307/1240918.

Roberts R. K., English B. C., Larson J. A., Cochran R. L., Goodman W. R., Larkin S. L., Marra M. C., Martin S. W., Shurley W. D., Reeves J. M. "Adoption of Site-Specific Information and Variable-Rate Technologies in Cotton Precision Farming." Journal of Agricultural and Applied Economics 36(2004):143-158. doi:10.1017/S107407080002191X.

Scheiber S., Beeson R. C. "Petunia Growth and Maintenance in the Landscape as Influenced by Alternative Irrigation Strategies." HortScience 41(2006):235-238.

Sharp E. B., Daley D. M., Lynch M. S. "Understanding Local Adoption and Implementation of Climate Change Mitigation Policy." Urban Affairs Review 47(2011):433-457. doi:10.1177/1078087410392348.

Shober A. L., Denny G. C., Broschat T. K. "Management of Fertilizers and Water for Ornamental Plants in Urban Landscapes: Current Practices and Impacts on Water Resources in Florida." HortTechnology 20(2010):94-106. 
Sinha T., Cherkauer K. A. "Impacts of Future Climate Change on Soil Frost in the Midwestern United States." Journal of Geophysical Research: Atmospheres (1984-2012) 115(2010). doi:10.1029/2009JD012188, 2010.

Smith L. S., Fellowes M. D. E. "The Grass-Free Lawn: Management and Species Choice for Optimum Ground Cover and Plant Diversity." Urban Forestry \& Urban Greening 13(2014):433-442. doi:10.1016/j.ufug.2014.04.008.

Sovocool K. A., Authority S. N. W., Morgan M. Xeriscape Conversion Study (Final Report. Southern Nevada Water Authority). 2005. Available online at http://www.snwa.com/assets/pdf/about_reports_xeriscape.pdf.

Sovocool K. A., Morgan M., Bennett D. “An In-Depth Investigation of Xeriscape as a Water Conservation Measure.” Journal (American Water Works Association) 98(2006):82-93

USDA Economic Research Service. US Drought 2012: Farm and Food Impacts. 2012. Available online at http://www.ers.usda.gov/topics/in-the-news/us-drought-2012-farm-and-food-i mpacts.aspx.

Volo T. J., Vivoni E. R., Ruddell B. L. “An Ecohydrological Approach to Conserving Urban Water through Optimized Landscape Irrigation Schedules." Landscape and Urban Planning 133(2015):127-132. doi:10.1016/j.landurbplan.2014.09.012.

Wamsler C., Brink E. "Moving Beyond Short-Term Coping and Adaptation." Environment and Urbanization 26(2014):86-111. doi:10.1177/0956247813516061.

Wanders N., Wada Y. "Human and Climate Impacts on the 21st Century Hydrological Drought." Journal of Hydrology 526(2015):208-220. doi:10.1016/j.jhydrol.2014.10.047.

Weber C., McCann L. "Adoption of Nitrogen-Efficient Technologies by US Corn Farmers." Journal of Environmental Quality 44(2015):391-401. doi:10.2134/jeq2014.02.0089.

West J. M., Julius S. H., Kareiva P., Enquist C., Lawler J. J., Petersen B., Johnson A. E., Shaw M. R. "US Natural Resources and Climate Change: Concepts and Approaches for Management Adaptation." Environmental Management 44(2009):1001-1021. doi:10.1007/s00267-009-9345-1.

Wooldridge J. M. Introductory Econometrics: A Modern Approach. Nelson Education, 2015 .

Yabiku S. T., Casagrande D. G., Farley-Metzger E. "Preferences for Landscape Choice in a Southwestern Desert City." Environment and Behavior 40(2008):382-400. doi:10.1177/0013916507300359. 


\section{CHAPTER 3. FARMERS' IRRIGATION DECISIONS AND ADOPTION OF PRESSURE IRRIGATION AND SCIENTIFIC SHEDULING PRACTICES}

Water scarcity is becoming more acute due to climate change and it poses substantial impacts on agriculture (Blanc and Reilly, 2015). To conserve water and use water more efficiently for irrigation, understanding farmers' decision-making on irrigation technology and practice adoption is essential. Using data from the national 2013 Farm and Ranch Irrigation Survey (FRIS) conducted by USDA, this study employs a mixed and multilevel approach to analyze both land- and crop-specific irrigation decisions. In the first stage, three land-level equations on irrigation share, irrigation rate, and harvest share are estimated. Results show that irrigation share, application rate and harvest share are associated with variables related to costs of water, equipment and labor, farm size, water sources, irrigation systems, barriers, information sources, etc. In the second stage, the adoption decisions are analyzed using multilevel models focusing on corn and soybean farms. The results suggest that, while adoption is affected by land area, off-farm surface water, various barriers and information sources, the variability of pressure irrigation adoption is mainly accounted for by factors at the state level, while the adoption of scientific scheduling practices is mainly accounted for by farm-level variation. Producers adopt pressure systems to respond to drought and reduce risk from extreme weather. Federal programs and policy should not only target specific barriers and increase the effectiveness of incentives at the farm level, but also address differing priorities in each state. Implications should benefit future policy design and improve education programs. 


\subsection{Introduction}

Climate change is expected to have substantial impacts on agriculture in the United States. For example, Ummenhofer et al. (2015) found that using multiple models, mean temperatures for the growing season in Iowa will increase by $5^{\circ} \mathrm{F}$ and corn yields decrease by $18 \%$ by the end of the $21^{\text {st }}$ century, thus having profound impacts on grain production and farmer livelihoods. The negative effects on crop yield may be reduced somewhat by farmers' adaptation responses (Blanc and Reilly, 2015). Midwestern farmers may plant drought tolerant varieties of their current crops and use no-till to increase infiltration, or they may instead change to deep-rooted perennials or begin to irrigate their crops.

Water scarcity is becoming more acute due to growing demand as a result of growing population and changing climate. In the U.S., agriculture is a major water user accounting for $80 \%$ of the national consumptive use of surface and ground water $^{13}$, and over $90 \%$ in many western states (Salazar et al., 2012). Regions of the U.S. that have not typically been associated with irrigation, such as the Southeast and Midwest, have seen increased adoption of irrigation in recent years to deal with potential dry conditions (Widmar, 2015). This indicates there will be more pressure to conserve water in agriculture and thus improve the sustainability of scarce water resources. Therefore understanding the factors affecting farmers' irrigation decisions and adoption of enhanced irrigation technologies such as drip irrigation or low-flow sprinklers, and of scientific scheduling practices for irrigation such as soil and plant moisture sensing devices, and commercial scheduling services, is needed to overcome

13 Rain water is not included in this estimate. 
real or perceived barriers to increasing adoption and conserving water through policy intervention or educational efforts.

While studies have focused on different combinations of factors to analyze the adoption of farm best management practices (BMP), the effects of various barriers, information and climate change have been understudied, in particular their effects at the farm level. In addition, the relationship between advanced irrigation methods and scientific scheduling practices needs to be examined. To better understand U.S. farmers' adaptation behaviors to climate change and the disincentives, we study the adoption of enhanced farm irrigation technologies and of scientific scheduling practices using an available USDA farm-level dataset. Specifically, this chapter aims to answer the following fundamental questions:

1) What affects farmers' decision-making regarding irrigation and harvest at the farm level?

2) What are the major barriers to adoption of enhanced farm irrigation technologies and of scientific irrigation scheduling practices, and what information is needed to overcome those barriers?

3) Are there any differences in adoption determinants between embodied technologies (e.g., pressure irrigation) and technologies that primarily provide improved information for irrigation practices (e.g., soil moisture sensors)?

4) How do farmers' perceptions of climate risks and climate variability affect their adoption behaviors and land-level irrigation decisions?

The analyses in this chapter are structured as in figure 3.1. Stage I consists of analyses of land-level irrigation decisions focusing on irrigation share, irrigation rate, and harvest share. Stage 2 is composed of analyses of crop-specific adoption 
decisions on pressure irrigation systems and scientific scheduling practices. The crop-specific adoption decisions are analyzed using multilevel models.

Figure 3.1. Layout of the analyses in chapter 3.

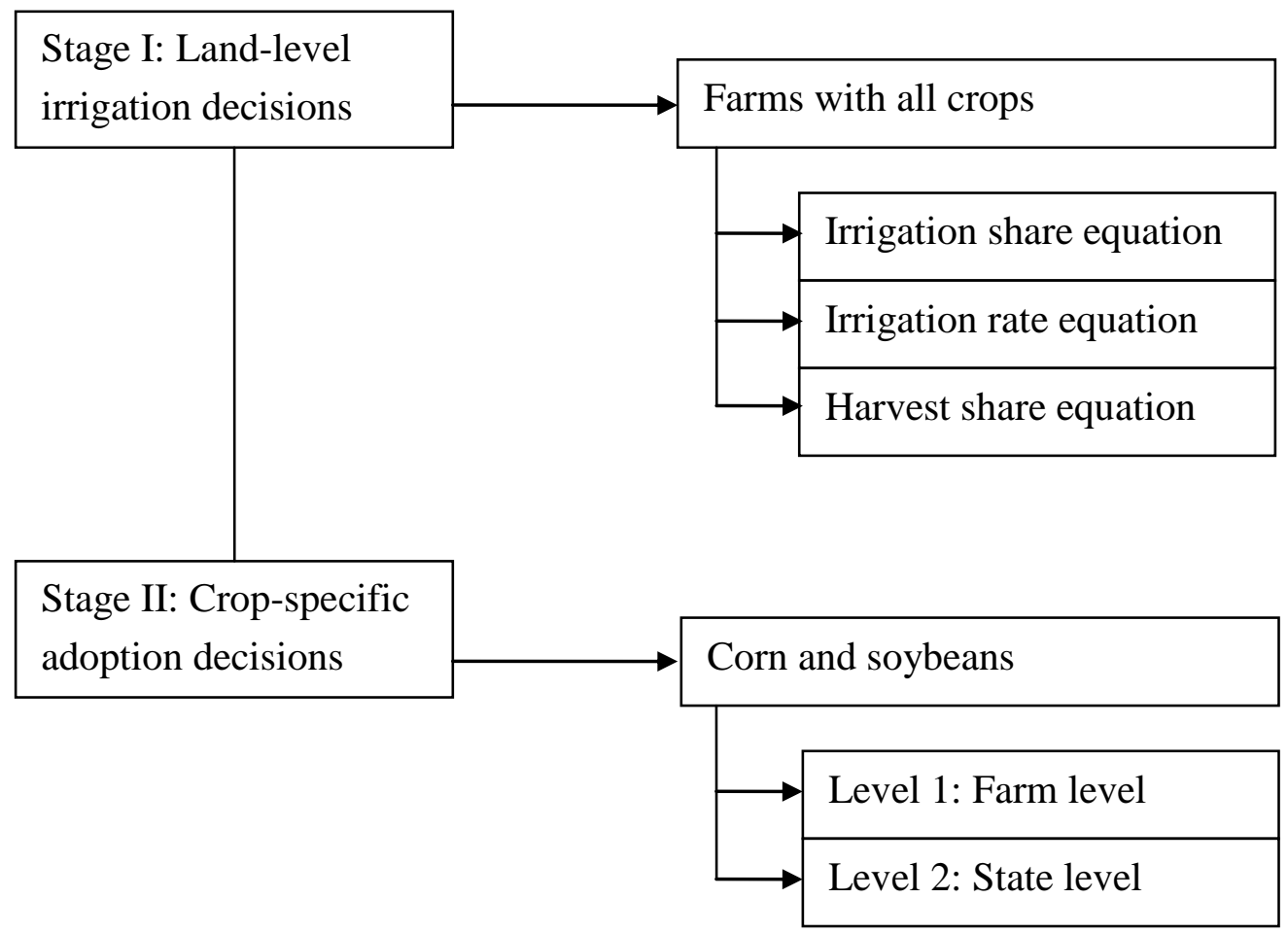

\subsection{Literature Review on Farmers' Water Conservation Practices}

Water conservation in the agriculture sector is fundamental to the sustainable use of scarce water resources (Ayars et al., 2015; Bozzola and Swanson, 2014).

Traditionally, farms have been irrigated using gravity irrigation systems (also known as surface or flood irrigation), where water carried by canals or pumped from wells flows to fields by the force of gravity. The water soaks slowly into the field to irrigate crops. In some cases small trenches or furrows are created in the field to guide water flow. This method is generally less efficient than newer technologies and its use has been decreasing in the U.S. according to the Census of Agriculture (NASS, 2014). 
Various approaches to water conservation have been explored, such as developing irrigation techniques (e.g., Tanwar et al. (2014)), improving water use efficiency, increasing investment in irrigation infrastructure such as canals, wells and drip systems (e.g., Kang et al. (2012)), and designing water conservation policies (e.g., Bozzola and Swanson (2014)). Water-conserving irrigation systems have been proposed and applied to various crops in many farming areas around the world. For instance, in eastern Australia (Sadras and Rodriguez, 2010), arid and semi-arid areas in China (e.g., Fan et al. (2014) and Kang et al. (2012)), and southern and southeastern U.S. (Salazar et al., 2012; Schneider and Howell, 2001; Vories et al., 2009). Examples include pressure (or pressurized) irrigation systems (versus gravity irrigation methods), including linear move, center pivot, sprinkler and drip irrigation methods. Field experiments with sprinkler and drip irrigation and their comparison with traditional flood or furrow irrigation have been conducted on various crops worldwide (e.g., Dağdelen et al. (2009), Ibragimov et al. (2007), Liu et al. (2010), Salvador et al. (2011), and Usman et al. (2010)). As a result, crop irrigation water use efficiency $^{14}$ (the amount of crop output per unit of water applied) can be improved and a substantial quantity of water could be conserved by the enhanced irrigation systems $^{15}$.

In addition, scientific irrigation scheduling has been adopted to determine when and how much to irrigate. Some common practices adopted by U.S. farmers include the condition of crops, reports on crop evapotranspiration, soil moisture sensors,

\footnotetext{
${ }^{14}$ The crop water use efficiency at the farm level will be examined in the next chapter.

15 According to the Jevons Paradox, increased efficiency tends to increase overall resource use. As water use efficiency increases, farmers might irrigate more acres. Given the limited availability of water and the fact that the overall irrigated area in U.S. was roughly flat in 1997-2012 (though we see variation of irrigated area in states like Mississippi, Illinois, Iowa, Kansas, etc.), the Jevons Paradox is less likely to be an issue for water resources across the U.S. Thus this paper will not focus on the paradox.
} 
irrigation scheduling models (George et al., 2004; George et al., 2000; Hurd et al., 2006; Leib et al., 2001; Sammis et al., 2012), irrigation scheduling services (Pereira, 1999), etc. Focusing on the application of irrigation scheduling tools in cotton production with under-surface irrigation in central Arizona, Hunsaker et al. (2015) compared ET-based irrigation scheduling methods with traditional border-irrigation scheduling practices. Their results showed that compared with experience-based irrigation decision-making, the ET-based irrigation scheduling could improve irrigation water productivity, and indicated that there was great potential for conserving water on surface-irrigated cotton fields.

Much research has shown advanced irrigation systems and scientific scheduling practices could improve irrigation water use efficiency, conserve water and/or increase grain yield. In studying application of improved practices for farm irrigation in Alberta, Canada, Bjornlund et al. (2009) concentrated on improved irrigation technologies including advanced pressurized methods, and improved management practices including monitoring soil moisture using hand-feel method, soil monitoring instruments, computer programs and private consultants. There was a potential of a $30 \%$ increase in water use efficiency which necessitated increasing the adoption of more efficient practices for farm management, and improving efficiencies of irrigation systems in the short term. Based on a database management system, George et al. (2000) built an irrigation model for the adoption of scheduling farm irrigation with multiple choices for improving both single and multiple field management. With the flexible and user-friendly tool for scheduling farm irrigation, water was used more efficiently, and simulations showed higher bean yield than measured yield.

Technologies can also be complementary and adopted as a package. Weber and McCann (2015) found that conservation tillage increased the adoption of nitrogen 
inhibitors and plant tissue testing, while irrigation decreased the adoption of nitrogen soil testing. Kara et al. (2008) confirmed that conservation practices are likely to be co-adopted with others, including conservation tillage, yield monitors, grassed waterways, commercial fertilizer plan, manure management plan, erosion plan, soil nutrient testing, and filter strips. Similarly, efficient use of irrigation water through enhanced irrigation methods can also be facilitated by other information provided by commercial companies, government, environmental organizations, etc.

\subsection{Hypotheses}

Factors affecting farmers' adoption behaviors and irrigation decisions are reviewed, and hypotheses are constructed in this section. Farmers' decision-making on farm irrigation and adoption of irrigation practices is hypothesized to be a function of expected profit, costs, perceived barriers, information availability, farm and farmer characteristics, and their environmental attitudes and perceptions of climate change.

Profitability, or lack thereof, is a leading determinant affecting adoption of farm conservation practices (Contant and Korsching, 1997; Gedikoglu and McCann, 2012; Gedikoglu et al., 2011; Núñez and McCann, 2005; Prokopy et al., 2008). Lambert et al. (2006) pointed out due to high expected profits of the management intensive BMP, their adoption rates were also high among commercial farmers. High expected profits were reported to be major factors for Iowa swine farmers when adopting manure management techniques (Fleming et al., 1998). Therefore, farmers are hypothesized to adopt the practices if they expect high profits.

Cost can be fundamental for farmers' decision-making in adopting new irrigation technologies. According to various reports, the capital and annual costs for surface irrigation range from $\$ 67$ (Colorado Agricultural Water Alliance, 2008) to \$200 per 
acre (Amosson et al., 2011). For sprinkler systems, total annual costs for capital, operating and ownership can range from $\$ 468$ (Amosson et al., 2011) to $\$ 1273$ per acre (Scherer, 2010). For drip irrigation systems, the annual costs for installation and operation is $\$ 1009$ (Amosson et al., 2011) to $\$ 1200$ per acre (Simonne et al., 2008). In addition, costs of moisture sensing devices include installation, manual measurement, data logging, data transmitting, and data interpretation. The annual costs differ based on technology and source, ranging from $\$ 500-\$ 900$ to measure one field with a specific soil type at three depths (Payero et al., 2013) to around $\$ 1300-\$ 2000$ or more to measure several fields (Morris and Energy, 2006). Per acre costs will depend on the size of the field. Low costs also increased the adoption of manure management techniques in Iowa swine farmers (Fleming et al., 1998). Adoption of these technologies and sensing devices thus requires financial investments (Bogena et al., 2007) and high costs are expected to decrease adoption.

Adoption of these irrigation practices faces many barriers. Using data on 17 western states from USDA Farm and Ranch Irrigation Survey (FRIS), Schaible et al. (2010) studied dynamic adjustment of irrigation technology and pointed out some major barriers impacting the adoption of enhanced irrigation technologies. The most important barriers were related to investment cost and financing issues. Greater sharing of costs by government or landlords for installation of advanced irrigation techniques can improve their adoption rates especially for beginning farmers with limited resources and social disadvantages (Schaible and Aillery, 2012). Moreover, uncertainty about future water availability and farming status could influence farmers' willingness to adopt. Hence, uncertainties regarding potential costs and future benefits will limit adoption of water conservation practices (Rogers, 2003; Sunding and Zilberman, 2001). 
Information availability and its sources can affect farm irrigation decisions (Prokopy et al., 2008). On the one hand, limited information can be an obstacle to adopting irrigation technologies. Rodriguez et al. (2009) pointed out that lack of information on irrigation, crop management, effectiveness of practices and government programs could be common obstacles for early adopters when facing the uncertainty of changing to something unknown. On the other hand, effective information can facilitate optimal irrigation decisions by farmers. Frisvold and Deva (2012) studied water information used by irrigators and the relationship of information acquisition and irrigation management. Their study indicated that appropriate information use could benefit irrigation management and crop production for farmers with varying acreage. Thus more information on how to conserve water is expected to increase adoption of water-saving irrigation practices (Nowak, 1987; Pannell et al., 2006; Rogers, 2003).

In addition, adoption can also be affected by farm characteristics including soil conditions, topography, farming system, size, etc. Schaible et al. (2010) found that some physical conditions of crop and field as well as topography affected irrigation adoption. Kadiyala et al. (2015) reported that soil properties and soil moisture were important indicators for adoption of irrigation management practices. Farm size (measured by sales or acres) is positively associated with the adoption of technologies (Feder et al., 1985; Kara et al., 2008) and farm BMP (Daberkow and McBride, 1998; Lambert et al., 2006; Prokopy et al., 2008). Larger farm size was positively associated with adoption of conservation tillage (Fuglie and Kascak, 2001), integrated pest management practices, soil testing, and precision soil sampling (Walton et al., 2008). Bekele and Drake (2003), and Jara-Rojas et al. (2012) showed that larger farm size significantly increases the adoption of recommended irrigation practices and of drip 
irrigation systems. Considering the large up-front cost involved with new irrigation technologies mentioned above, farm size is hypothesized to have a positive effect.

Furthermore, water sources can be good indicators of water supply institutions. Olen et al. (2016) found among west coast farms, the adoption of sprinkler and drip irrigation were negatively associated with water from federal and surface supply, while positively associated with ground water supply. Thus more wells are expected to increase the adoption of irrigation practices, while surface water decreases the adoption. In addition, surface water in the West is a "use it or lose it" system, so producers have little incentive to conserve.

Regional variables could capture the differences in climate, water institutions, and supporting infrastructure (Negri et al., 2005) as well as farming systems. More generally, which irrigation technologies are appropriate will vary spatially. For example, western states tend to have concentrated irrigation acreage and their irrigation institutions are well established (Negri et al., 2005). Eastern and southern states receive moderate amounts of rainfall to support agriculture and do not rely as heavily on irrigation. Thus we hypothesize that compared with those in the high plains states, more farmers in western states will adopt irrigation practices, while fewer farmers in eastern and southern states adopt.

Specific farming systems need to be considered in the adoption decisions. Research has shown adoption rates of BMPs can be affected by compatibility with values and goals of the farmer (Rogers, 2003) and previous investments (Stoneman, 2001). Some irrigation technologies may not be compatible with some crops such as potatoes which need to be dug up, while drip irrigation is more suitable for perennial crops. Thus varying effects on the adoption decisions are expected considering each specific crop. 
Individuals should not only have adequate knowledge about the consequences of their activities on the environment but also be able and motivated to respond. As far as irrigation technology and BMP adoption, awareness of climate change (e.g., drought and heat waves) could motivate farmers to prepare for and take actions to adapt to future risks on production (Jin et al., 2015; Li et al., 2010). Olen et al. (2016) found farmers were more likely to adopt advanced water-saving irrigation systems, for instance, sprinkler, to mitigate and adapt to various weather and climate impacts including frost, heat, drought, etc. Therefore, farmers are hypothesized to adopt if they perceive less precipitation, higher temperature or more losses due to droughts.

\subsection{Data}

A national dataset from the USDA 2013 Farm and Ranch Irrigation Survey was used in this study. The survey was designed by the USDA Water Initiative Team, collaborating with the National Agricultural Statistics Service (NASS) and the Economic Research Service (ERS), as well as personnel from government organizations and universities with expertise in agricultural irrigation and the irrigation industry. The survey was conducted primarily by mail in January-May of 2014 after pretesting and modification, and the mailings were initially sent out to approximately 31,300 farm and ranch operations covering the major irrigators in each state. Data were also collected by Electronic Data Reporting via the internet, telephone, and personal enumeration with the input of NASS field office staff. The final response rate was 77.8 percent with data available on 34,966 farms in the 50 states, and thus FRIS represents a very high quality dataset.

Because there are missing values in one or more variables, FRIS provides varying numbers of observations. As mentioned below, for the three dependent variables in the first stage equations, the share of irrigated cropland (IS), irrigation application rate 
(AR), and share of harvested cropland (HS) ${ }^{16}$, there is valid information on 19,272 irrigated farms covering the lower 48 US states, which are used to estimate the three equations.

At the farm level, farmers' irrigation decisions and water conservation practices are studied. As presented in the descriptive statistics below, this study incorporates independent variables on water cost, expenditures on irrigation equipment, labor payment, area of land owned or leased, water sources, irrigation systems, barriers for improvements, information sources, production regions, crop diversity, etc.

At the state level, the explanatory variables are state-level average changes in precipitation and temperature in 2012 and 2013 compared with that of 1981-2010 (National Oceanic and Atmospheric Administration (NOAA)). The application of a two-level model focuses on corn and soybean farms regarding the adoption of pressure irrigation systems and scientific irrigation scheduling practices ${ }^{17}$. Pressure (or pressurized) irrigation systems include linear move, center pivot, spray, sprinklers, drip irrigation, etc. Adoption of scientific scheduling practices refers to application of at least one among soil/plant moisture-sensing devices, commercial and government irrigation scheduling services, and reports on daily crop-water evapotranspiration use from internet, TV, etc.

Though the FRIS dataset is regarded as a high-quality, highly representative sample, the study sample is fairly good as there are more than 30 variables included in

\footnotetext{
16 Share of irrigated cropland is defined as irrigated acreage divided by the total area of planted cropland (percentage). Irrigation application rate is the amount of water applied per acre (acre-feet per acre). Share of harvested cropland is acres harvested divided by the total area of planted cropland (percentage).

17 Traditional irrigation typically uses gravity systems, including flood, furrow, and border irrigation. Traditional irrigation scheduling practices include condition of crop based on farmers' observation or experience, and feel of soil. In the later analysis, the benchmark for the adoption of pressure irrigation systems is gravity systems, while the benchmark for the adoption of scientific scheduling practices is traditional scheduling practices only.
} 
each equation and one or more of these variables have missing values ${ }^{18}$. By excluding and/or appropriately transforming variables with missing values, this study includes 19,272 farms to estimate the IS, AR and HS equations.

\subsection{Methods}

Farmers are assumed to make irrigation and adoption decisions towards the maximization of the expected utility, which is affected by a set of influential factors. Given the complexity of the FRIS data mentioned above, an approach combining mixed and multilevel models could deal with factors at multiple hierarchical levels affecting the variation of responses (Lu and Yang, 2012). To study the effects of these factors, this research considers an irrigation decision and adoption framework incorporating equations at two stages (Olen et al., 2016). The first stage explores effects of the influential factors on the share of irrigated cropland (eq. 3.1a), on the water allocation rates (eq. 3.1b), and on the share of harvested cropland ${ }^{19}$ (eq. 3.1c). The models are specified and estimated based on farm-level equations using multiple estimation techniques.

$$
\begin{aligned}
& \boldsymbol{Y}_{1 \boldsymbol{i}}=\beta_{10}+\boldsymbol{\beta}_{1 i} \boldsymbol{X}_{\boldsymbol{i}}+e_{1} \\
& \boldsymbol{Y}_{2 \boldsymbol{i}}=\beta_{20}+\boldsymbol{\beta}_{2 i} \boldsymbol{X}_{\boldsymbol{i}}+e_{2} \\
& \boldsymbol{Y}_{3 \boldsymbol{i}}=\beta_{30}+\boldsymbol{\beta}_{3 i} \boldsymbol{X}_{\boldsymbol{i}}+e_{3}
\end{aligned}
$$

where $\boldsymbol{Y}_{\mathbf{1}}, \boldsymbol{Y}_{\mathbf{2}}$ and $\boldsymbol{Y}_{\mathbf{3}}$ are share of irrigated land, water application rates and share of harvested cropland; $\boldsymbol{X}$ are independent variables mentioned above; and

\footnotetext{
18 Though there are multiple techniques to deal with the missing values, this study is not focusing on any. Appropriate treatment of the missing values may determine the quality of the analysis, biasedness and validity of the results.

${ }^{19}$ Land includes cropland and pasture. Both cropland and pasture are investigated in the survey and may be irrigated or not. This chapter just focuses on irrigated cropland.
} 
$\boldsymbol{\beta}_{1}, \boldsymbol{\beta}_{\mathbf{2}}$ and $\boldsymbol{\beta}_{\mathbf{3}}$ are corresponding parameters. Subscript $i$ indicates the $i^{\text {th }}$ farm $(i=1,2, \ldots, N)$.

The second stage includes both farm- and state-level equations. The farm-level equation specifies effects of the influential factors on farmers' decisions regarding adoption of pressure irrigation methods and scientific scheduling practices (eq. 3.2). The state-level equation enables us to access whether some state-level factors account for the variability in adoption behaviors. For the two-level model, this chapter just takes corn and soybean farms as an example $\mathrm{e}^{20}$ and a general model specification is constructed as follows.

For the research questions, I have an individual farm $i$ growing one specific crop $\left(i=1, \ldots, N_{j}\right.$, and $\left.\sum_{1}^{J} N_{j}=N\right)$ in $j^{\text {th }}$ state in U.S. $(j=1, \ldots, J)$. Specifically, at the farm level, dependent variables include famers' decisions regarding adoption of irrigation methods and scientific scheduling practices, and a series of independent variables $\left(\boldsymbol{X}_{\boldsymbol{i} \boldsymbol{j}}\right)$ represent all the influential factors mentioned above. At the state level, I have a set of variables $\left(\boldsymbol{Z}_{\boldsymbol{j}}\right)$ measuring climate variability. The model estimation takes two steps. In the first step, a single regression equation can be specified in each state to estimate the effects of the explanatory variables. The estimation can be specified as:

$$
\boldsymbol{Y}_{i j}=\beta_{0 j}+\boldsymbol{\beta}_{1 j} \boldsymbol{X}_{i j}+e_{i j}
$$

where $\boldsymbol{Y}_{\boldsymbol{i} \boldsymbol{j}}$ can be one of the crop-specific dependent variables in $i^{\text {th }}$ individual farm $\left(i=1, \ldots, N_{j}\right)$ in the $j^{t h}$ state $(j=1, \ldots, J)$.

In the second step, the intercepts, $\boldsymbol{\beta}_{\mathbf{0} \boldsymbol{j}}$ 's, are considered as parameters varying across states as a function of an overall mean $\left(\gamma_{00}\right)$ and a random error term $\left(u_{0 j}\right)$.

\footnotetext{
${ }^{20}$ Corn and soybeans are the most commonly planted crop and accounts for $30 \%$ and $20 \%$ of total number of irrigated farmers in the survey. Results on other crops turn out to be very similar.
} 
The $\beta_{1 j}$ 's are assumed fixed across states and are presented as a function of constant parameters $\left(\gamma_{10}\right)$.

$$
\boldsymbol{\beta}_{0 j}=\gamma_{00}+\gamma_{01} \boldsymbol{Z}_{j}+u_{0 j}
$$

and

$$
\beta_{1 j}=\gamma_{10}
$$

The model is called a random-intercept only model ${ }^{21}$, as "the key feature of such models is that only the intercept parameter in the Level-1 model, $\beta_{0 j}$, is assumed to vary at Level-2" (Raudenbush and Bryk, 2002). The $\gamma_{01}$ coefficient represents the effects of the state-level variables $\left(Z_{j}\right)$ on the $\beta_{0 j}$ 's, and $\gamma_{10}$ represents the constant parameter, $\beta_{1 j}$. This multilevel model has been applied in social science research (Dolisca et al. (2009) and Guerin et al. (2001)).

With official permission, the FRIS dataset was analyzed using software SAS 9.4 at the USDA-NASS National Operations Division offices in St. Louis, Missouri.

\subsection{Results}

\subsubsection{Descriptive statistics}

The summary statistics of independent variables are presented in table 3.1. Water cost is measured by the mean values of energy expenses for pumping groundwater and payment for off-farm surface water. The expenditures on facility and infrastructure and labor payment are measured by the farm mean values. The average water price is 177 dollars/acre-foot. The mean average facility expenses and labor payments are 55 and 93 dollars/acre, respectively. The variables on farming area

\footnotetext{
${ }^{21}$ The detailed model specifications for categorical and continuous dependent variables are provided in the appendix.
} 
include the areas of land owned and land rented. The mean areas of land owned and rented are 1,391 and 1,079 acres/farm.

Farmers may use water for irrigation from one or more sources. Four water sources are investigated including groundwater only, on- and off- farm surface water only, and two or more water sources (Yes $=1, \mathrm{No}=0)$. About $53 \%$ use groundwater only, while water from on- and off-farm surface sources only account for $11 \%$ and $20 \%$, respectively. About $17 \%$ of farms get water from two or more sources. Number of wells used to irrigate crops is also included in the regressions and on average 5.44 wells are used on each farm. For irrigation systems, about $22 \%$ use gravity systems only, while those only using sprinkler or drip irrigation take $45 \%$ and $12 \%$, respectively. About $22 \%$ of the farms use two or more types of irrigation systems.

Regarding the barriers to implementing improvements for the reduction of energy costs or water use, nine barriers are investigated in the national survey. Respondents can select one or more barriers they are facing. Major ones include: investigating improvement is not a priority at this time, limitation of physical yield or poorer quality crop, not enough to recover implementation costs, cannot finance improvements, and uncertainty about future water availability.

For the eight sources of irrigation information, the top ones are extension agents, irrigation equipment dealers, private irrigation specialists, neighboring farmers, e-information services, and government specialists, indicated by $33 \%, 29 \%, 21 \%$, $22 \%, 15 \%$ and $13 \%$, respectively. 
Table 3.1. Summary statistics of farm-level independent variables $(N=19,272)$.

\begin{tabular}{|c|c|c|c|c|c|c|}
\hline Variable & Description (Unit) & Mean & Std Dev & $\mathbf{C V}$ & Min & Max \\
\hline \multicolumn{7}{|l|}{ Payments } \\
\hline Water cost & $\begin{array}{l}\text { Average water costs, including energy costs and } \\
\text { water payment (\$/acre-foot) }\end{array}$ & 177 & 1238 & 6.98 & (D) & \\
\hline Irrigation equipment expense & $\begin{array}{l}\text { Average expenditures for irrigation facilities and } \\
\text { equipment (\$/acre) }\end{array}$ & 55 & 637 & 11.56 & (D) & \\
\hline Labor payment & Average labor payment (\$/acre) & 93 & 1826 & 19.53 & (D) & \\
\hline \multicolumn{7}{|l|}{ Farm Size } \\
\hline Land owned & Land owned - leased to others (Acres) & 1391 & 10734 & 7.72 & (D) & \\
\hline Land leased & Land rented or leased from others (Acres) & 1079 & 5851 & 5.42 & (D) & \\
\hline \multicolumn{7}{|l|}{ Water Source } \\
\hline Groundwater only (Base) & $\mathrm{Yes}=1 ; \mathrm{No}=0$ & 0.5254 & 0.4994 & 0.95 & 0 & 1 \\
\hline On farm surface water only & $\mathrm{Yes}=1 ; \mathrm{No}=0$ & 0.1083 & 0.3108 & 2.87 & 0 & 1 \\
\hline Off farm surface water only & Yes $=1 ; \mathrm{No}=0$ & 0.1976 & 0.3982 & 2.02 & 0 & 1 \\
\hline Two or more water sources & $\mathrm{Yes}=1 ; \mathrm{No}=0$ & 0.1686 & 0.3744 & 2.22 & 0 & 1 \\
\hline \# of Wells & Number of wells used in 2013 & 5.4440 & 12.2542 & 2.25 & $\mathrm{a}$ & \\
\hline \multicolumn{7}{|l|}{ Irrigation System } \\
\hline Gravity only (Base) & $\mathrm{Yes}=1 ; \mathrm{No}=0$ & 0.2172 & 0.4123 & 1.90 & 0 & 1 \\
\hline Sprinkler only & $\mathrm{Yes}=1 ; \mathrm{No}=0$ & 0.4496 & 0.4975 & 1.11 & 0 & 1 \\
\hline Drip only & $\mathrm{Yes}=1 ; \mathrm{No}=0$ & 0.1180 & 0.3226 & 2.73 & 0 & 1 \\
\hline Two or more systems & $\mathrm{Yes}=1 ; \mathrm{No}=0$ & 0.2152 & 0.4110 & 1.91 & 0 & 1 \\
\hline
\end{tabular}




\section{Barriers for Improvements}

Investigating improvement is not a priority

Risk of reduced yield or poorer quality crop Limitation of physical field or crop conditions

Not enough to recover implementation costs

Cannot finance improvements

Landlords will not share improvement costs

Uncertainty about future water availability

Will not be farming long enough

Will increase management time or cost

\section{Information Source}

Extension agents

Private irrigation specialists

Irrigation equipment dealers

Local irrigation district employees

Government specialists

Media reports

Neighboring farmers

E-information services

\section{Improvements and Assistance}

Irrigation improvements

Technical and financial assistance

Value of Sales

\$0-9,999

$\$ 10,000-24,999$
$\mathrm{Yes}=1 ; \mathrm{No}=0$

$\mathrm{Yes}=1 ; \mathrm{No}=0$

$\mathrm{Yes}=1 ; \mathrm{No}=0$

$\mathrm{Yes}=1 ; \mathrm{No}=0$

$\mathrm{Yes}=1 ; \mathrm{No}=0$

$\mathrm{Yes}=1 ; \mathrm{No}=0$

$\mathrm{Yes}=1 ; \mathrm{No}=0$

$\mathrm{Yes}=1 ; \mathrm{No}=0$

$\mathrm{Yes}=1 ; \mathrm{No}=0$

$\mathrm{Yes}=1 ; \mathrm{No}=0$

$\mathrm{Yes}=1 ; \mathrm{No}=0$

$\mathrm{Yes}=1 ; \mathrm{No}=0$

Yes $=1 ; \mathrm{No}=0$

$\mathrm{Yes}=1 ; \mathrm{No}=0$

$\mathrm{Yes}=1 ; \mathrm{No}=0$

$\mathrm{Yes}=1 ; \mathrm{No}=0$

$\mathrm{Yes}=1 ; \mathrm{No}=0$

Yes $=1 ; \mathrm{No}=0$

Yes $=1 ; \mathrm{No}=0$

$\mathrm{Yes}=1 ; \mathrm{No}=0$

Yes $=1 ; \mathrm{No}=0$

$\begin{array}{lllll}0.1880 & 0.3908 & 2.08 & 0 & 1 \\ 0.0849 & 0.2788 & 3.28 & 0 & 1 \\ 0.0992 & 0.2990 & 3.01 & 0 & 1 \\ 0.1538 & 0.3608 & 2.35 & 0 & 1 \\ 0.1537 & 0.3607 & 2.35 & 0 & 1 \\ 0.0853 & 0.2793 & 3.28 & 0 & 1 \\ 0.0940 & 0.2919 & 3.10 & 0 & 1 \\ 0.0761 & 0.2652 & 3.48 & 0 & 1 \\ 0.0705 & 0.2559 & 3.63 & 0 & 1 \\ & & & & \\ 0.3255 & 0.4686 & 1.44 & 0 & 1 \\ 0.2102 & 0.4075 & 1.94 & 0 & 1 \\ 0.2966 & 0.4568 & 1.54 & 0 & 1 \\ 0.0635 & 0.2439 & 3.84 & 0 & 1 \\ 0.1293 & 0.3355 & 2.59 & 0 & 1 \\ 0.1011 & 0.3015 & 2.98 & 0 & 1 \\ 0.2244 & 0.4172 & 1.86 & 0 & 1 \\ 0.1548 & 0.3618 & 2.34 & 0 & 1 \\ & & & & \\ 0.4117 & 0.4922 & 1.20 & 0 & 1 \\ 0.1669 & 0.3729 & 2.23 & 0 & 1 \\ & & & & \\ 0.1275 & 0.3336 & 2.62 & 0 & 1 \\ 0.0567 & 0.2313 & 4.08 & 0 & 1\end{array}$


$\$ 25,000-49,999$

$\$ 50,000-99,999$

$\$ 100,000-249,999$ (Base)

$\$ 250,000-499,999$

$\$ 500,000-999,999$

$\$ 1,000,000$ and above

$$
\begin{aligned}
& \text { Yes }=1 ; \mathrm{No}=0 \\
& \text { Yes }=1 ; \mathrm{No}=0 \\
& \text { Yes }=1 ; \mathrm{No}=0 \\
& \text { Yes }=1 ; \mathrm{No}=0 \\
& \text { Yes }=1 ; \mathrm{No}=0 \\
& \text { Yes }=1 ; \mathrm{No}=0
\end{aligned}
$$

Yes $=1 ; \mathrm{No}=0$

Yes $=1 ; \mathrm{No}=0$

Yes $=1 ; \mathrm{No}=0$

$\mathrm{Yes}=1 ; \mathrm{No}=0$

Yes $=1 ; \mathrm{No}=0$

Number of crops planted per farm

$\begin{array}{lllll}0.0530 & 0.2240 & 4.23 & 0 & 1 \\ 0.0704 & 0.2558 & 3.63 & 0 & 1 \\ 0.1202 & 0.3252 & 2.71 & 0 & 1 \\ 0.1208 & 0.3259 & 2.70 & 0 & 1 \\ 0.1464 & 0.3535 & 2.41 & 0 & 1 \\ 0.3050 & 0.4604 & 1.51 & 0 & 1\end{array}$

2.76

$\begin{array}{ll}0.4146 & 1.88\end{array}$

$\begin{array}{lll}0.1849 & 0.3882 & 2.10\end{array}$

0.1808

0.3848

2.13

0.67

(D): Extreme values withheld to avoid disclosing data for individual farms. 
About $42 \%$ of the farmers made irrigation and/or drainage improvement above regular maintenance, and $17 \%$ received technical or financial assistance. Regarding value of sales, top categories are $\$ 100,000-249,999, \$ 250,000-499,999$, $\$ 500,000-999,999$, and $\$ 1,000,000$ and above, accounting for approximately $12 \%$, $12 \%, 15 \%$, and $31 \%$, respectively. For the location, this study includes more farms in the West and Midwest, 30\% and 22\%, receptively, and fewer farms in the high plains, which account for $12 \%$. These patterns are different regarding corn and soybean farms included in the MLMs later (see table A3.1 in the appendix). The mean number of crops planted on each farm is 2.13 .

The state-wide average weather related variables are presented in table 3.2 for the 43 states planting corn. Compared with the 1981-2010 normal precipitation, the changes for 2012 and 2013 are -3.89 and 2.87 inches. Compared with the 1981-2010 normal temperature, the changes for 2012 and 2013 are 2.41 and $-0.50^{\circ} \mathrm{F}$. Therefore, 2013, the year covered by the survey, was more favorable as far as rainfall.

The summary statistics of dependent variables are also presented in table $3.2^{22}$, among the 19,272 farms with irrigated croplands, about $67 \%$ of total area is irrigated. The average irrigation water application rate is 1.22 acre-feet per acre. The share of the harvested cropland is $91 \%$ for 6389 farms. In addition, for the dependent variables related with corn and soybeans. There are a total of 6030 irrigated farms planting corn in 2013 with $81 \%$ utilizing pressure irrigation systems, and 34\% adopting at least one of the four scientific irrigation scheduling practices. There are 3933 soybean farms with $72 \%$ adopting pressure irrigation, and $34 \%$ adopting scientific scheduling practices.

\footnotetext{
${ }^{22}$ The crop-specific analyses just focus on (partially) irrigated farms, while excluding absolutely non-irrigated farms.
} 
Table 3.2. Summary statistics of farm-level and crop-specific dependent variables and state-level independent variables.

\begin{tabular}{|c|c|c|c|c|c|c|c|}
\hline Variable & Description (Unit) & $\mathbf{N}$ & Mean & Std Dev & $\mathbf{C V}$ & Min & Max \\
\hline \multicolumn{8}{|c|}{ Farm-level dependent variables } \\
\hline IrrigationShare & Percent of cropland irrigated (\%) & 19272 & 0.6716 & 0.3449 & 0.51 & 0 & 1 \\
\hline WaterApplicationRate & Average irrigation water applied (Acre-feet per acre) & 19272 & 1.2168 & 1.0232 & 0.84 & 0 & 1 \\
\hline HarvestShare & Percent of cropland harvested $(\%)$ & 19272 & 0.9091 & 0.2035 & 0.22 & 0 & 1 \\
\hline \multicolumn{8}{|c|}{ Crop-specific dependent variables } \\
\hline \multicolumn{8}{|l|}{ Corn } \\
\hline PressureIrrigation & Adoption of pressure irrigation systems, $\mathrm{Yes}=1 ; \mathrm{No}=0$ & 6030 & 0.81 & 0.39 & 0.48 & 0 & 1 \\
\hline SchedulingPractice & $\begin{array}{l}\text { Adoption of scientific scheduling practices: at least one of soil/plant } \\
\text { moisture-sensing devices, commercial/government scheduling } \\
\text { services, and reports on daily crop-water evapotranspiration use, } \\
\text { Yes }=1 ; \text { No=0 }\end{array}$ & 6030 & 0.34 & 0.47 & 1.40 & 0 & 1 \\
\hline \multicolumn{8}{|c|}{ 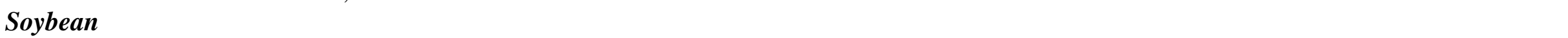 } \\
\hline PressureIrrigation & Same as above & 3933 & 0.72 & 0.45 & 0.62 & 0 & 1 \\
\hline SchedulingPractice & & 3933 & 0.30 & 0.46 & 1.52 & 0 & 1 \\
\hline \multicolumn{8}{|c|}{ State-wide average weather-related variables } \\
\hline PrecipChange 2012 & Precipitation in $2012-$ Average precipitation in 1981-2010 (inch) & 43 & -3.89 & 4.91 & 1.26 & -13.40 & 10.30 \\
\hline TempChange2012 & Temperature in $2012-$ Average temperature in $1981-2010(\mathrm{~F})$ & 43 & 2.41 & 1.17 & 0.49 & -1.70 & 4.00 \\
\hline PrecipChange 2013 & Precipitation in $2013-$ Average precipitation in 1981-2010 (inch) & 43 & 2.87 & 10.23 & 3.57 & -15.19 & 59.00 \\
\hline TempChange2013 & Temperature in $2013-$ Average temperature in $1981-2010(\mathrm{~F})$ & 43 & -0.50 & 0.74 & 1.49 & -2.20 & 0.90 \\
\hline
\end{tabular}




\subsubsection{Estimation results}

\subsubsection{Irrigation share}

The estimated results for the share of irrigated land equation ${ }^{23}$ are presented in table 3.3. Three models are estimated for the fractional dependent variable, including OLS with log odds, fractional logit and Tobit ${ }^{24}$. The R-squared for OLS-log odds is 0.29. When comparing AIC and BIC (smaller is better) from fractional logit and Tobit models, the Tobit model has a much better fit. The results from these models are relatively consistent. Comparisons show the signs are the same in all three models, while some variables about the barriers and crop types have different significance levels. These indicate the results are robust across multiple models. The interpretation will focus on the results of the Tobit model as its coefficients are easy to interpret, and are similar to the OLS coefficients.

Payments. The results show a negative effect of water cost on irrigation share, indicating higher water cost decreases the proportion of irrigated cropland. Irrigation share is positively correlated with irrigation equipment expenses.

Farm size. The results show that a negative association exists between the percentage of irrigated land and the areas of both owned and leased land, indicating farmers are less likely to irrigate large farms. The number of wells has a positive relationship; one more well is associated with an increase of irrigation share by $0.5 \%$. Water from both off-farm surface only and two or more sources increases the

\footnotetext{
${ }^{23}$ The results for the share of harvest cropland equation are provided in table A3.2 in the appendix.

${ }^{24}$ The chapter just presents the results of the same parsimonious model, which also facilitates comparison across equations. Specification for each type of model is provided in the appendix, as well their characteristics.
} 
irrigation share, by $7 \%$ and $6 \%$, respectively compared to the base of groundwater only.

Irrigation system. Compared with only using gravity systems, sprinkler, drip, and multiple irrigation systems decrease the irrigation share. This may be due to the high costs of installing and maintaining the systems, which can be a major barrier for increasing irrigated acreage. Alternatively, these more efficient systems may be implemented in areas with relatively scarce water resources.

Barriers for improvement. My results indicate that the effects of barriers on IS are not consistent with expectations. Not a priority and uncertainty about future water availability decrease irrigated land share, while cost not shared by landlords has a positive association with irrigated land.

Information source. The results show getting information from irrigation equipment dealers has a negative effect on IS, while information from local irrigation district employees, government specialists, and neighboring farmers has a positive effect.

Value of sales. The results show that the irrigation share is influenced by higher sales. Compared to the base of $\$ 100,000-249,999$, lower sale categories have negative effects on IS, and higher sale categories have positive effects. Together, the results show larger farms tend to have a larger percentage of irrigated lands.

Region. Compared with the Plains, being in the West and South has a positive effect on irrigation share, while being in the Midwest and Atlantic states has a negative effect. These findings are in line with the hypotheses.

Crop diversity. The results show farms growing more types of crops tend to have a lower irrigation share. 
Table 3.3. Results for irrigation share equation.

\begin{tabular}{|c|c|c|c|c|c|c|}
\hline \multirow[b]{2}{*}{ Variable } & \multicolumn{2}{|c|}{ OLS_logOdds } & \multicolumn{2}{|c|}{ Fractional logit } & \multicolumn{2}{|l|}{ Tobit } \\
\hline & Estimate & Std Err & Estimate & Std Err & Estimate & Std Err \\
\hline Intercept & $3.0225^{* * *}$ & 0.1150 & $0.9027 * * *$ & 0.0955 & $0.7095 * * *$ & 0.0107 \\
\hline \multicolumn{7}{|l|}{ Payments } \\
\hline Water cost & $-1.8 \mathrm{E}-05$ & $1.84 \mathrm{E}-05$ & $-2 \mathrm{E}-05$ & $1.5 \mathrm{E}-05$ & $-2.9 \mathrm{E}-06^{*}$ & $1.72 \mathrm{E}-06$ \\
\hline Irrigation equipment expense & $9.28 \mathrm{E}-05^{* * *}$ & $3.58 \mathrm{E}-05$ & $0.0002 * * *$ & 0.0001 & $7.4 \mathrm{E}-06^{* *}$ & $3.34 \mathrm{E}-06$ \\
\hline Labor payment & $1.76 \mathrm{E}-05$ & $1.25 \mathrm{E}-05$ & $5 \mathrm{E}-05$ & $3.3 \mathrm{E}-05$ & 7.9E-07 & $1.17 \mathrm{E}-06$ \\
\hline \multicolumn{7}{|l|}{ Farm Size } \\
\hline Land owned & $-0.0917 * * *$ & 0.0052 & $-0.0485 * * *$ & 0.0046 & $-0.0092 * * *$ & 0.0005 \\
\hline Land leased & $-0.0969 * * *$ & 0.0047 & $-0.0501 * * *$ & 0.0040 & $-0.0094 * * *$ & 0.0004 \\
\hline \multicolumn{7}{|l|}{ Water Source (Base: Groundwater only) } \\
\hline On-farm surface water only & 0.0664 & 0.0784 & 0.0134 & 0.0623 & -0.0107 & 0.0073 \\
\hline Off-farm surface water only & $0.8565^{* * *}$ & 0.0703 & $0.4071 * * *$ & 0.0625 & $0.0700 * * *$ & 0.0066 \\
\hline Two or more water sources & $0.5604 * * *$ & 0.0675 & $0.3467 * * *$ & 0.0581 & $0.0614 * * *$ & 0.0063 \\
\hline \# of Wells & $0.0385 * * *$ & 0.0022 & $0.0385 * * *$ & 0.0028 & $0.0050 * * *$ & 0.0002 \\
\hline \multicolumn{7}{|l|}{ Irrigation System (Base: Gravity only) } \\
\hline Sprinkler only & $-0.9047 * * *$ & 0.0662 & $-0.3390 * * *$ & 0.0575 & $-0.0714 * * *$ & 0.0062 \\
\hline Drip only & $-0.9229 * * *$ & 0.0858 & $-0.4181 * * *$ & 0.0723 & $-0.0884 * * *$ & 0.0080 \\
\hline Two or more systems & $-0.3088^{* * *}$ & 0.0734 & -0.0346 & 0.0659 & -0.0038 & 0.0069 \\
\hline \multicolumn{7}{|l|}{ Barriers for Improvements } \\
\hline Investigating improvement is not a priority & $-0.1481 * *$ & 0.0593 & $-0.0943 *$ & 0.0488 & $-0.0190 * * *$ & 0.0055 \\
\hline Limitation of physical field or crop conditions & 0.0559 & 0.0831 & 0.0635 & 0.0705 & 0.0108 & 0.0078 \\
\hline
\end{tabular}


Not enough to recover implementation costs

Cannot finance improvements

Landlords will not share improvement costs

Uncertainty about future water availability

\section{Information Source}

Extension agents

Private irrigation specialists

Irrigation equipment dealers

Local irrigation district employees

Government specialists

Neighboring farmers

\section{Improvements and Assistance}

(6) Irrigation improvements

Technical and financial assistance

Value of Sales (Base: \$100,000-249,999)

\$0-9,999

$\$ 10,000-24,999$

$\$ 25,000-49,999$

$\$ 50,000-99,999$

$\$ 250,000-499,999$

$\$ 500,000-999,999$

$\$ 1,000,000$ and above

Regions (Base: Plains)

West

\begin{tabular}{|c|c|c|c|c|c|}
\hline 0.0442 & 0.0699 & 0.0350 & 0.0588 & 0.0067 & 0.0065 \\
\hline 0.0168 & 0.0671 & 0.0346 & 0.0567 & 0.0086 & 0.0063 \\
\hline $0.2393 * * *$ & 0.0915 & 0.1014 & 0.0777 & $0.0215 * * *$ & 0.0085 \\
\hline$-0.3112 * * *$ & 0.0846 & $-0.1963 * * *$ & 0.0737 & $-0.0320 * * *$ & 0.0079 \\
\hline-0.0346 & 0.0529 & 0.0103 & 0.0437 & 0.0008 & 0.0049 \\
\hline 0.0037 & 0.0603 & 0.0376 & 0.0505 & 0.0064 & 0.0056 \\
\hline$-0.1071 *$ & 0.0555 & -0.0472 & 0.0457 & $-0.0092 *$ & 0.0052 \\
\hline $0.2538 * * *$ & 0.0982 & $0.1604^{*}$ & 0.0934 & $0.0201 * *$ & 0.0092 \\
\hline $0.1217 *$ & 0.0734 & 0.0605 & 0.0634 & $0.0152 * *$ & 0.0069 \\
\hline $0.1413 * *$ & 0.0577 & 0.0731 & 0.0484 & $0.0128 * *$ & 0.0054 \\
\hline-0.0456 & 0.0571 & 0.0162 & 0.0478 & 0.0051 & 0.0053 \\
\hline 0.0359 & 0.0733 & 0.0420 & 0.0613 & 0.0097 & 0.0068 \\
\hline-0.0471 & 0.0939 & $-0.2391 * * *$ & 0.0785 & $-0.0418 * * *$ & 0.0088 \\
\hline$-0.2702 * *$ & 0.1170 & $-0.3124 * * *$ & 0.0950 & $-0.0572 * * *$ & 0.0109 \\
\hline$-0.3611 * * *$ & 0.1189 & $-0.2712 * * *$ & 0.0969 & $-0.0501 * * *$ & 0.0111 \\
\hline-0.1353 & 0.1075 & $-0.1584 *$ & 0.0876 & $-0.0280 * * *$ & 0.0100 \\
\hline $0.1806^{*}$ & 0.0926 & 0.0914 & 0.0758 & $0.0177 * *$ & 0.0086 \\
\hline $0.3492 * * *$ & 0.0906 & $0.1719 * *$ & 0.0744 & $0.0353 * * *$ & 0.0085 \\
\hline $0.5806 * * *$ & 0.0844 & $0.2170 * * *$ & 0.0708 & $0.0518 * * *$ & 0.0079 \\
\hline $2.6994 * * *$ & 0.0844 & $1.3333 * * *$ & 0.0722 & $0.2271 * * *$ & 0.0079 \\
\hline
\end{tabular}




\begin{tabular}{|c|c|c|c|c|c|c|}
\hline Midwest & $-0.4071 * * *$ & 0.0852 & $-0.1660 * *$ & 0.0658 & $-0.0484 * * *$ & 0.0080 \\
\hline South & $0.8618 * * *$ & 0.0890 & $0.4216 * * *$ & 0.0713 & $0.0874 * * *$ & 0.0083 \\
\hline Atlantic & $-0.4399 * * *$ & 0.0917 & $-0.2696 * * *$ & 0.0711 & $-0.0691 * * *$ & 0.0086 \\
\hline Crop Diversity & $-0.4834 * * *$ & 0.0188 & $-0.2004 * * *$ & 0.0157 & $-0.0398 * * *$ & 0.0018 \\
\hline $\mathrm{N}$ & 19272 & & $\mathrm{~N}$ & 19272 & & 19272 \\
\hline F Value & 204 & & $-2 \mathrm{LL}$ & 21222 & & 7309 \\
\hline $\operatorname{Pr}>\mathrm{F}$ & $<.0001$ & & AIC & 21300 & & 7389 \\
\hline R-Squared & 0.2882 & & $\mathrm{BIC}$ & 21607 & & 7704 \\
\hline Adj R-Sq & 0.2868 & & & & & \\
\hline VIF & Mean: 1.54 & $1-\max : 1$ & 97) & & & \\
\hline
\end{tabular}

Significance level: * $10 \%$; ** 5\%; *** $1 \%$. 


\subsubsection{Application rate}

The estimated results for the equation of irrigation water application rate for cropland are presented in table 3.4. The equation is estimated using OLS as the dependent variable is continuous. The adjusted $\mathrm{R}$-squared value is 0.30 . A comparison with the full model shows the significance levels and signs of the estimates are consistent.

Payments. The results show water cost has a negative effect on water application rate, indicating a reduction in water use can be achieved with higher water cost as predicted by economic theory.

Farm size. The results show larger areas of both owned and leased land decrease the average application rate on the farm's irrigated acres.

Water source. Surface water from on-farm sources has a negative effect on water application relative to groundwater use, while water from off-farm surface sources has a positive effect. More wells increase the average water use as more wells make it easier for farmers to get more water for crops.

Irrigation system. Adoption of sprinkler and drip irrigation systems has a negative effect on application rate, which indicates the enhanced systems reduce average water use compared with gravity irrigation systems.

Barriers for improvements. In line with expectations, improvement costs not shared by landlords has a positive effect on application rate, indicating they impede farmers from conserving water. However, not a priority and limitation of physical conditions have negative effects, implying producers cannot increase irrigation due to these limitations and poor irrigation systems.

Information sources. The application rate is negatively associated with information from irrigation equipment dealers, while positively associated with that 
from private irrigation specialists, local irrigation district employees, and government specialists. This indicates different information may be conveyed by different information providers. While irrigation equipment dealers may work on increasing crop yield per drop of water, others may focus on the increase of total yield through increasing the irrigation. Alternatively, different information sources may be associated with different farming systems or regions.

Value of sales. The results show higher sales have a positive association with water application, which means that larger farms have the financial ability to irrigate or perhaps that irrigation improves profitability.

Regions. The results show Western farms have much higher irrigation rates compared with Plains farms. Meanwhile, farms in the Midwest, South, and Atlantic states irrigate less than the Plains, which is in line with the expectations.

Crop diversity. The results show more types of crop planted decease the average water application on a farm. 
Table 3.4. Results for water application rate equation.

\begin{tabular}{|c|c|c|}
\hline \multirow[b]{2}{*}{ Variable } & \multicolumn{2}{|l|}{ OLS } \\
\hline & Estimate & Std Err \\
\hline Intercept & $1.4054 * * *$ & 0.0314 \\
\hline \multicolumn{3}{|l|}{ Payments } \\
\hline Water cost & $-5.60 \mathrm{E}-05 * * *$ & 5.02E-06 \\
\hline Irrigation equipment expense & $3.86 \mathrm{E}-07$ & 9.77E-06 \\
\hline Labor payment & $-4.4 \mathrm{E}-06$ & $3.41 \mathrm{E}-06$ \\
\hline \multicolumn{3}{|l|}{ Farm Size } \\
\hline Land owned & $-0.0162 * * *$ & 0.0014 \\
\hline Land leased & $-0.0115 * * *$ & 0.0013 \\
\hline \multicolumn{3}{|l|}{ Water Source (Base: Groundwater only) } \\
\hline On-farm surface water only & $-0.0598 * * *$ & 0.0214 \\
\hline Off-farm surface water only & $0.1023 * * *$ & 0.0192 \\
\hline Two or more water sources & -0.0008 & 0.0184 \\
\hline \# of Wells & $0.0034 * * *$ & 0.0006 \\
\hline \multicolumn{3}{|l|}{ Irrigation System (Base: Gravity only) } \\
\hline Sprinkler only & $-0.3897 * * *$ & 0.0181 \\
\hline Drip only & $-0.3389 * * *$ & 0.0234 \\
\hline Two or more systems & $-0.2243 * * *$ & 0.0200 \\
\hline \multicolumn{3}{|l|}{ Barriers for Improvements } \\
\hline Investigating improvement is not a priority & $-0.0421 * * *$ & 0.0162 \\
\hline Limitation of physical field or crop conditions & $-0.0402^{*}$ & 0.0227 \\
\hline Not enough to recover implementation costs & -0.0205 & 0.0191 \\
\hline Cannot finance improvements & 0.0061 & 0.0183 \\
\hline Landlords will not share improvement costs & $0.0566 * *$ & 0.0250 \\
\hline Uncertainty about future water availability & 0.0125 & 0.0231 \\
\hline \multicolumn{3}{|l|}{ Information Source } \\
\hline Extension agents & 0.0010 & 0.0145 \\
\hline Private irrigation specialists & $0.0411 * *$ & 0.0164 \\
\hline Irrigation equipment dealers & $-0.0400 * * *$ & 0.0151 \\
\hline Local irrigation district employees & $0.1001 * * *$ & 0.0268 \\
\hline Government specialists & $0.0394 * *$ & 0.0200 \\
\hline Neighboring farmers & -0.0112 & 0.0157 \\
\hline \multicolumn{3}{|l|}{ Improvements and Assistance } \\
\hline Irrigation improvements & $0.0417 * * *$ & 0.0156 \\
\hline Technical and financial assistance & -0.0245 & 0.0200 \\
\hline \multicolumn{3}{|l|}{ Value of Sales (Base: \$100,000-249,999) } \\
\hline$\$ 0-9,999$ & $-0.0882 * * *$ & 0.0256 \\
\hline$\$ 10,000-24,999$ & -0.0408 & 0.0319 \\
\hline$\$ 25,000-49,999$ & -0.0127 & 0.0325 \\
\hline$\$ 50,000-99,999$ & 0.0276 & 0.0293 \\
\hline$\$ 250,000-499,999$ & $0.0688 * * *$ & 0.0253 \\
\hline
\end{tabular}


$\$ 500,000-999,999$

$0.1054 * * *$

0.0247

$\$ 1,000,000$ and above

$0.2336^{* * * *}$

0.0230

Regions (Base: Plains)

West

$0.7936 * * * \quad 0.0230$

Midwest

$-0.3009 * * *$

0.0233

South

$-0.2299 * * *$

0.0243

Atlantic

$-0.2636 * * *$

0.0250

Crop Diversity

$-0.0262 * * *$

0.0051

\section{Model Fit}

$\mathrm{N}$

19272

F Value

220

$\mathrm{Pr}>\mathrm{F}$

$<.0001$

R-Squared

0.3037

Adj R-Sq

0.3024

Significance level: * 10\%; ** 5\%; *** $1 \%$. 


\subsubsection{Crop-specific adoption of pressure irrigation systems and scientific} scheduling practices

For the crop-specific adoption decisions, the multi-level models are utilized to analyze the adoption of pressure irrigation systems and scientific scheduling practices for corn and soybean farms. Given the adoption decisions of pressure systems and scientific scheduling practices are dichotomous, three sequential models are estimated for each decision, that is, a two-level model with random effects for the intercept only without any predictors (model $1^{25}$ ), random effects for the intercept and only level-1 fixed effects (model 2), and random effects for the intercept and both level-1 and level-2 fixed effects (model 3).

To determine how much of the variability in the responses is accounted for by the factors at the state level, the intraclass correlation coefficient (ICC) is usually computed. Regarding corn farms, the ICC is 0.7233 and 0.0557 for the adoption of pressure irrigation systems (table 3.5) and scientific irrigation scheduling practices (table 3.7), respectively, while for soybean farms, the values are 0.8143 and 0.0881 (table 3.6 and table 3.8). To understand this measure, for example, 0.7233 means $72.33 \%$ of the variability in the adoption of pressure systems is accounted for by the variation between states. We can find a very high proportion of the variability in adoption of pressure systems for both corn and soybeans are accounted for by the state-level differences, while a very low proportion of the variability in adoption of scientific scheduling practices is accounted for by the states.

In four tables, AIC indicates a better fit for the last model. So the following interpretation will focus on model 3 in tables $3.5,3.6,3.7$ and 3.8 as they incorporate

\footnotetext{
${ }^{25}$ From the null model (model 1), intraclass correlation coefficient can be calculated. It tells the percentage of variability in the responses accounted for by the state-level differences.
} 
the state-wide variables and have a better fit. A comparison of the same type of adoption on different crops can provide a better understanding of farming systems. Therefore, this section will interpret and compare the best model in each table as previously indicated.

\subsection{Pressure irrigation systems}

Results for the adoption of pressure irrigation systems are presented in table 3.5 for corn and in table 3.6 for soybeans. The reference category is gravity irrigation for both crops.

Payments. The results show high water cost has a negative effect on the adoption of pressure irrigation systems on soybean farms.

Farm size. Area of land owned has a positive effect on corn farmers' adoption, and areas of both owned and leased land show positive effects on adoption of pressure irrigation systems for soybeans. These findings indicate that more land is associated with farmers who adopt irrigation systems with higher water use efficiency, which saves water and thus decreases water application for irrigated farms.

Water source. Using water from off-farm surface and multiple sources decreases the adoption of pressure irrigation systems compared to farm irrigation using groundwater only, when controlling for water cost. More wells are negatively associated with adoption of pressure systems. This is consistent with the hypothesis as mentioned above that more wells provide farmers more and easier access to water.

Barriers for improvements. The barriers that investigating improvements is not a priority and that landlords will not share improvement costs decreases the adoption of pressure systems for both crops. This is consistent with the hypotheses as the adoption requires high initial investments. 
Information sources. For the adoption of pressure systems, information from extension agents, and neighboring farmers has a negative effect on both corn and soybean farms, while information from private irrigation specialists and local irrigation district employees has positive effects on corn farms, and media reports have a positive effect on soybeans. These finding may be true if the extension agents primarily help producers reduce irrigation costs through less irrigation.

State-wide average weather-related variables. The multi-level model incorporates fixed effects at the state level. Enhanced irrigation systems can be introduced before the growing season and afterward used when needed. Similarly, the pressure system adoption by both corn and soybean farmers is also influenced by the precipitation and temperature changes in 2012, indicating a major effect of perceptions of climate variability on the adoption of advanced irrigation systems. The change of precipitation in 2012 and 2013 is negatively associated with the application of pressure systems on corn farms, indicating more water availability decreases producers' initiative to save water and to irrigate farms more efficiently, or they even don't need to irrigate that much. 
Table 3.5. Results of multilevel models for the adoption of pressure irrigation systems by CORN farmers.

\begin{tabular}{|c|c|c|c|c|c|c|}
\hline & \multicolumn{2}{|c|}{$\begin{array}{l}\text { Model 1: } \\
\text { Random intercept only }\end{array}$} & \multicolumn{2}{|c|}{$\begin{array}{l}\text { Model 2: } \\
\text { M1+Level-1 fixed effects }\end{array}$} & \multicolumn{2}{|c|}{$\begin{array}{l}\text { Model 3: } \\
\text { M2+Level-2 fixed effects }\end{array}$} \\
\hline \multicolumn{7}{|l|}{ Fixed Effects } \\
\hline \multicolumn{7}{|l|}{ Payments } \\
\hline Water cost & & & -0.0016 & 0.0016 & -0.0012 & 0.0016 \\
\hline Irrigation equipment expense & & & 0.0011 & 0.0009 & 0.0011 & 0.0009 \\
\hline Land owned & & & $0.0297 * * *$ & 0.0090 & $0.0298 * * *$ & 0.0090 \\
\hline Land leased & & & 0.0008 & 0.0121 & -0.0004 & 0.0121 \\
\hline \multicolumn{7}{|l|}{ Water Source (Base: Groundwater only) } \\
\hline On-farm surface water only & & & 0.1088 & 0.2697 & 0.1509 & 0.2712 \\
\hline Off-farm surface water only & & & $-2.2221 * * *$ & 0.2099 & $-2.1690 * * *$ & 0.2100 \\
\hline Limitation of physical field or crop conditions & & & -0.1061 & 0.1708 & -0.1091 & 0.1708 \\
\hline Not enough to recover implementation costs & & & -0.0579 & 0.1465 & -0.0511 & 0.1466 \\
\hline Cannot finance improvements & & & $-0.2963 *$ & 0.1524 & $-0.3112 * *$ & 0.1523 \\
\hline Landlords will not share improvement costs & & & $-0.6233 * * *$ & 0.1550 & $-0.6270 * * *$ & 0.1551 \\
\hline Will not be farming long enough & & & $-0.4941 * *$ & 0.2128 & $-0.4261 * *$ & 0.2131 \\
\hline
\end{tabular}




\section{Information Source}

Extension agents

Private irrigation specialists

Irrigation equipment dealers

Local irrigation district employees

Media reports

Neighboring farmers

E-information services

\section{Improvements and Assistance}

Irrigation improvements

Technical and financial assistance

State-wide average weather-related variables

PrecipChange2012

TempChange2012

PrecipChange2013

\begin{tabular}{rrrr}
$-0.2842 * *$ & 0.1154 & $-0.3076 * * *$ & 0.1154 \\
$0.3339 * * *$ & 0.1168 & $0.3388^{* * *}$ & 0.1168 \\
$0.3762 * * *$ & 0.1194 & $0.3753^{* * *}$ & 0.1194 \\
-0.0640 & 0.1961 & -0.0809 & 0.1961 \\
0.2585 & 0.1800 & 0.2877 & 0.1803 \\
$-0.4714 * * *$ & 0.1263 & $-0.4979 * * *$ & 0.1265 \\
0.1687 & 0.1469 & 0.2068 & 0.1471 \\
& & & \\
0.1790 & 0.1263 & 0.1993 & 0.1264 \\
$-0.3043^{* *}$ & 0.1387 & $-0.3205^{* *}$ & 0.1388 \\
& & & \\
& & $-0.1210^{*}$ & 0.0639 \\
& & $0.5997 *$ & 0.3700 \\
& & $-0.2564 * * *$ & 0.0811 \\
& & 0.4160 & 0.5760 \\
\hline
\end{tabular}

TempChange2013

\begin{tabular}{|c|c|c|c|c|c|c|}
\hline \multicolumn{7}{|l|}{ Error Variance } \\
\hline \multicolumn{7}{|l|}{ Fit Statistics } \\
\hline$-2 \mathrm{LL}$ & 2996 & & 2714 & & 2698 & \\
\hline AIC & 3000 & & 2766 & & 2758 & \\
\hline BIC & 3004 & & 2767 & & 2758 & \\
\hline
\end{tabular}

$\mathrm{ICC}=8.6011 /(8.6011+3.29)=0.7233$.

Significance level: * $10 \%$; ** 5\%; *** $1 \%$. 
Table 3.6. Results of multilevel models for the adoption of pressure irrigation systems by SOYBEAN farmers.

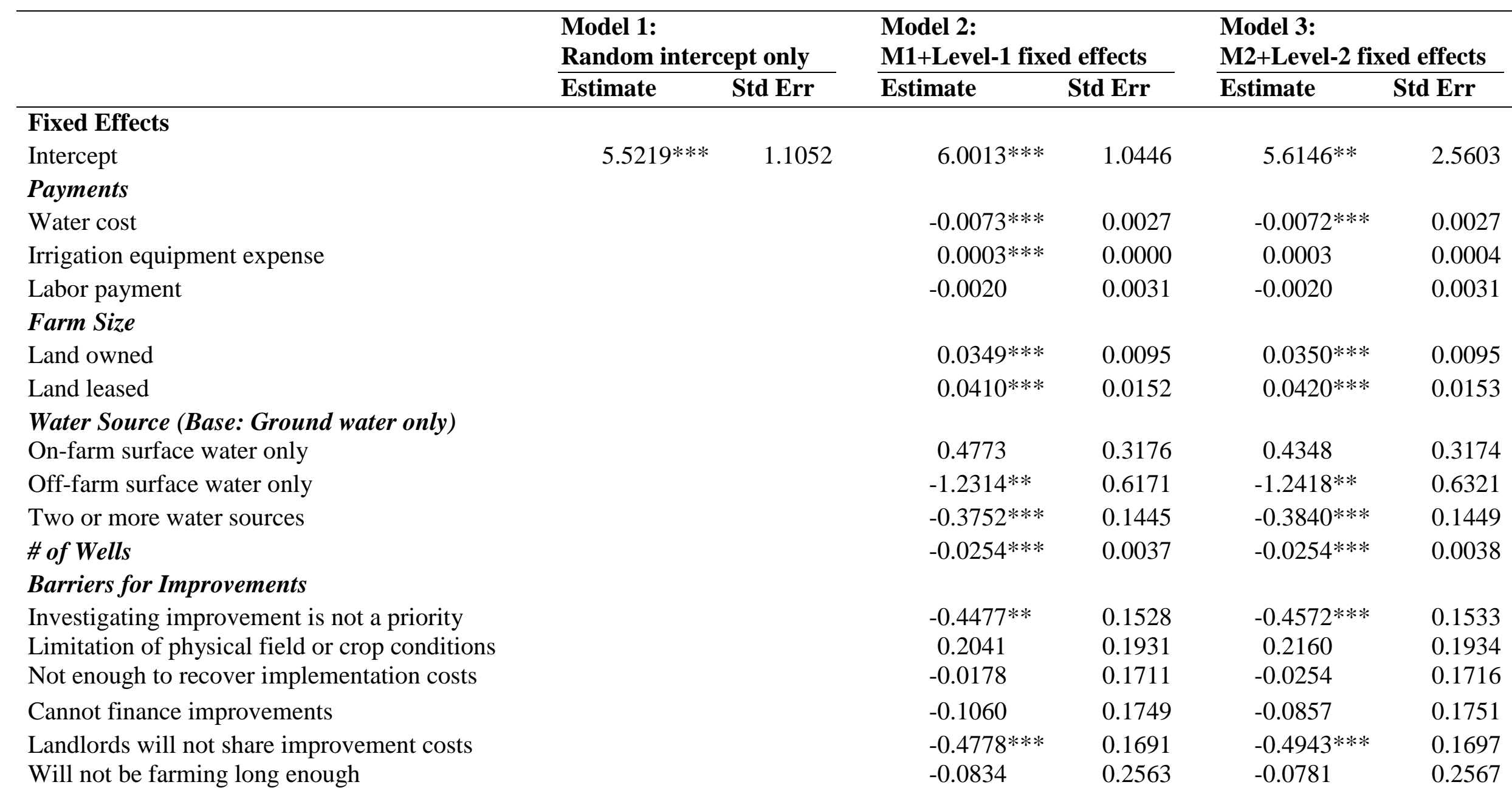




\section{Information Source}

Extension agents

Private irrigation specialists

Irrigation equipment dealers

Local irrigation district employees

Media reports

Neighboring farmers

E-information services

Improvements and Assistance

Irrigation improvements

Technical and financial assistance

$\begin{array}{lccc}-0.4213^{* * *} & 0.1190 & -0.4206^{* * *} & 0.1192 \\ 0.1709 & 0.1241 & 0.1763 & 0.1244 \\ 0.0250 & 0.1297 & 0.0311 & 0.1300 \\ 0.1022 & 0.2898 & 0.0174 & 0.2904 \\ 0.6256^{* * *} & 0.1977 & 0.6424^{* * *} & 0.1983 \\ -0.3338^{* *} & 0.1384 & -0.3370^{* *} & 0.1388 \\ -0.3247^{* *} & 0.1640 & -0.3305^{* *} & 0.1646 \\ & & & \\ 0.0132 & 0.1315 & 0.0065 & 0.1318 \\ -0.2317 & 0.1534 & -0.2233 & 0.1537 \\ & & & \\ & & -0.1475^{*} & 0.8060 \\ & & 0.6030^{*} & 0.3388 \\ & & 0.2313 & 0.1901 \\ & & 0.1662 & 1.4058\end{array}$

\section{State-wide average weather-related variables}

PrecipChange2012

TempChange2012

PrecipChange 2013

0.1662

\begin{tabular}{|c|c|c|c|c|c|c|}
\hline $\begin{array}{l}\text { Error Variance } \\
\text { Subject } \\
\text { Intercept (STATE) }\end{array}$ & $\begin{array}{l}\text { Estimate } \\
\quad 14.4229 * *\end{array}$ & $\begin{array}{l}\text { Std Err } \\
7.1869\end{array}$ & $\begin{array}{l}\text { Estimate } \\
12.791 * *\end{array}$ & $\begin{array}{l}\text { Std Err } \\
6.2319\end{array}$ & $\begin{array}{l}\text { Estimate } \\
26.9515^{* *}\end{array}$ & $\begin{array}{l}\text { Std Err } \\
\quad 11.3602\end{array}$ \\
\hline \multicolumn{7}{|l|}{ Fit Statistics } \\
\hline$-2 \mathrm{LL}$ & 2340 & & 2174 & & 2173 & \\
\hline AIC & 2344 & & 2234 & & 2225 & \\
\hline BIC & 2347 & & 2282 & & 2267 & \\
\hline
\end{tabular}

$\mathrm{ICC}=14.4229 /(14.4229+3.29)=0.8143$.

Significance level: * 10\%; ** 5\%; *** $1 \%$. 


\subsection{Adoption of scientific irrigation scheduling practices}

The estimation results of the SIS adoption are presented in table 3.7 for corn farmers and in table 3.8 for soybean farmers.

Payments. The results show both water cost and labor payment have positive effects on the adoption of scientific scheduling practices for soybean farmers.

Water source. Compared with groundwater, on-farm surface water use decreases the adoption of scientific scheduling practices on both corn and soybean farms.

Barriers for improvements. The variable that investigating improvements is not a priority and that farmers will not be farming long enough show a negative effect on the adoption of scheduling practices for both crops, which is in alignment with the hypotheses on barriers. The statement on physical limitation and high costs not recovered or shared has a positive effect. This perhaps is true as farmers may be able to access some public, government reports to get some idea of soil moisture conditions even lacking other financial support. However, more information should be obtained to better understand these effects.

Information sources. Regarding the adoption of scheduling practices on both corn and soybean farms, positive effects are found with information from extension agents, private irrigation specialists, irrigation equipment dealers, government specialists, and e-information services, however, information from neighboring farmers shows a negative effect.

Improvements and assistance. For producers of soybeans, those who made irrigation and drainage improvements tended to adopt SSP, and those who received technical and financial assistance are more likely to adopt. 
Table 3.7. Results of multilevel models for the adoption of scientific irrigation scheduling practices by CORN farmers.

\begin{tabular}{|c|c|c|c|c|c|c|}
\hline & \multicolumn{2}{|c|}{$\begin{array}{l}\text { Model 1: } \\
\text { Random intercept only }\end{array}$} & \multicolumn{2}{|c|}{$\begin{array}{l}\text { Model 2: } \\
\text { M1+Level-1 fixed effects }\end{array}$} & \multicolumn{2}{|c|}{$\begin{array}{l}\text { Model 3: } \\
\text { M2+Level-2 fixed effects }\end{array}$} \\
\hline \multicolumn{7}{|l|}{ Fixed Effects } \\
\hline \multicolumn{7}{|l|}{ Payments } \\
\hline Water cost & & & $0.0011^{*}$ & 0.0007 & 0.0010 & 0.0007 \\
\hline Irrigation equipment expense & & & $1.7 \mathrm{E}-05$ & 0.0003 & $3.9 \mathrm{E}-05$ & 0.0003 \\
\hline Land owned & & & -0.0059 & 0.0065 & -0.0054 & 0.0065 \\
\hline Land leased & & & 0.0034 & 0.0069 & 0.0042 & 0.0069 \\
\hline \multicolumn{7}{|l|}{ Water Source (Base: Groundwater only) } \\
\hline On-farm surface water only & & & $-0.4177 * * *$ & 0.1504 & $-0.3669 * *$ & 0.1501 \\
\hline Off-farm surface water only & & & -0.2460 & 0.1570 & -0.2024 & 0.1587 \\
\hline Limitation of physical field or crop conditions & & & $0.2554 * *$ & 0.1017 & $0.2551 * *$ & 0.1017 \\
\hline Not enough to recover implementation costs & & & $0.3195^{* * *}$ & 0.0861 & $0.3228 * * *$ & 0.0861 \\
\hline Cannot finance improvements & & & -0.0333 & 0.1021 & -0.0315 & 0.1021 \\
\hline Landlords will not share improvement costs & & & $0.2539 * *$ & 0.1014 & $0.2507 * *$ & 0.1015 \\
\hline Will not be farming long enough & & & $-0.2817 * *$ & 0.1358 & $-0.2788 * *$ & 0.1358 \\
\hline
\end{tabular}




\section{Information Source}

Extension agents

Private irrigation specialists

Irrigation equipment dealers

Local irrigation district employees

Media reports

Neighboring farmers

E-information services

\section{Improvements and Assistance}

Irrigation improvements

Technical and financial assistance

$\begin{array}{llll}0.6022^{* * *} & 0.0693 & 0.6050^{* * *} & 0.0694 \\ 1.0452 * * * & 0.0667 & 1.0408^{* * *} & 0.0667 \\ 0.4355^{* * *} & 0.0689 & 0.4377^{* * *} & 0.0690 \\ 0.2607 * & 0.1400 & 0.2532^{*} & 0.1404 \\ 0.1559 & 0.0988 & 0.1613^{*} & 0.0988 \\ -0.5216^{* * *} & 0.0776 & -0.5260^{* * *} & 0.0776 \\ 0.9536^{* * *} & 0.0793 & 0.9576^{* * *} & 0.0793\end{array}$

\section{State-wide average weather-related variables}

PrecipChange 2012

TempChange2012

PrecipChange2013

$0.3412 * * * \quad 0.0765$

$0.3459 * * *$

0.0765

$0.2436 * * *$

0.0824

$0.2503 * * *$

0.0824

TempChange2013

\begin{tabular}{|c|c|c|c|c|c|c|}
\hline $\begin{array}{l}\text { Error Variance } \\
\text { Subject } \\
\text { Intercept (STATE) }\end{array}$ & $\begin{array}{l}\text { Estimate } \\
\quad 0.1939 * * *\end{array}$ & $\begin{array}{l}\text { Std Err } \\
0.05439\end{array}$ & $\begin{array}{l}\text { Estimate } \\
0.223 * * *\end{array}$ & $\begin{array}{l}\text { Std Err } \\
0.06604\end{array}$ & $\begin{array}{l}\text { Estimate } \\
0.1956 * * *\end{array}$ & $\begin{array}{l}\text { Std Err } \\
0.05767\end{array}$ \\
\hline \multicolumn{7}{|l|}{ Fit Statistics } \\
\hline$-2 \mathrm{LL}$ & 7488 & & 6345 & & 6349 & \\
\hline AIC & 7492 & & 6405 & & 6401 & \\
\hline BIC & 7495 & & 6458 & & 6447 & \\
\hline
\end{tabular}

ICC $=0.1939 /(0.1939+3.29)=0.0557$.

Significance level: * $10 \%$; ** 5\%; *** $1 \%$.

$\begin{array}{cc}0.0094 & 0.0229 \\ 0.1389 & 0.1025 \\ -0.0234 * & 0.0125 \\ 0.0212 & 0.1268\end{array}$$$
\text { 年 }
$$ 
Table 3.8. Results of multilevel models for the adoption of scientific irrigation scheduling practices by SOYBEAN farmers.

\begin{tabular}{|c|c|c|c|c|c|c|}
\hline & \multicolumn{2}{|c|}{$\begin{array}{l}\text { Model 1: } \\
\text { Random intercept only }\end{array}$} & \multicolumn{2}{|c|}{$\begin{array}{l}\text { Model 2: } \\
\text { M1+Level-1 fixed effects }\end{array}$} & \multicolumn{2}{|c|}{$\begin{array}{l}\text { Model 3: } \\
\text { M2+Level-2 fixed effects }\end{array}$} \\
\hline \multicolumn{7}{|l|}{ Fixed Effects } \\
\hline \multicolumn{7}{|l|}{ Payments } \\
\hline Water cost & & & $0.0066 * * *$ & 0.0022 & $0.0068 * * *$ & 0.0022 \\
\hline Irrigation equipment expense & & & -0.0002 & 0.0004 & -0.0002 & 0.0004 \\
\hline Land owned & & & 0.0029 & 0.0082 & 0.0031 & 0.0082 \\
\hline Land leased & & & 0.0036 & 0.0095 & 0.0039 & 0.0095 \\
\hline \multicolumn{7}{|l|}{ Water Source (Base: Groundwater only) } \\
\hline On-farm surface water only & & & $-0.6102 * * *$ & 0.2227 & $-0.4913 * *$ & 0.2199 \\
\hline Off-farm surface water only & & & -0.0019 & 0.2970 & 0.0346 & 0.2966 \\
\hline Two or more water sources & & & 0.1177 & 0.1084 & 0.1194 & 0.1085 \\
\hline Cannot finance improvements & & & 0.0568 & 0.1361 & 0.0604 & 0.1362 \\
\hline Landlords will not share improvement costs & & & 0.0684 & 0.1277 & 0.0617 & 0.1278 \\
\hline Will not be farming long enough & & & $-0.3819 * *$ & 0.1741 & $-0.3934 * *$ & 0.1742 \\
\hline \multicolumn{7}{|l|}{ Information Source } \\
\hline Extension agents & & & $0.5311 * * *$ & 0.0874 & $0.5488 * * *$ & 0.0875 \\
\hline Private irrigation specialists & & & $0.8934 * * *$ & 0.0858 & $0.8965 * * *$ & 0.0858 \\
\hline
\end{tabular}


Irrigation equipment dealers

Local irrigation district employees

Media reports

Neighboring farmers

E-information services

\section{Improvements and Assistance}

Irrigation improvements

Technical and financial assistance

State-wide average weather-related variables

PrecipChange2012

TempChange2012

PrecipChange2013

TempChange2013

\section{Error Variance}

Subject

\section{e}

Intercept (STATE)

Fit Statistics

$\mathrm{N}$

$-2 \mathrm{LL}$

AIC

BIC

ATE)

ATE)

\begin{tabular}{llll}
$0.3858^{* * *}$ & 0.0882 & $0.3841 * * *$ & 0.0882 \\
0.1725 & 0.2187 & 0.1380 & 0.2188 \\
$0.2570^{* *}$ & 0.1246 & $0.2604 * *$ & 0.1247 \\
$-0.3822^{* * *}$ & 0.0971 & $-0.3871 * * *$ & 0.0971 \\
$1.0045^{* * *}$ & 0.1006 & $1.0053 * * *$ & 0.1006 \\
& & & \\
$0.2773 * * *$ & 0.0980 & $0.2703 * * *$ & 0.0980 \\
$0.4640^{* * *}$ & 0.1044 & $0.4684 * * *$ & 0.1045 \\
& & & \\
& & 0.0052 & 0.0320 \\
& & $0.2365 * *$ & 0.1203 \\
& & -0.0166 & 0.0397 \\
& & -0.1720 & 0.2156 \\
\hline
\end{tabular}

$\mathrm{ICC}=0.3180 /(0.3180+3.29)=0.0881$.

Significance level: * 10\%; ** 5\%; *** $1 \%$. 
State-level variables on climate variability. The ICC in the null model of both crops showed a low percentage of the scheduling adoption accounted for by the factors at the state level. Thus the adoption of scientific irrigation scheduling is not very responsive to climate variability. The temperature change in 2012 is found to have a positive association with the adoption by corn farmers, and the precipitation change in 2013 has a negative effect on the adoption by soybean farmers. It seems these would be lower cost practices that could more easily be implemented, while other factors like information should be more considered.

\subsection{Discussion and Conclusions}

Using 2013 FRIS data, this study analyzes US farmers' irrigation decisions and adoption of irrigation practices using a mixed and multilevel modeling approach. Given the heterogeneity of farms across the country (Olen et al., 2016) and complexity of large survey data (Lu and Yang, 2012), analyses are conducted in two stages: 1) three land-level equations are formulated for farms growing major crops, and 2) two crop-specific equations using a two-level model with corn and soybeans as examples. The two-stage analytical framework, including the incorporation of both farm- and state-level determinants for corn and soybean farms, allows us to look at both land- and crop-specific decisions of farm irrigation and practice adoption. The analysis could help improve the design of educational programs and policies, and provide input to those who develop new technologies and techniques.

Perceived barriers to improvements show fairly consistent effects on irrigation decisions and farmers' adoption behaviors on specific crops. Though farmers may receive some technical and financial assistance from government, overall the assistance is not significant in increasing the adoption of advanced irrigation systes. Due to various important impediments, the effectiveness of support programs is 
weakened and some even fail to achieve their intended goals due to the lack of funding, potential uncertainties, and physical limitations (Rodriguez et al., 2009). This finding has important policy implications because federal assistance is commonly deemed as a means to conserve water by encouraging adoption of water saving irrigation technologies. The conflict between government to conserve water and farmers to increase short term profits also hampers farmers' adoption (Wang et al., 2015). Though improved irrigation technologies and scheduling practices can improve crop yield or quality, and reduce energy costs, labor costs, and water use (George et al., 2000; Ward et al., 2007), given the needs of heterogeneous farmers, federal programs and policy should target specific barriers and increase the effectiveness of the incentives. For instance, an irrigation technology subsidy is more effective in a preventive stage to save water (Wang et al., 2015), and adoption decisions should be made before the growing season.

Information from various providers matters. Most of the adoption decisions are adviser-driven rather than farmer-driven (Stevens, 2007), thus increasing farmers' dependence on information providers. Inadequate information clarifying the costs/benefits of adopting, the technical details of implementation, and the likely environmental impacts of new practices can also be other barriers to conserving irrigation water (Rodriguez et al., 2009).

Compared with irrigation scheduling, the adoption of pressure systems are more likely to be affected by climate variability. The findings provide valuable information about how farmers might respond to perceptions of climate change and adapt to climate risks in agricultural production. Producers can adopt pressure irrigation systems to respond to drought that may lead to high crop losses, thus reducing risks from extreme weather. Using water more efficiently, farmers can improve their 
resilience and coping capacity to deal with climate risks and mitigate the adverse effects. High values of ICC for adoption of pressure irrigation suggest the variation at the state level takes a larger proportion than the variation at the farm level. This finding indicates that federal policy design should not only recognize the heterogeneity of farms, but also address differing priorities including adaptation to various climate risks in each state.

This study calls for further investigation on crop-specific irrigation decisions and the interaction effect of water shortage and climate change. Adoption of pressure irrigation systems and scheduling practices can be estimated simultaneously if more detailed farm-level data on climate change are available, as well as their joint effects on the irrigation rate of specific crops. Ideally a farm-level survey can be conducted to generate data investigating various aspects of climate change perceptions by farmers growing specific crops (Arbuckle et al., 2015) and their association with adoption of various irrigation practices. Also the joint decision-making to conserve water can be analyzed considering irrigation of multiple crops. Further research could address these limitations. 


\section{References}

Amosson, S., Almas, L., Girase, J.R., Kenny, N., Guerrero, B., Vimlesh, K., Marek, T., 2011. Economics of irrigation systems. Available at: http://amarillo.tamu.edu/files/2011/2010/Irrigation-Bulletin-FINAL-B6113.pd f.

Arbuckle, J.G., Morton, L.W., Hobbs, J., 2015. Understanding farmer perspectives on climate change adaptation and mitigation: The roles of trust in sources of climate information, climate change beliefs, and perceived risk. Environment and Behavior. 47, 205-234.

Ayars, J.E., Fulton, A., Taylor, B., 2015. Subsurface drip irrigation in California-Here to stay? Agricultural Water Management. 157, 39-47.

Bekele, W., Drake, L., 2003. Soil and water conservation decision behavior of subsistence farmers in the Eastern Highlands of Ethiopia: a case study of the Hunde-Lafto area. Ecological Economics. 46, 437-451.

Bjornlund, H., Nicol, L., Klein, K.K., 2009. The adoption of improved irrigation technology and management practices - A study of two irrigation districts in Alberta, Canada. Agricultural Water Management. 96, 121-131.

Blanc, E., Reilly, J., 2015. Climate Change Impacts on US Crops. Choices. 30.

Bogena, H., Huisman, J., Oberdörster, C., Vereecken, H., 2007. Evaluation of a low-cost soil water content sensor for wireless network applications. Journal of Hydrology. 344, 32-42.

Bozzola, M., Swanson, T., 2014. Policy implications of climate variability on agriculture: Water management in the Po river basin, Italy. Environmental Science \& Policy. 43, 26-38.

Colorado Agricultural Water Alliance, 2008. Meeting Colorado's Future Water Supply Needs: Opportunities and Challenges Associated with Potential Agricultural Water Conservation Measures. Available at: http://cwrri.colostate.edu/other_files/Ag\%20water\%20conservation\%20paper $\% 20 \mathrm{Feb} \% 2011 \% 2020(2012)$.pdf.

Contant, C.K., Korsching, P.F., 1997. Farmers' commitment to continued use of the late spring soil nitrogen test. American Journal of Alternative Agriculture. 12, 20-27.

Daberkow, S.G., McBride, W.D., 1998. Socioeconomic profiles of early adopters of precision agriculture technologies. Journal of Agribusiness. 16, 151-168. 
Dağdelen, N., Başal, H., Yılmaz, E., Gürbüz, T., Akçay, S., 2009. Different drip irrigation regimes affect cotton yield, water use efficiency and fiber quality in western Turkey. Agricultural Water Management. 96, 111-120.

Dolisca, F., McDaniel, J.M., Shannon, D.A., Jolly, C.M., 2009. A multilevel analysis of the determinants of forest conservation behavior among farmers in Haiti. Society and Natural Resources. 22, 433-447.

Fan, Y., Wang, C., Nan, Z., 2014. Comparative evaluation of crop water use efficiency, economic analysis and net household profit simulation in arid Northwest China. Agricultural Water Management. 146, 335-345.

Feder, G., Just, R.E., Zilberman, D., 1985. Adoption of agricultural innovations in developing countries: A survey. Economic Development and Cultural Change. $33,255-298$.

Fleming, R.A., Babcock, B., Wang, E., 1998. Resource or waste? The economics of swine manure storage and management. Review of Agricultural Economics. 20, 96-113.

Frisvold, G.B., Deva, S., 2012. Farm size, irrigation practices, and conservation program participation in the US Southwest. Irrigation and Drainage. 61, $569-582$.

Fuglie, K.O., Kascak, C.A., 2001. Adoption and diffusion of natural-resource-conserving agricultural technology. Review of Agricultural Economics. 23, 386-403.

Gedikoglu, H., McCann, L., 2012. Adoption of win-win, environment-oriented, and profit-oriented practices among livestock farmers. Journal of Soil and Water Conservation. 67, 218-227.

Gedikoglu, H., McCann, L., Artz, G., 2011. Off-farm employment effects on adoption of nutrient management practices. Agricultural and Resource Economics Review. 40, 293.

George, B.A., Raghuwanshi, N.S., Singh, R., 2004. Development and testing of a GIS integrated irrigation scheduling model. Agricultural Water Management. 66, 221-237.

George, B.A., Shende, S.A., Raghuwanshi, N.S., 2000. Development and testing of an irrigation scheduling model. Agricultural Water Management. 46, 121-136.

Guerin, D., Crete, J., Mercier, J., 2001. A multilevel analysis of the determinants of recycling behavior in the European countries. Social Science Research. 30, 195-218. 
Hunsaker, D., French, A., Waller, P.M., Bautista, E., Thorp, K., Bronson, K., Andrade-Sanchez, P., 2015. Comparison of traditional and ET-based irrigation scheduling of surface-irrigated cotton in the arid southwestern USA. Agricultural Water Management. 159, 209-224.

Hurd, B.H., Hilaire, R.S., White, J.M., 2006. Residential landscapes, homeowner attitudes, and water-wise choices in New Mexico. HortTechnology. 16, 241-246.

Ibragimov, N., Evett, S.R., Esanbekov, Y., Kamilov, B.S., Mirzaev, L., Lamers, J.P.A., 2007. Water use efficiency of irrigated cotton in Uzbekistan under drip and furrow irrigation. Agricultural Water Management. 90, 112-120.

Jara-Rojas, R., Bravo-Ureta, B.E., Díaz, J., 2012. Adoption of water conservation practices: A socioeconomic analysis of small-scale farmers in Central Chile. Agricultural Systems. 110, 54-62.

Jin, J., Gao, Y., Wang, X., Nam, P.K., 2015. Farmers' risk preferences and their climate change adaptation strategies in the Yongqiao District, China. Land Use Policy. 47, 365-372.

Kadiyala, M.D.M., Jones, J.W., Mylavarapu, R.S., Li, Y.C., Reddy, M.D., 2015. Identifying irrigation and nitrogen best management practices for aerobic rice-maize cropping system for semi-arid tropics using CERES-rice and maize models. Agricultural Water Management. 149, 23-32.

Kang, Y., Wang, R., Wan, S., Hu, W., Jiang, S., Liu, S., 2012. Effects of different water levels on cotton growth and water use through drip irrigation in an arid region with saline ground water of Northwest China. Agricultural Water Management. 109, 117-126.

Kara, E., Ribaudo, M., Johansson, R.C., 2008. On how environmental stringency influences adoption of best management practices in agriculture. Journal of Environmental Management. 88, 1530-1537.

Lambert, D., Sullivan, P., Claassen, R., Foreman, L., 2006. Conservation-compatible practices and programs: Who participates? United States Department of Agriculture, Economic Research Service.

Leib, B.G., Elliott, T.V., Matthews, G., 2001. WISE: a web-linked and producer oriented program for irrigation scheduling. Computers and Electronics in Agriculture. 33, 1-6.

Li, C., Ting, Z., Rasaily, R.G., 2010. Farmer's Adaptation to Climate Risk in the Context of China: A research on Jianghan Plain of Yangtze River Basin. Agriculture and Agricultural Science Procedia. 1, 116-125. 
Liu, Y., Li, S., Chen, F., Yang, S., Chen, X., 2010. Soil water dynamics and water use efficiency in spring maize (Zea mays L.) fields subjected to different water management practices on the Loess Plateau, China. Agricultural Water Management. 97, 769-775.

Lu, M., Yang, W., 2012. Multivariate logistic regression analysis of complex survey data with application to BRFSS data. Journal of Data Science. 10, 157-173.

Morris, M., Energy, N., 2006. Soil moisture monitoring: low-cost tools and methods. National Center for Appropriate Technology (NCAT), 1-12.

Núñez, J., McCann, L., 2005. Determinants of the Adoption of Manure Management Practices in the Midwest. Selected paper at the Symposium on the State of the Science: Animal Manure and Waste Management, January 5-7, San Antonio, Texas.

NASS, 2014. 2013 Farm and Ranch Irrigation Survey. Available at: http://www.agcensus.usda.gov/Publications/2012/Online_Resources/Farm_an d_Ranch_Irrigation_Survey/.

Negri, D.H., Gollehon, N.R., Aillery, M.P., 2005. The effects of climatic variability on US irrigation adoption. Climatic Change. 69, 299-323.

Nowak, P.J., 1987. The adoption of agricultural conservation technologies: economic and diffusion explanations. Rural Sociology. 52, 208.

Olen, B., Wu, J., Langpap, C., 2016. Irrigation decisions for major west coast crops: Water scarcity and climatic determinants. American Journal of Agricultural Economics. 98, 254-275.

Pannell, D.J., Marshall, G.R., Barr, N., Curtis, A., Vanclay, F., Wilkinson, R., 2006. Understanding and promoting adoption of conservation practices by rural landholders. Australian Journal of Experimental Agriculture. 46, 1407-1424.

Payero, J., Khalilian, A., Miller, G., Davis, R., 2013. Irrigation Water Management Guide (IWMG: 2-13). Available at: https://www.clemson.edu/extension/rowcrops/publications/iwmg2.pdf.

Pereira, L.S., 1999. Higher performance through combined improvements in irrigation methods and scheduling: a discussion. Agricultural Water Management. 40, 153-169.

Prokopy, L., Floress, K., Klotthor-Weinkauf, D., Baumgart-Getz, A., 2008. Determinants of agricultural best management practice adoption: Evidence from the literature. Journal of Soil and Water Conservation. 63, 300-311.

Raudenbush, S.W., Bryk, A.S., 2002. Hierarchical linear models: Applications and data analysis methods. Sage. 
Rodriguez, J.M., Molnar, J.J., Fazio, R.A., Sydnor, E., Lowe, M.J., 2009. Barriers to adoption of sustainable agriculture practices: Change agent perspectives. Renewable Agriculture and Food Systems. 24, 60-71.

Rogers, E.M., 2003. Diffusion of innovations. Fifth Edition. Free Press, New York.

Sadras, V., Rodriguez, D., 2010. Modelling the nitrogen-driven trade-off between nitrogen utilisation efficiency and water use efficiency of wheat in eastern Australia. Field Crops Research. 118, 297-305.

Salazar, M.R., Hook, J.E., Garcia y Garcia, A., Paz, J.O., Chaves, B., Hoogenboom, G., 2012. Estimating irrigation water use for maize in the Southeastern USA: A modeling approach. Agricultural Water Management. 107, 104-111.

Salvador, R., Latorre, B., Paniagua, P., Playán, E., 2011. Farmers'scheduling patterns in on-demand pressurized irrigation. Agricultural Water Management. 102, 86-96.

Sammis, T., Sharma, P., Shukla, M.K., Wang, J., Miller, D., 2012. A water-balance drip-irrigation scheduling model. Agricultural Water Management. 113, 30-37.

Schaible, G., Aillery, M., 2012. Water conservation in irrigated agriculture: Trends and challenges in the face of emerging demands. USDA-ERS Economic Information Bulletin.

Schaible, G.D., Kim, C.S., Aillery, M.P., 2010. Dynamic adjustment of irrigation technology/water management in western US agriculture: Toward a sustainable future. Canadian Journal of Agricultural Economics/Revue canadienne d'agroeconomie. 58, 433-461.

Scherer, T., 2010. Selecting a sprinkler irrigation system. Available at: http://www.ag.ndsu.edu/waterquality/documents/ae91_Selecting_a_Sprinkler_ Irrigation_System.pdf.

Schneider, A.D., Howell, T.A., 2001. Scheduling deficit wheat irrigation with data from an evapotranspiration network. Transactions of the ASAE. 44, 1617-1623.

Simonne, E., Hochmuth, R., Breman, J., Lamont, W., Treadwell, D., Gazula, A., 2008. Drip-irrigation systems for small conventional vegetable farms and organic vegetable farms. University of Florida IFAS Extension, Available at: http://edis.ifas.ufl.edu/hs388.

Stevens, J.B., 2007. Adoption of irrigation scheduling methods in South Africa. University of Pretoria.

Stoneman, P., 2001. The economics of technological diffusion. Wiley-Blackwell. 
Sunding, D., Zilberman, D., 2001. The agricultural innovation process: research and technology adoption in a changing agricultural sector. Handbook of Agricultural Economics. 1, 207-261.

Tanwar, S., Rao, S., Regar, P., Datt, S., Jodha, B., Santra, P., Kumar, R., Ram, R., 2014. Improving water and land use efficiency of fallow-wheat system in shallow Lithic Calciorthid soils of arid region: Introduction of bed planting and rainy season sorghum-legume intercropping. Soil and Tillage Research. $138,44-55$.

Ummenhofer, C.C., Xu, H., Twine, T.E., Girvetz, E.H., McCarthy, H.R., Chhetri, N., Nicholas, K.A., 2015. How climate change affects extremes in maize and wheat yield in two cropping regions. Journal of Climate. 28, 4653-4687.

Usman, M., Arshad, M., Ahmad, A., Ahmad, N., Zia-Ul-Haq, M., Wajid, A., Khaliq, T., Nasim, W., Ali, H., Ahmad, S., 2010. Lower and upper baselines for crop water stress index and yield of Gossypium hirsutum L. under variable irrigation regimes in irrigated semiarid environment. Pakistan Journal of Botany. 42, 2541-2550.

Vories, E.D., Tacker, P.L., Lancaster, S.W., Glover, R.E., 2009. Subsurface drip irrigation of corn in the United States Mid-South. Agricultural Water Management. 96, 912-916.

Walton, J.C., Lambert, D.M., Roberts, R.K., Larson, J.A., English, B., Larkin, S.L., Martin, S.W., Marra, M.C., Paxton, K.W., Reeves, J.M., 2008. Adoption and abandonment of precision soil sampling in cotton production. Journal of Agricultural and Resource Economics, 428-448.

Wang, T., Park, S.C., Jin, H., 2015. Will farmers save water? A theoretical analysis of groundwater conservation policies. Water Resources and Economics. 12, 27-39.

Ward, F.A., Michelsen, A.M., DeMouche, L., 2007. Barriers to water conservation in the Rio Grande Basin1. Wiley Online Library.

Weber, C., McCann, L., 2015. Adoption of nitrogen-efficient technologies by US corn farmers. Journal of Environmental Quality. 44, 391-401.

Widmar, D.A., 2015. Acres and Acre-Feet; A Look at Irrigation Trends in the US. Agricultural Economic Insights, http://ageconomists.com/2015/2004/2020/acres-and-acre-feet-a-look-at-irrigati on-trends-in-the-us/ (accessed July 2015). 


\section{CHAPTER 4. MULTICROP PRODUCTION DECISIONS AND CROP IRRIGATION WATER USE EFFICIENCY: EFFECTS OF WATER PRICE, PRESSURE IRRIGATION ADOPTION AND CLIMATIC DETERMINANTS}

In a multicrop production system with irrigation, farmers make sequential decisions on crop choice, land allocated to each crop, and irrigation water application, which determines crop yield. The focus of this dissertation is water application on multiple crops at the farm level along with the effect on irrigation water use efficiency (IWUE) of adoption of enhanced irrigation systems. Sustainability of water resources requires producers to take account of marginal user costs, i.e., the scarcity value of water, when making production decisions. Adoption of enhanced irrigation systems and higher water price can achieve potential improvements in irrigation water use efficiency. To better deal with the farm-level data embedded in states, the multilevel models (MLMs) are employed in this chapter, and it permits the incorporation of state-level variables. As its applicability has been examined in the previous chapter, application of MLMs into analyzing multiple production decisions and irrigation water use efficiency provides new insights on the proportion of variability in each response accounted for by farm and state levels.

\subsection{Introduction}

In many countries, agricultural production relies heavily on water resources. Most of the cropland needs irrigation, and some traditionally rain-fed agriculture systems have seen growing irrigation to increase production and mitigate climate risks. Accounting for more than $80 \%$ of total water withdrawals, irrigated agriculture needs to contribute an increasing share of food production to meet the growing demands of a rising population. Faced with the dramatic impacts of climate change, many arid and 
semiarid areas are suffering from severe water shortages, for instance, the Western U.S. (EPA, 2014) and Northwestern China (Jin et al., 2015). At the same time, some areas that were not facing water deficiency are experiencing more droughts, for instance, the Midwestern U.S. (Zhang and Lin, 2016; Zhang et al., 2015), thus increasing the stress on current water resources. In addition, in many areas, the water demand from other sectors is expected to grow faster. Though a large proportion of water demand could be satisfied through new investments in water supply and irrigation systems, and expansion of water supply could be met with some non-traditional sources, the shrinking water availability increases both economic and environmental costs of developing new water supplies (Murray et al., 2012; Schaible and Aillery, 2012; Wanders and Wada, 2015). Therefore, investments in water systems and developing new water sources to meet growing demands will not be a sufficient solution.

As a more practical path to achieve sustainability of water resources, water can saved in current uses through increasing irrigation water use efficiency (total yield per unit of land divided by total irrigation water received) in agricultural production (George et al., 2000). The traditional flood (also called furrow or gravity) irrigation systems have been reported to lose $50-70 \%$ of the water applied as soil evaporation, seepage, deep drainage, etc. (Batchelor et al., 1996; Dalton et al., 2001). Potential improvements in irrigation water use efficiency can be realized through adopting enhanced pressure irrigation systems.

Most of the studies on irrigation water use efficiency are conducted at the field level based on experiments (Gheysari et al., 2015; Qin et al., 2016). Two foci of field experiments include comparison of irrigation water use efficiency at different water application levels and utilizing various irrigation methods, and interaction and 
compatibility of improved irrigation systems and other farm best management practices (film or straw mulching, irrigation scheduling, etc.) (Ibragimov et al., 2007; Kang et al., 2012; Schneider and Howell, 2001). Previous IWUE studies typically use experimental data in one field, collected over 1-5 years. Due to lack of available farm-level data, an evaluation of crop IWUE in multiple fields is impossible mainly due to limited research funding, heterogeneity of experimental fields, and diversity of cropping systems and farming structures. As a matter of fact, at the farm level, producers usually grow two or more crops on their farms. In addition to the adoption of irrigation systems analyzed in the previous chapter, farmers also need to make other decisions on land allocation and irrigation water application for each crop they choose to plant. All of these decisions can determine whether water is used efficiently or not.

The farm-level irrigation production decisions to improve crop irrigation water use efficiency in a multicrop system are understudied, in particular across regions with different cropping patterns and climatic conditions (Olen et al., 2016). In addition, production decisions in irrigated agriculture may be affected by other factors like water sources, input costs, farming area, etc. Analysis of irrigation decisions and crop irrigation water use efficiency, as affected by these and other factors, could help farmers and policy makers adapt to potential climate risks, better manage irrigation water application and achieve sustainable use of limited water resources. Furthermore, given the differences among farms and states, the multi-level models (MLMs) introduced in the previous chapter can be readily utilized to deal with the hierarchical nature of the farm-level data, and to extract the percentage of variability in each response accounted for by farm- and state-level factors. 
Therefore, the objective of this chapter is to better understand production decisions for irrigated agriculture and irrigation water use efficiency of major crops in U.S., as well as the effects of water cost, adoption of pressure irrigation methods and climatic determinants in a multicrop production system.

Specifically, this study aims to answer the following fundamental questions:

1) Is higher water price conserving water in irrigated agriculture?

2) Are enhanced irrigation systems conserving water and more efficient than the traditional systems under farm conditions?

3) How does climate variability affect production decisions in irrigated agriculture?

4) What are the influential factors and how are the production decisions affected by these factors at the farm and state levels?

The layout of the analyses in this chapter is presented in figure 4.1. Focusing on irrigated farms in a multicrop production system, four equations on land allocation, water demand, crop supply, and irrigation water use efficiency are estimated using multilevel models. Intensive and extensive margins of water use to water price are calculated. Intraclass correlation coefficients as defined later are calculated to find out the proportion of variability in each response accounted for by each level. Econometric results are provided regarding the effects of exogenous variables on each response variable. 
Figure 4.1. Layout of the analyses in chapter 4.

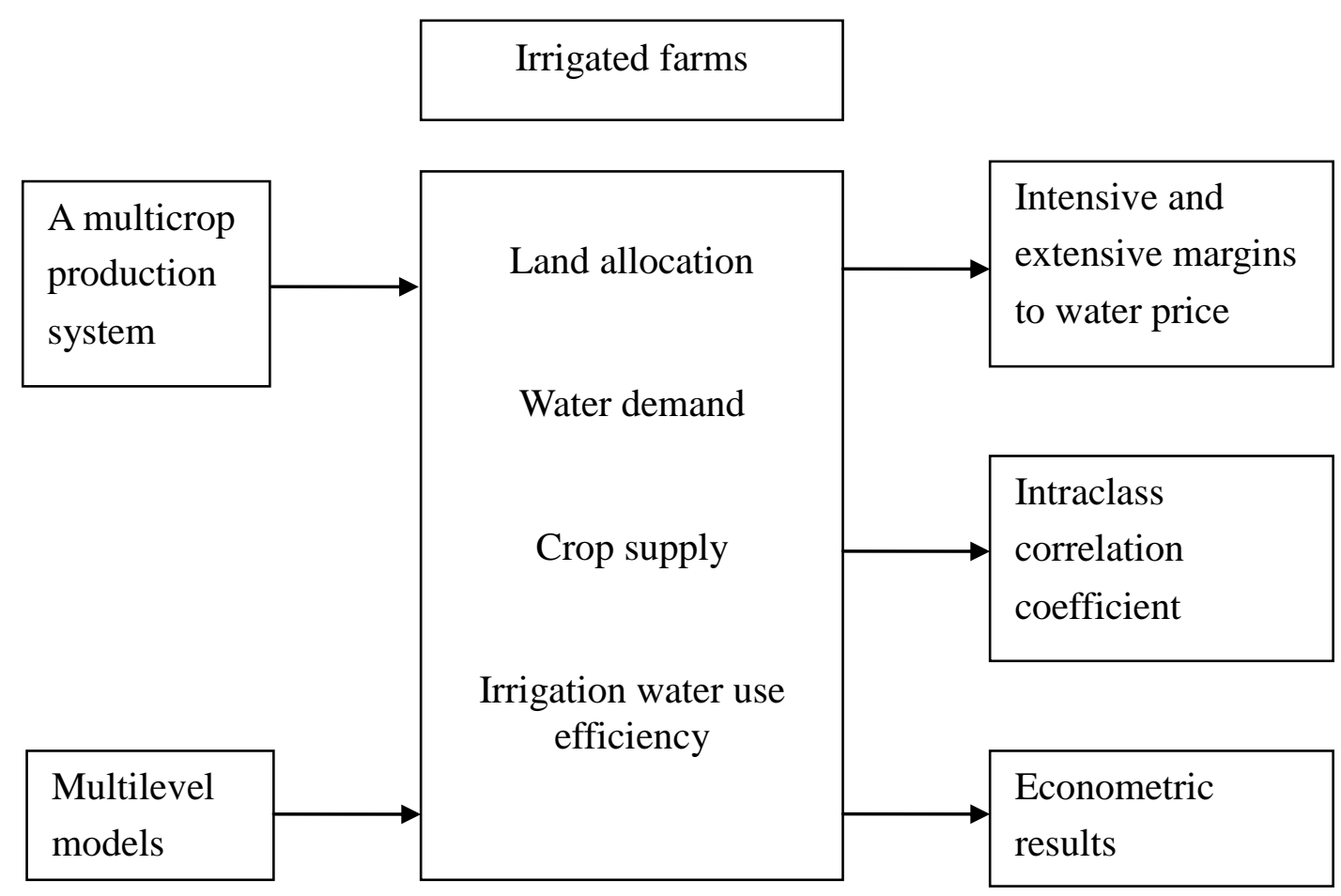

\subsection{Literature Review}

\subsubsection{Crop water use efficiency (WUE)}

In general, water management includes issues relating to five sub-systems existing on most irrigated farms: supply systems, on-farm storage systems, on-farm distribution systems, application systems and recycling systems (Dalton et al., 2001). In a report on the Australian cotton industry, Dalton et al. (2001) defined water use efficiency at the farm level focusing on three dimensions: agronomic efficiency, economic efficiency and volumetric efficiency. The agronomic water use efficiency includes a gross production water use index (yield/total water applied), an irrigation water use index (yield/irrigation water applied), a marginal irrigation water use index (marginal yield due to irrigation/irrigation water applied), and a crop water use index (yield/evapotranspiration). The economic water use efficiency includes a gross production economic water use index (total value/total water applied), an economic 
irrigation water use index (value/irrigation water applied), a marginal economic irrigation water use index (value due to irrigation/irrigation water applied), and a crop economic water use index (value/evapotranspiration). The volumetric water use efficiency includes overall project efficiency, conveyance efficiency, distribution efficiency, and field application efficiency, which emphasize irrigation uniformity to avoid over- and under-irrigation issues (reducing the water use efficiency and yield, respectively). Moreover, Pereira (1999) discussed various measurements for both distribution uniformity and application efficiency in various irrigation systems.

From a multi-disciplinary perspective, Nair et al. (2013) reviewed the efficiency of irrigation water use. Among all the measures of WUE, agronomists defined it as yield per unit area divided by the water used to produce the yield. The yield can be grain yield or total aboveground biomass depending on the use of the crop produced, and the water can refer to crop evapotranspiration, soil water balance, or precipitation plus irrigation. However, from an economist's perspective, the efficient level of irrigation water occurs "when the marginal revenue (price of the crop produced in a perfectly competitive market) is equal to the price of water)" (Nair et al., 2013): p.359). The water application level at Stage II in the classical production function was identified as the economically efficient water use amount. Stage II ranges from point where marginal product equals average product, i.e., $w / p=Y / X(M P P=A P P)$ with $w$ the water cost, $p$ the output price, $Y$ the output quantity, and $X$ the input quantity, to the yield maximizing point, where $d Y / d X=w / p=0$ (i.e., $M P P=0$ ). Other research proposed an operating profit water use index to evaluate water use efficiency, which is defined as: (gross return - variable costs - overhead costs)/ total water used (Harris, 2007). 
Comparing WUE measures from the perspectives of agronomists and economists, a major difference is whether to consider output price. For example, the economic irrigation water use index (value/irrigation water applied) is the product of the irrigation water use index (yield/ irrigation water applied) and the crop price. Because producers are price takers in a competitive market, different farmers growing the same crop will sell it for the same price in the same market. Thus exogenous variables affecting economic irrigation efficiency and agronomic irrigation efficiency will have the same effects in terms of the signs and significance levels, though the magnitude will be different proportionally. To make analyses easier and follow the mainstream of decision-making on land allocation and water use to maximize the expected profit as formulated in the model section below, this study uses the economic measure of irrigation water use efficiency (EIWUE) (crop value/irrigation water use) incorporating state-average crop prices in the econometric estimation.

\subsection{Hypotheses}

Literature reviews from this chapter and the previous chapter show that many changes in socioeconomic, agronomic, technical, and institutional aspects can have considerable positive/negative effects on water use efficiencies, and thus diverse effects on the profitability of crop production. Farm management practices including controlling the amount and timing of irrigation water, fertilizer/manure use, mulching and tillage can affect farm returns and profits (Abd El-Wahed and Ali, 2013). Through analyzing various measurement of water use efficiency, Pereira (1999) recommended combining improved irrigation methods and scheduling strategies to achieve higher performance. Pressure irrigation systems are thus expected to decrease water application and increase efficiency. 
Based on field-level measurements, Canone et al. (2015) assessed surface irrigation efficiency in Italy. The results from both simulated scenarios and monitored irrigation events highlighted the necessary strategies to improve irrigation efficiencies through reducing the flow rates and increasing the duration of irrigation events. Thus I hypothesize more water availability from various sources and more wells decrease crop water use efficiency.

In addition, diverse effects of physical factors on farm yield and profits have been reported based on farm-level studies. For instance, with carrot farmer interviews in Pakistan, Ahmad et al. (2005) found that farm-level yield and profitability were affected by many factors including expenditures on facility and labor investments regarding application of fertilizer, irrigation and weeding. In a similar study, Dahmardeh and Asasi (2014) evaluated the effects of costs of fertilizer, seeds and water on the profitability of corn farms as well as the effects of income sources. Thus, the facility expenses and labor payment at the farm level are hypothesized to have positive effects on water application and crop yield, but a negative effect on water use efficiency.

Furthermore, climate conditions can influence farm yield and revenue, and irrigation can be considered as a strategy to mitigate the adverse effects and increase profits (Kresovic et al., 2014). Therefore, climate risks decreasing precipitation are expected to promote irrigation and decrease irrigation water use efficiency.

\subsection{Model}

In irrigated agriculture, producers make decisions on crop choices, land allocation, and amount of water for irrigation ${ }^{26}$. Choosing from common crops, a typical

\footnotetext{
${ }^{26}$ Producers also need to choose which type of irrigation system(s) to adopt, and this was the
} 
producer may plant two or more crops on a farm. Then decisions on the land allocation and water supply can be made to maximize the expected total profit. In this section, I start by building a model of profit maximization, and then turn to the maximization of economic irrigation water use efficiency to deal with market failure in water management.

Following a multicrop production model by Moore et al. (1994b), the expected profit functions of the multicrop system and specific crop $i$ can be represented by $\Pi(\boldsymbol{p}, \boldsymbol{r}, b, N ; \boldsymbol{x})$ and $\pi_{i}\left(p_{i}, \boldsymbol{r}, b, n_{i} ; \boldsymbol{x}\right)$, respectively. $\boldsymbol{p}$ is a vector of crop prices; $p_{i}$ is the price of crop $i, i=1, \ldots, m ; \boldsymbol{r}$ is a vector of variable input prices excluding water price; $b$ is the water price; $N$ is the total farming area as a constraint; $n_{i}$ is the land allocation for crop $i ; \boldsymbol{x}$ represents other exogenous variables including land characteristics, adoption of various irrigation systems, climate perceptions, etc. Each crop-specific profit function $\pi_{i}$ is assumed to be convex and homogenous of degree one in output prices, water price, and other prices of variable inputs, nondecreasing in output price and land allocation, and nonincreasing in water prices and other variable input prices.

I extend the model of (Moore et al., 1994a, b) by adding crop irrigation water use efficiency. At the beginning of the growing season, a producer decides to grow crop $i$ depending on input and output prices, the land constraint, and climate variables. The discrete choice can be represented by:

$$
d_{i}=f_{i}(\boldsymbol{p}, \boldsymbol{r}, b, N ; \boldsymbol{x}) \quad i=1, \ldots, m
$$

where $d_{i}=1$ if crop $i$ is planted, and $d_{i}=0$ if not planted.

Subsequently, decisions on how much land is allocated to grow crop $i$ can be made. To obtain the land allocation function, we need to solve the producer's profit 
maximization problem when land allocations for all crops are constrained by the total farming area.

With a set of chosen crops and the land constraint ${ }^{27}$, the multicrop profit maximization function can be formulated as:

$$
\Pi(\boldsymbol{p}, \boldsymbol{r}, b, N ; \boldsymbol{x})=\max _{n_{1} \ldots n_{m}}\left\{\sum_{i=1}^{m} \pi_{i}\left(p_{i}, \boldsymbol{r}, b, n_{i} ; \boldsymbol{x}\right)\right\}
$$

which is subject to the land constraint equation $\sum_{i=1}^{m} n_{i}=N$.

A typical method to solve for the solution is to set the Lagrangian function, and take the first-order conditions for an interior solution (combining the constraint equation). $\partial \pi_{i}\left(p_{i}, \boldsymbol{r}, b, n_{i} ; \boldsymbol{x}\right) / \partial n_{i}=\lambda$, where $\lambda$ is Lagrange multiplier. The optimal land allocation functions $n_{i}^{*}(\boldsymbol{p}, \boldsymbol{r}, b, N ; \boldsymbol{x})$ are linear in the exogenous variables for the normalized quadratic profit functions ${ }^{28}$ (Moore et al., 1994a).

$$
\begin{aligned}
& \boldsymbol{n}_{i}^{*}=\alpha^{i}+\sum_{i=1}^{m} \beta_{j}^{i} p_{i}+\sum_{i=1}^{z} \gamma_{j}^{i} r_{i}+\delta^{i} b+\psi^{i} N+\sum_{s=1}^{t} \eta_{j}^{i} x_{i} \\
& i=1, \ldots, m
\end{aligned}
$$

With the optimal land allocation, the multicrop profit function can be rewritten as:

$$
\begin{aligned}
& \Pi(\boldsymbol{p}, \boldsymbol{r}, b, N ; \boldsymbol{x})=\max _{n_{1} \ldots n_{m}}\left\{\sum_{i=1}^{m} \pi_{i}\left(p_{i}, \boldsymbol{r}, b, n_{i}^{*}(\boldsymbol{p}, \boldsymbol{r}, b, N ; \boldsymbol{x}) ; \boldsymbol{x}\right)\right\} \\
& i=1, \ldots, m
\end{aligned}
$$

The duality theory can be used to derive the water demand and crop supply functions. By applying Hotelling's lemma, the crop supply functions can be obtained.

$$
\begin{aligned}
& y_{i}(\boldsymbol{p}, \boldsymbol{r}, b, N ; \boldsymbol{x})=\frac{\partial \Pi(\boldsymbol{p}, \boldsymbol{r}, b, N ; \boldsymbol{x})}{\partial p_{i}}=\frac{\partial \pi_{i}\left(p_{i}, \boldsymbol{r}, b, n_{i}^{*} ; \boldsymbol{x}\right)}{\partial p_{i}}=y_{i}\left(p_{i}, \boldsymbol{r}, b, n_{i}^{*} ; \boldsymbol{x}\right) \\
& i=1, \ldots, m
\end{aligned}
$$

27 Producers may also face a water constraint, especially in western and high plains states.

28 The full specification of normalized quadratic function can incorporate exogenous variables in linear, squared, and cross-product forms (Moore et al., 1994a, b). 
where $y_{i}$ is the yield for crop $i$. The equivalence of the two forms is supported by the envelope theorem. Here $y_{i}(\boldsymbol{p}, \boldsymbol{r}, b, N ; \boldsymbol{x})$ is preferred as crop prices are treated explicitly rather than embedded in the land allocation function.

Similarly, applying Hotelling's lemma to the profit functions gives the water demand functions.

$$
w_{i}(\boldsymbol{p}, \boldsymbol{r}, b, N ; \boldsymbol{x})=-\frac{\partial \Pi(\boldsymbol{p}, \boldsymbol{r}, b, N ; \boldsymbol{x})}{\partial b} \quad i=1, \ldots, m
$$

where $w_{i}$ is the water demand of crop $i$. In a similar vein, the estimated equations for $y_{i}$ and $w_{i}$ are linear in the exogenous variables following Moore et al. (1994b).

$$
\begin{aligned}
& y_{i}=\theta^{i}+\sum_{i=1}^{m} \kappa_{j}^{i} p_{i}+\sum_{i=1}^{z} \xi_{j}^{i} r_{i}+\tau^{i} b+\rho^{i} N+\sum_{s=1}^{t} v_{j}^{i} x_{i} \quad i=1, \ldots, m \\
& \mathrm{w}_{\mathrm{i}}=\mu^{\mathrm{i}}+\sum_{\mathrm{i}=1}^{\mathrm{m}} v_{\mathrm{j}}^{\mathrm{i}} \mathrm{p}_{\mathrm{i}}+\sum_{\mathrm{i}=1}^{\mathrm{z}} \omega_{\mathrm{j}}^{\mathrm{i}} \mathrm{r}_{\mathrm{i}}+\varphi^{\mathrm{i}} \mathrm{b}+\vartheta^{\mathrm{i}} \mathrm{N}+\sum_{\mathrm{s}=1}^{\mathrm{t}} 1_{\mathrm{j}}^{\mathrm{i}} \mathrm{x}_{\mathrm{i}} \quad \mathrm{i}=1, \ldots, \mathrm{m}
\end{aligned}
$$

The above derivation is based on the profit maximization function of a single producer. While to achieve sustainability of the water resource, the total profit function of the whole society needs to consider the marginal user cost and higher pumping costs externality of extracting water by every farmer. Thus, in addition to the decision-making on conserving water use and increasing crop yield, the way to achieve higher crop irrigation water use efficiency should be explored. Following the discussion on indicators of water use performance and productivity by Pereira et al. (2012), applying the following definition can be used to calculate the farm-level crop-specific economics irrigation water use efficiency.

$$
E I W U E=\frac{\text { Crop yield } \cdot \mathrm{P}}{\text { Total irrigation water appied }}
$$

where EIWUE is economic irrigation water use efficiency, crop yield is the saleable grain yield, $\mathrm{P}$ is average crop price in each state, and irrigation water applied is measured based on all irrigation water sources: well, on- and off-farm surface water. 
The greater the EIWUE value ${ }^{29}$, the higher the efficiency due to irrigation water application.

To analyze the effects, EIWUE can be a function of the exogenous variables affecting both yield and water demand.

$$
E I W U E_{i}=h_{i}(\boldsymbol{p}, \boldsymbol{r}, b, N ; \boldsymbol{x}) \quad i=1, \ldots, m
$$

In addition, the farm-level water demand can be decomposed to analyze the role of water price on production decisions regarding each crop. The crop-specific water demand can be decomposed into extensive margin of water use (an indirect effect on water use due to land allocation change) and intensive margin of water use (a direct effect on water use due to water demand).

The farm-level total water demand $(W)$ equals the sum of water demands for each crop grown on the farm with the optimal land allocation (Moore et al., 1994a):

$$
W=\sum_{i=1}^{m} w_{i}\left(p_{i}, \boldsymbol{r}, b, n_{i}^{*}(\boldsymbol{p}, \boldsymbol{r}, b, N ; \boldsymbol{x}) ; \boldsymbol{x}\right) \quad i=1, \ldots, m
$$

Taking the derivative of the equation with respect to water price gives:

$$
\frac{\partial W}{\partial \mathrm{b}}=\sum_{i=1}^{m}\left(\frac{\partial w_{i}}{\partial \mathrm{b}}+\frac{\partial w_{i}}{\partial n_{i}^{*}} \frac{\partial n_{i}^{*}}{\partial \mathrm{b}}\right)
$$

where $\frac{\partial w_{i}}{\partial \mathrm{b}}$ is the intensive margin, and $\frac{\partial w_{i}}{\partial n_{i}^{*}} \frac{\partial n_{i}^{*}}{\partial \mathrm{b}}$ is the extensive margin. The total effect can be obtained by summing the effects on all the crops. The intensive margin will decrease in price, and $\frac{\partial w_{i}}{\partial \mathrm{b}}$ should have a negative sign for each crop. The sign of the extensive margin depends on $\frac{\partial n_{i}^{*}}{\partial \mathrm{b}}$. The total farm-level effect on water use should be negative, which indicates decreasing water demand as water price increases.

\footnotetext{
29 The calculated EIWUE (and also IWUE) just considers irrigation water applied, while excluding rainfall amounts, but the state-level variation is controlled in the MLMs presented below.
} 


\subsection{Data and Variables}

The same national dataset from the USDA 2013 Farm and Ranch Irrigation Survey (FRIS) is used. Null models for all equations of each crop are estimated to calculate the intraclass correlation coefficient (ICC). However, only models in further steps on land allocation, water demand, crop supply, and EIWUE are estimated for corn and soybeans as they have the most observations but different distribution patterns across the five regions (specified below).

The lower 48 states are grouped into five regions according to USDA National Agricultural Statistics Services (NASS) ${ }^{30}$, including West, Plains, Midwest, South, and Atlantic states ${ }^{31}$. The descriptive statistics of the corn and soybean farms are presented in table 4.1 (table A4.1 in the appendix presents the summary statistics for all other crops, and table A4.2 and A4.3 in the appendix provide more information on irrigated acres in each state for corn and soybeans, respectively). Of the 19,272 irrigated farms, 6,030 farms grow corn for grain with an average area of 626 acres, and 3,933 farms grow soybeans with an average area of 570 acres. For corn farms, the mean water application is 0.95 acre-feet/acre; mean yield is $191 \mathrm{bu} / \mathrm{acre}$; and EIWUE is 1667 dollars/acre-foot on average. For soybean farms, the mean water, yield, and EIWUE are 0.69 acre-feet/acre, 54 bu/acre, and 1519 dollar/acre-foot, respectively.

\footnotetext{
${ }^{30}$ A map can be found on the USDA NASS website: https://www.nass.usda.gov/Charts_and_Maps/Farm_Production_Expenditures/reg_map_c.php 31 Ideally, analyses on all the production decisions (i.e., 5 equations, including the equation on crop choice decisions) regarding all crops (17 crops) can be conducted at the region level (i.e., 5 regions). Given the huge amount of work and the focus of this chapter, such analyses are not conducted.
} 
Table 4.1. Summary statistics of dependent variables: irrigated farms, mean farming area, mean water use, mean yield and water use efficiency.

\begin{tabular}{|c|c|c|c|c|c|c|c|}
\hline & \multirow[b]{2}{*}{ Units } & \multirow[b]{2}{*}{ National } & \multicolumn{5}{|c|}{ Regions } \\
\hline & & & West & Plains & Midwest & South & Atlantic \\
\hline \multicolumn{8}{|c|}{ Number of irrigated farms } \\
\hline All farms & Farms & 19272 & 5737 & 2237 & 4251 & 3563 & 3484 \\
\hline Corn for grain & Farms & 6030 & 692 & 1230 & 2308 & 1223 & 577 \\
\hline Soybeans & Farms & 3933 & 15 & 615 & 1590 & 1286 & 427 \\
\hline \multicolumn{8}{|l|}{ Mean Acres } \\
\hline Corn for grain & Acres/farm & 626 & 545 & 1088 & 465 & 668 & 289 \\
\hline Soybeans & Acres/farm & 570 & 162 & 414 & 331 & 1061 & 221 \\
\hline \multicolumn{8}{|c|}{ Mean water applied } \\
\hline Corn for grain & Acre-feet/acre & 0.95 & 2.19 & 1.16 & 0.62 & 0.87 & 0.44 \\
\hline Soybeans & Acre-feet/acre & 0.69 & 1.41 & 0.85 & 0.56 & 0.87 & 0.40 \\
\hline \multicolumn{8}{|l|}{ Mean yield } \\
\hline Corn for grain & $\mathrm{Bu} / \mathrm{acre}$ & 191 & 187 & 193 & 191 & 189 & 193 \\
\hline Soybeans & $\mathrm{Bu} / \mathrm{acre}$ & 54 & 49 & 57 & 53 & 52 & 52 \\
\hline \multicolumn{8}{|c|}{ Economics irrigation water use efficiency } \\
\hline Corn for grain & \$/acre-foot & 1667 & 606 & 1007 & 1871 & 1742 & 3369 \\
\hline Soybeans & \$/acre-foot & 1519 & 563 & 1177 & 1735 & 1082 & 2550 \\
\hline
\end{tabular}


The independent variables are at two levels. At the farm level, the explanatory variables are related with water cost, expenditures on irrigation equipment, labor payment, farming area owned and leased, water sources, number of wells, irrigation systems, barriers for improvements, information sources, and improvements and assistance. All of these independent variables are coded and defined the same as in the previous chapter. In particular, dummy variables $(\mathrm{Yes}=1, \mathrm{No}=0)$ are used regarding water sources, various barriers to improvements, information sources, irrigation improvements and assistance. The summary statistics of the farm-level independent variables for all irrigated farms are the same as presented in table 3.1 in the previous chapter (and table A3.1 in the appendix provides more specific statistics on the 6,030 corn farms and 3,933 soybean farms.)

At the state level, four explanatory variables on state-wide weather conditions are used as in the previous chapter using the data from NOAA. The variables are state average precipitation changes in 2012 and 2013, and temperature changes in 2012 and 2013.

\subsection{Econometric Methods}

Multilevel models have the advantage of examining individual farms embedded within states and assess the variation at both farm- and state-levels. The multilevel regression model is commonly viewed as a hierarchical regression model (Hox, 1995). A multilevel linear modeling technique is utilized to analyze the effects of influential factors on crop choice, land allocation, crop yield, and EIWUE. The same multilevel 
modeling is applied as in the previous chapter, but the dependent variables are continuous in this chapter ${ }^{32}$.

For my research questions, I have $N$ individual crop-specific farms $\left(i=1, \ldots, N_{j}\right)$ in $J$ states $(j=1, \ldots, J)$. The $X_{i j}$ represent a set of independent variables at the farm level, and a series of state-level independent variables are represented by $Z_{j}$. The model estimation includes two steps. For the first step, a separate regression equation can be specified in each state to predict the effects of the independent variables on the dependent variables.

$$
\boldsymbol{Y}_{i j}=\beta_{0 j}+\boldsymbol{\beta}_{1 j} \boldsymbol{X}_{1 i j}+e_{i j}
$$

For the second step, the intercepts, $\beta_{0 j}$ 's are considered parameters varying across states as a function of a grand mean $\left(\gamma_{00}\right)$ and a random term $\left(u_{0 j}\right)$. The $\beta_{1 j}$ 's are assumed constant across states and are presented as a function of fixed parameters $\left(\gamma_{10}\right)$

$$
\boldsymbol{\beta}_{0 j}=\gamma_{00}+\gamma_{01} Z_{j}+u_{0 j}
$$

and

$$
\boldsymbol{\beta}_{1 j}=\gamma_{10}+u_{1 j}
$$

The model is called a random-intercept and random-slope model, as the key feature is that not only the intercept parameter in the Level-1 model, $\beta_{0 j}$, is assumed to vary at Level-2 (state) (Raudenbush and Bryk, 2002), but the slope is also random with an error term $u_{1 j}$. The $\gamma_{01}$ coefficient captures the effects of the state-level variables $\left(Z_{j}\right)$ on the $\beta_{0 j}$ 's, whereas $\gamma_{10}$ predicts the constant parameter, $\beta_{1 j}$, (with errors). This multilevel model has been applied in social science research (e.g.,

\footnotetext{
32 This requires a different SAS syntax. Refer to the appendix for the differences of conducting MLMs for categorical and continuous dependent variables.
} 
Dolisca et al. (2009) and Guerin et al. (2001)). However, MLMs have never been used to analyze crop production or farm irrigation. Given the FRIS data structure and its applicability as examined in the previous chapter, I apply the MLMs to multiple equations relating to production decisions in irrigated multicrop agriculture.

The data were analyzed using the SAS package in the USDA data lab in St. Louis, Missouri, with official permission.

\subsection{Results}

\subsubsection{Decomposition of farm-level water demand}

To decompose the effect of water cost on farm-level water demand, the extensive and intensive margins are provided in table $4.2^{33}$. This chapter takes corn and soybeans as examples ${ }^{34}$. The estimated coefficients on crop acreage and water cost in the water demand equation suggest: a change in water use given a change in land use $\left(\frac{\partial w_{i}}{\partial n_{i}}\right)$, and a marginal change in water use given a change in water cost $\left(\frac{\partial w_{i}}{\partial \mathrm{b}}\right)$. The estimated coefficients on water cost in the land allocation equation represent a change in land use given a change in water cost $\left(\frac{\partial n_{i}}{\partial b}\right)$. The intensive margin can be obtained with $\frac{\partial w_{i}}{\partial \mathrm{b}}$ while adjusting for the estimated probability the crop is grown. The extensive margin can be calculated using $\frac{\partial w_{i}}{\partial n_{i}} \frac{\partial n_{i}}{\partial b}$. Summing the intensive and

$33 \frac{\partial w_{i}}{\partial n_{i}}$ is the estimated coefficient on crop acreage in the water demand equations, where $w_{i}$ is the acre-feet of irrigation water on crop $i$ and $n_{i}$ is acres of growing crop $i . \frac{\partial n_{i}}{\partial b}$ is the estimated coefficient on water price in the land allocation equations, with $\mathrm{b}$ the water prices. $\frac{\partial w_{i}}{\partial \mathrm{b}}$ is the estimated coefficients on water price in the water demand equation. The calculation of both intensive and extension margin should be adjusted by the share of the crop planted.

${ }^{34}$ Ideally, equations on water demand and land allocation for each crop can be estimated to obtain both extensive and intensive margins for each crop, and then the aggregate effect can be calculated for a typical farm growing all crops. Equations on production decisions can also be estimated for each region to calculate the aggregate effect for a typical farm growing all crops in each region. Similar reasons are followed here as noted in footnote 5. 
extensive margins for each crop gives the total effect of a change in water cost. Further summing the effects on all crops gives the total effect on a typical farm growing both crops.

As expected, both $\frac{\partial w_{i}}{\partial \mathrm{b}}$ and $\frac{\partial n_{i}}{\partial b}$ decrease in water cost. A numerical illustration can help understand the effects of water price. A 1 dollar increase in water price $(\Delta \mathrm{b}=\$ 1)$ would lead to a decrease of 0.00063 and 0.00019 acre-feet of water application per acre of land. In a multicrop system, a typical farm growing both corn and soybeans would decrease water demand by 0.50277 acre-feet. These results show water use is highly inelastic in water cost (Moore et al., 1994b). While this may be different for regions/states with varying availability of water resources, an in-depth analysis of regional or state effect of water cost on water use can be helpful.

\subsubsection{Intraclass correlation coefficients from MLMs}

The first step in conducting a multilevel model is to calculate the ICC which shows how much of the variability in one response variable is accounted for by the level 2. The intraclass correlation coefficients (ICC) for all null crop-specific multilevel models are presented in table 4.3 (and in table A4.4 in the appendix). For example, the ICC for the crop choice equation of corn is 0.5346 , which suggests about $53 \%$ of the variability in crop choice decisions is accounted for by the factors at the state level, leaving $47 \%$ of the variability to be accounted for by the farm-level factors. More variability in crop choice ${ }^{35}$, water demand, and EIWUE is accounted by the state-level factors, with a majority of ICC greater than 0.40 . However, more variability of land allocation ${ }^{36}$ and crop supply is accounted for by farm-level factors.

\footnotetext{
35 Further models on crop choice are not estimated below.

36 Estimation results from the MLMs on land allocation are provided in the appendix, table A4.5 and A4.6 for corn and soybeans, respectively.
} 
In the following sections, results for each estimated equation are presented for corn and soybeans jointly to facilitate the comparison of the effects on the two crops. 
Table 4.2. Crop-specific extensive and intensive margins to water cost.

\begin{tabular}{|c|c|c|c|c|c|c|c|c|}
\hline & dw/dn & $\mathrm{dn} / \mathrm{db}$ & $\mathrm{dw} / \mathrm{db}$ & $\begin{array}{c}\text { Share of } \\
\text { crop-specific farms }\end{array}$ & $\begin{array}{c}\text { Extensive } \\
\text { margin }\end{array}$ & $\begin{array}{c}\text { Intensive } \\
\text { margin }\end{array}$ & $\begin{array}{c}\text { Total effect } \\
\text { (acre-feet per acre) }\end{array}$ & $\begin{array}{c}\text { Total effect-farm } \\
\text { (acre-feet per farm) }\end{array}$ \\
\hline Corn & 0.00001 & -0.0493 & -0.00202 & 0.31289 & -0.0000001697 & -0.000632 & -0.00063 & -0.39576 \\
\hline Soybeans & -0.00001 & -0.01718 & -0.00092 & 0.20408 & 0.0000000228 & -0.00019 & -0.00019 & -0.10701 \\
\hline
\end{tabular}

Table 4.3. Intraclass correlation coefficients (ICC) for null models of each crop-specific multilevel model.

\begin{tabular}{lccccc}
\hline \multicolumn{1}{c}{ State level } & Crop choice & Land allocation & Water demand & Crop supply & EIWUE \\
\hline Corn for grain & 0.5346 & 0.0959 & 0.7304 & 0.1206 & 0.4161 \\
Soybeans & 0.7485 & 0.1391 & 0.5178 & 0.1731 & 0.3437 \\
\hline
\end{tabular}

Notes: Higher level models for crop choice are not presented in the dissertation.

EIWUE: Economics irrigation water use efficiency. 


\subsubsection{Water application equation}

The parameter estimates for water application equations of corn and soybeans are presented in table 4.4 and table 4.5. Both water application equations have high ICC values indicating about $73 \%$ and $52 \%$ of the variability for water application of corn and soybeans is accounted for by the differences at the state level. Water cost has a negative effect on irrigation water application of both corn and soybeans. In alignment with expectations, this finding suggests higher water cost decreases water demand. Labor payment on corn farms shows a positive correlation with water use, which suggests that these factors are complements; more labor use facilitates more irrigation, or producers who need more irrigation to maximize profits use more labor.

Large farming area owned by farmers has a negative association with the average water application on corn farms. More wells are positively associated with water application on both corn and soybean farms, which is consistent with the hypothesis as mentioned above that more wells provide farmers more and easier access to water. Adoption of pressure irrigation systems reduces irrigation water application for soybean farms, which is consistent with the hypothesis that pressure (enhanced) irrigation methods reduce water use.

Information from extension agents has a negative effect on the water use of both corn and soybean farms, while information from local irrigation district employees has a positive effect, which indicates that the extension agents are more helpful in conserving water.

The state-level variables on climate variability show a very consistent pattern on both corn and soybean water use. Compared with the average temperature in 1981-2010, the higher temperature in 2012 is negatively associated with the water application of both corn and soybeans in 2013. Compared with the average 
precipitation in 1981-2010, more precipitation in 2013 leads to less irrigation water application on corn and soybean farms. While the negative association between temperature change in 2013 and soybean water use is very interesting. 
Table 4.4. Results of multilevel models for mean water application for CORN farms.

\begin{tabular}{|c|c|c|c|c|c|c|c|c|}
\hline & \multicolumn{2}{|c|}{$\begin{array}{l}\text { Model 1: Random } \\
\text { intercept only }\end{array}$} & \multicolumn{2}{|c|}{$\begin{array}{l}\text { Model 2: M1+fixed } \\
\text { Level 1 }\end{array}$} & \multicolumn{2}{|c|}{$\begin{array}{l}\text { Model 3: M2+random } \\
\text { Level 1 }\end{array}$} & \multicolumn{2}{|c|}{$\begin{array}{l}\text { Model 4: M3+fixed } \\
\text { Level } 2\end{array}$} \\
\hline \multicolumn{9}{|l|}{ Fixed Effects } \\
\hline \multicolumn{9}{|l|}{ Payments } \\
\hline Water cost & & & $-0.0001 * * *$ & $2.4 \mathrm{E}-05$ & $-0.0020 * * *$ & 0.0005 & $-0.0020 * * *$ & 0.0005 \\
\hline Irrigation equipme & texpense & & -0.0001 & $5.9 \mathrm{E}-05$ & $4 \mathrm{E}-05$ & $5.6 \mathrm{E}-05$ & $-4 \mathrm{E}-05$ & 5.6E-05 \\
\hline \multicolumn{9}{|l|}{ Farm Size } \\
\hline Land owned & & & $-0.0033 * *$ & 0.0014 & $-0.0030 * *$ & 0.0013 & $-0.0030 * *$ & 0.0013 \\
\hline Land leased & & & $-0.0032 * *$ & 0.0014 & -0.0019 & 0.0024 & -0.0018 & 0.0024 \\
\hline \multicolumn{9}{|c|}{ Water Source (Base: Ground water only) } \\
\hline On-farm surface w & ter only & & -0.0173 & 0.0300 & -0.0532 & 0.0521 & -0.0555 & 0.0525 \\
\hline \multicolumn{9}{|c|}{ Barriers for Improvements } \\
\hline Investigating imprc & vement is not a pr & ority & -0.0025 & 0.0179 & 0.0073 & 0.0170 & 0.0071 & 0.0170 \\
\hline Cannot finance im & ovements & & -0.0096 & 0.0207 & -0.0003 & 0.0210 & 0.0003 & 0.0203 \\
\hline \multicolumn{9}{|c|}{ Information Source } \\
\hline Extension agents & & & $-0.0255^{*}$ & 0.0147 & $-0.0262 *$ & 0.0139 & $-0.0260 *$ & 0.0139 \\
\hline
\end{tabular}


Irrigation equipment dealers

Local irrigation district employees

Neighboring farmers

Improvements and Assistance

Irrigation improvements

Technical and financial assistance

State-wide average weather-related variables

PrecipChange2012

TempChange2012

PrecipChange2013

TempChange2013

Error Variance

\begin{tabular}{|c|c|c|c|c|c|c|c|c|}
\hline Subject & Estimate & Std Err & Estimate & Std Err & Estimate & Std Err & Estimate & Std Err \\
\hline Intercept (STATE) & $0.7015 * * *$ & 0.1545 & $0.6506 * * *$ & 0.1438 & $0.7761 * * *$ & 0.1888 & $0.2732 * * *$ & 0.0792 \\
\hline Residual & $0.2589 * * *$ & 0.0047 & $0.2534 * * *$ & 0.0046 & $0.2174 * * *$ & 0.0042 & $0.2175^{* * *}$ & 0.0042 \\
\hline \multicolumn{9}{|l|}{ Fit Statistics } \\
\hline$-2 \mathrm{LL}$ & 9195 & & 9061 & & 8624 & & 8588 & \\
\hline AIC & 9201 & & 9105 & & 8694 & & 8666 & \\
\hline
\end{tabular}

$\mathrm{ICC}=0.7015 /(0.7015+0.2589)=0.7304$.

Significance level: * $10 \%$; ** 5\%; *** $1 \%$.

\begin{tabular}{llllll}
0.0051 & 0.0146 & 0.0107 & 0.0139 & 0.0108 & 0.0139 \\
$0.0656^{* *}$ & 0.0298 & 0.0339 & 0.0405 & 0.0344 & 0.0404 \\
0.0100 & 0.0157 & 0.0150 & 0.0148 & 0.0149 & 0.0148 \\
-0.0080 & 0.0159 & 0.0242 & 0.0289 & 0.0258 & 0.0294 \\
$0.0327^{*}$ & 0.0182 & 0.0278 & 0.0238 & 0.0280 & 0.0237 \\
& & & & $-0.0511^{*}$ & 0.0263 \\
& & & $-0.4206^{* * *}$ & 0.1135 \\
& & & $-0.1008^{* * *}$ & 0.0189 \\
& & & & -0.0296 & 0.1405 \\
\hline
\end{tabular}


Table 4.5. Results of multilevel models for mean water applied on SOYBEAN farms.

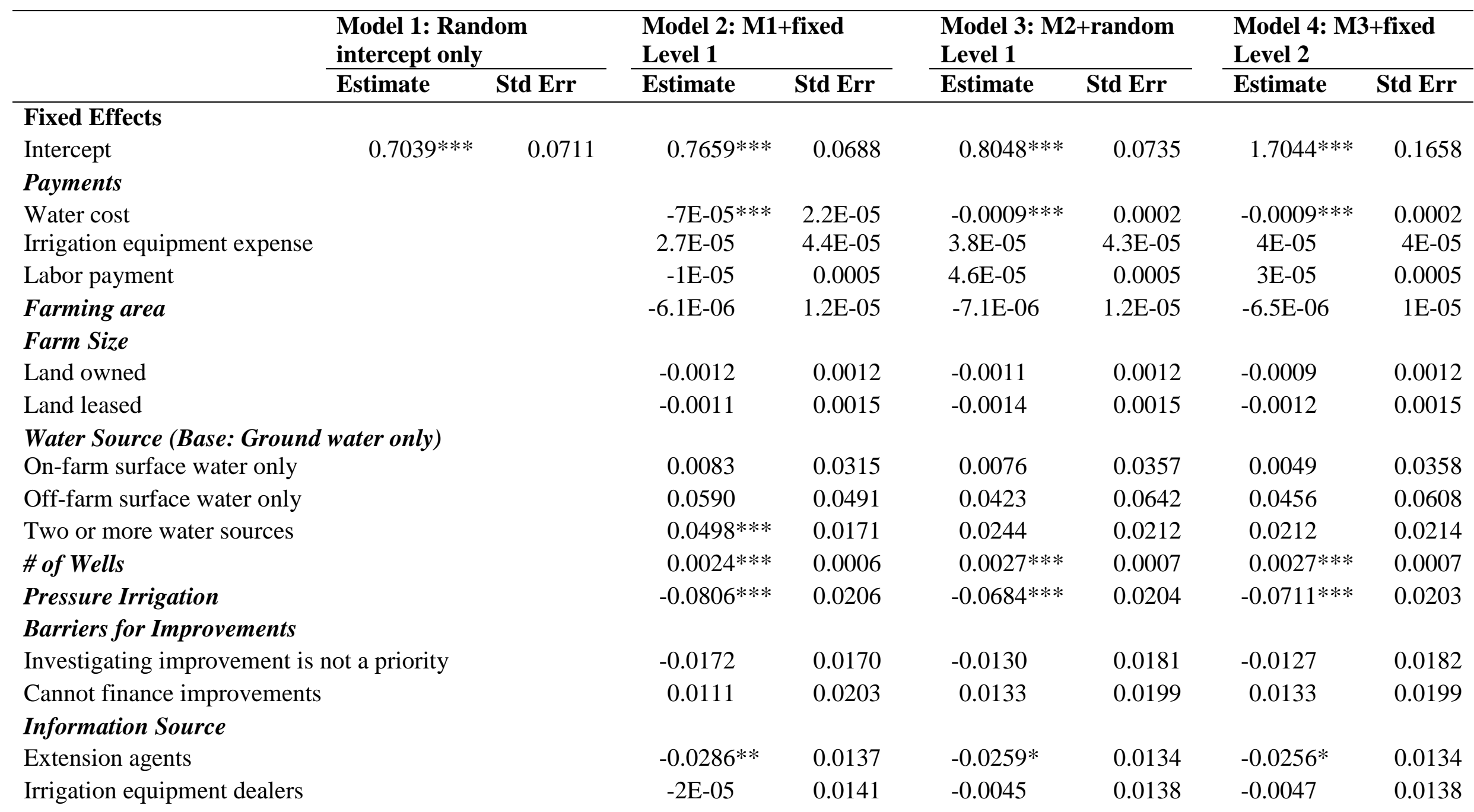


Local irrigation district employees

Neighboring farmers

Improvements and Assistance

Irrigation improvements

Technical and financial assistance

State-wide average weather-related variables

PrecipChange2012

TempChange2012

PrecipChange2013

TempChange2013

\section{Error Variance}

Subject

N Intercept (STATE)

Residual

\section{Fit Statistics}

$\mathrm{N}$

$-2 \mathrm{LL}$

AIC

AICC

BIC

$\mathrm{ICC}=0.1662 /(0.1662+0.1548)=0.5178$.

Estimate
$0.1662 * * *$
$0.1548 * * *$
3933
3959
3965
3965
3970


$5 \%=0.5178$.
$5 \% * 1 \%$.

Significance level: * $10 \%$; ** 5\%; *** $1 \%$.

\begin{tabular}{ccccll}
$0.0595^{*}$ & 0.0352 & 0.0534 & 0.0345 & $0.0562 *$ & 0.0344 \\
-0.0047 & 0.0148 & 0.0008 & 0.0172 & 0.0009 & 0.0169 \\
& & & & & \\
$-0.0274 *$ & 0.0150 & -0.0235 & 0.0147 & -0.0232 & 0.0147 \\
$0.0518^{* * *}$ & 0.0174 & $0.0471^{* *}$ & 0.0189 & $0.0472 * *$ & 0.0189 \\
& & & & $-0.0224 *$ & 0.0113 \\
& & & & $-0.3082^{* * *}$ & 0.0642 \\
& & & & $-0.0736^{* * *}$ & 0.0104 \\
& & & & $-0.1153^{*}$ & 0.0644 \\
\hline
\end{tabular}

Std Err $\quad$ Estimate $\quad$ Std Err

Estimate Std Err

0.0519

Estimate Std Err

0.0538

$0.1344 * * * \quad 0.0461$

$0.1547 * * *$
$0.1434 * * *$

0.0033

$0.0440 * * *$

$0.1434 * * *$

0.0143

0.0033
3933

3734

3802

3803

3857 


\subsubsection{Crop supply equation}

The MLMs results for crop supply equations of corn and soybeans are presented in table 4.6 and table 4.7. Both yield equations have low ICC values suggesting approximately $12 \%$ and $17 \%$ of the variability for yields of corn and soybeans is accounted for by the state-level factors. Water cost does not have a significant effect on farm average yield, which is consistent with the fact that more irrigation generally increases crop yield and farm profits.

Larger area of leased land has a positive association with both corn and soybean yield. Irrigation using water from both on- and off-farm surface only shows a negative association with corn yield. More wells used on soybean farms increase the yield. The adoption of pressure irrigation systems shows a positive effect on corn yield, indicating corn yield is increased under the enhanced irrigation method.

Lack of financing to make improvements is a major barrier for both corn and soybean production. Irrigation information from neighboring farmers has a negative effect on soybean yield. Farmers who made irrigation and/or drainage improvements tend to increase crop yield, which indicates farm management can be helpful to achieve higher yield. Interestingly, precipitation and temperature changes in 2012 and 2013 are not significantly related to yield. Given the results from the water application regressions, it seems that farmers who have access to irrigation were able to fully off-set the effects of weather variability. 
Table 4.6. Results of multilevel models for mean yield of CORN farms.

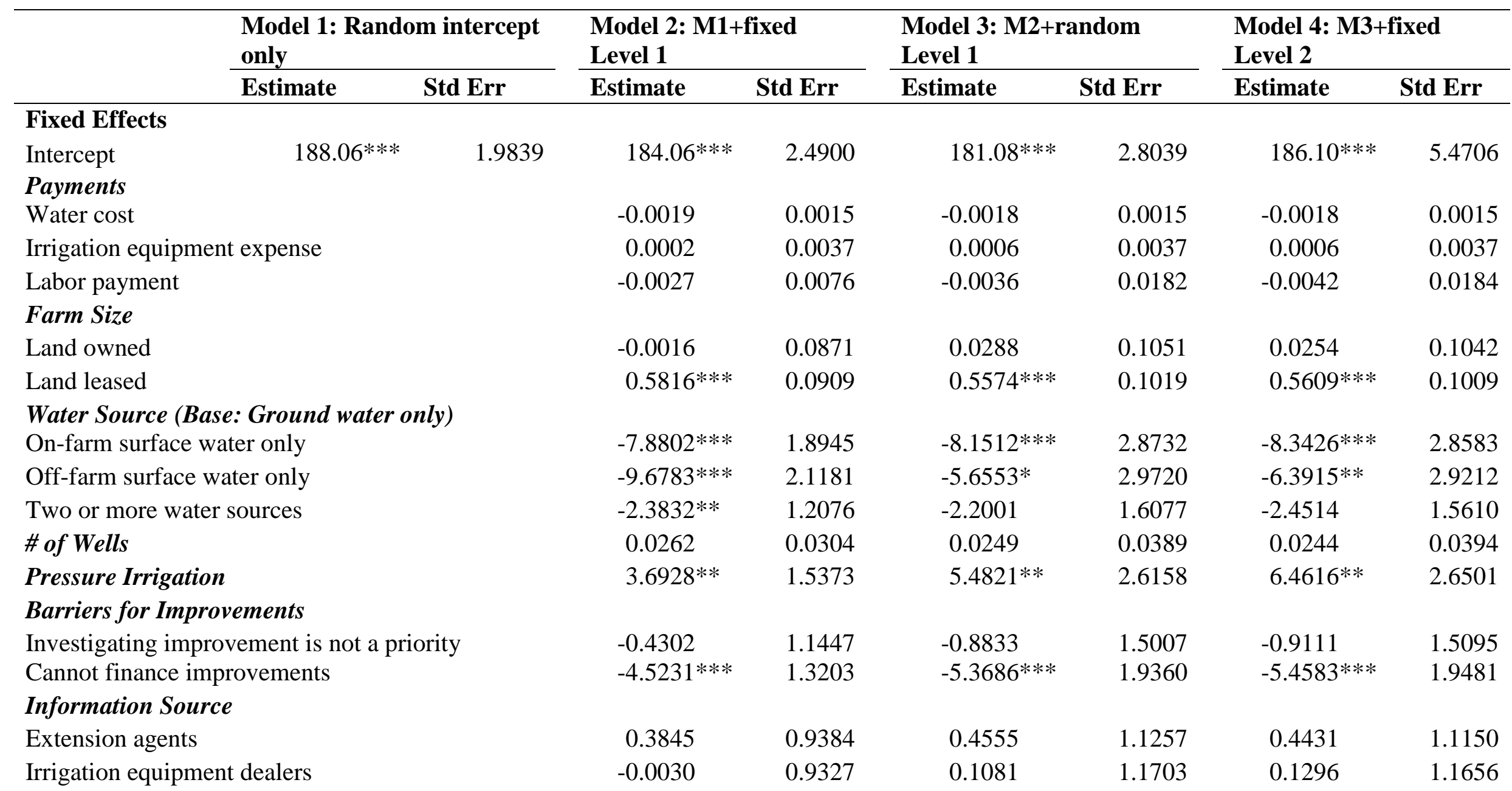


Local irrigation district employees

Neighboring farmers

Improvements and Assistance

Irrigation improvements

Technical and financial assistance

State-wide average weather-related variables

PrecipChange2012

TempChange2012

PrecipChange2013

TempChange2013

Error Variance

$\begin{array}{rr}0.4939 & 1.8999 \\ -0.5300 & 1.0023\end{array}$

$3.2398 * * *$

$-0.1072$

1.0168

1.1625

\subsection{5}

1.1610

$3.1479 * * *$

0.0657

1.0113

1.1521

0.0596

1.0114

$-0.2013$

$-2.1253$

$-0.5107$

0.2811

0.5541

0.4136

3.1709

$\begin{array}{lc}\text { Subject } & \text { Estimate } \\ \text { Intercept (STATE) } & 145 * * *\end{array}$

Std Err $1058 * * *$

40
19

Estimate

Std Err

Estimate

Std Err

Estimate

Std Err

Residual

$1036 * * *$

19

$994 * * *$

46

19

6030
59022
59090
59091
59150

6030

6030
59086

59128

59128

59165

59150

59019

59095

59096

59230

59162

ICC $=145 /(145+1058)=0.1206$.

Significance level: * 10\%; ** 5\%; *** $1 \%$. 
Table 4.7. Results of multilevel models for mean yield of SOYBEAN farms.

\begin{tabular}{|c|c|c|c|c|c|c|c|c|}
\hline & \multicolumn{2}{|c|}{$\begin{array}{l}\text { Model 1: Random intercept } \\
\text { only }\end{array}$} & \multicolumn{2}{|c|}{$\begin{array}{l}\text { Model 2: M1+fixed } \\
\text { Level 1 }\end{array}$} & \multicolumn{2}{|c|}{$\begin{array}{l}\text { Model 3: M2+random } \\
\text { Level 1 }\end{array}$} & \multicolumn{2}{|c|}{$\begin{array}{l}\text { Model 4: M3+fixed } \\
\text { Level 2 }\end{array}$} \\
\hline & Estimate & Std Err & Estimate & Std Err & Estimate & Std Err & Estimate & Std Err \\
\hline \multicolumn{9}{|l|}{ Fixed Effects } \\
\hline Intercept & $52.7665^{* * *}$ & 0.8399 & $50.5929 * * *$ & 1.0110 & $50.5063 * * *$ & 1.1584 & $45.3981 * * *$ & 3.7571 \\
\hline \multicolumn{9}{|l|}{ Payments } \\
\hline Water cost & & & -0.0003 & 0.0005 & -0.0003 & 0.0005 & -0.0003 & 0.0005 \\
\hline Irrigation equipme & t expense & & 0.0007 & 0.0011 & 0.0006 & 0.0011 & 0.0006 & 0.0011 \\
\hline Labor payment & & & -0.0201 & 0.0124 & -0.0180 & 0.0123 & -0.0180 & 0.0123 \\
\hline \multicolumn{9}{|l|}{ Farm Size } \\
\hline Land owned & & & -0.0123 & 0.0305 & -0.0078 & 0.0305 & -0.0091 & 0.0305 \\
\hline Land leased & & & $0.1090 * * *$ & 0.0360 & $0.1187 * * *$ & 0.0418 & $0.1210 * * *$ & 0.0419 \\
\hline \multicolumn{9}{|c|}{ Water Source (Base: Ground water only) } \\
\hline On-farm surface w & ter only & & -0.2453 & 0.7634 & -0.4850 & 0.8900 & -0.4574 & 0.8960 \\
\hline Off-farm surface $n$ & ter only & & 1.0272 & 1.1841 & 1.0189 & 1.1838 & 1.0605 & 1.1857 \\
\hline Two or more wate & sources & & 0.3291 & 0.4181 & 0.2207 & 0.5311 & 0.2424 & 0.5350 \\
\hline \# of Wells & & & $0.0606 * * *$ & 0.0112 & $0.0604 * * *$ & 0.0113 & $0.0605 * * *$ & 0.0113 \\
\hline Pressure Irrigatio & & & 0.5080 & 0.5013 & 0.3614 & 0.9103 & 0.2989 & 0.9036 \\
\hline \multicolumn{9}{|c|}{ Barriers for Improvements } \\
\hline Investigating impr & vement is not a pric & rity & 0.3100 & 0.4156 & 0.2949 & 0.4498 & 0.2875 & 0.4484 \\
\hline Cannot finance im & rovements & & $-2.2918 * * *$ & 0.4960 & $-2.0026^{* * *}$ & 0.5882 & $-2.0056 * * *$ & 0.5856 \\
\hline \multicolumn{9}{|c|}{ Information Source } \\
\hline Extension agents & & & 0.4460 & 0.3345 & 0.6926 & 0.4539 & 0.6947 & 0.4532 \\
\hline Irrigation equipme & t dealers & & 0.3761 & 0.3450 & 0.2271 & 0.3455 & 0.2211 & 0.3455 \\
\hline Local irrigation dis & rict employees & & 0.9288 & 0.8593 & 0.9709 & 0.8573 & 0.9784 & 0.8573 \\
\hline
\end{tabular}




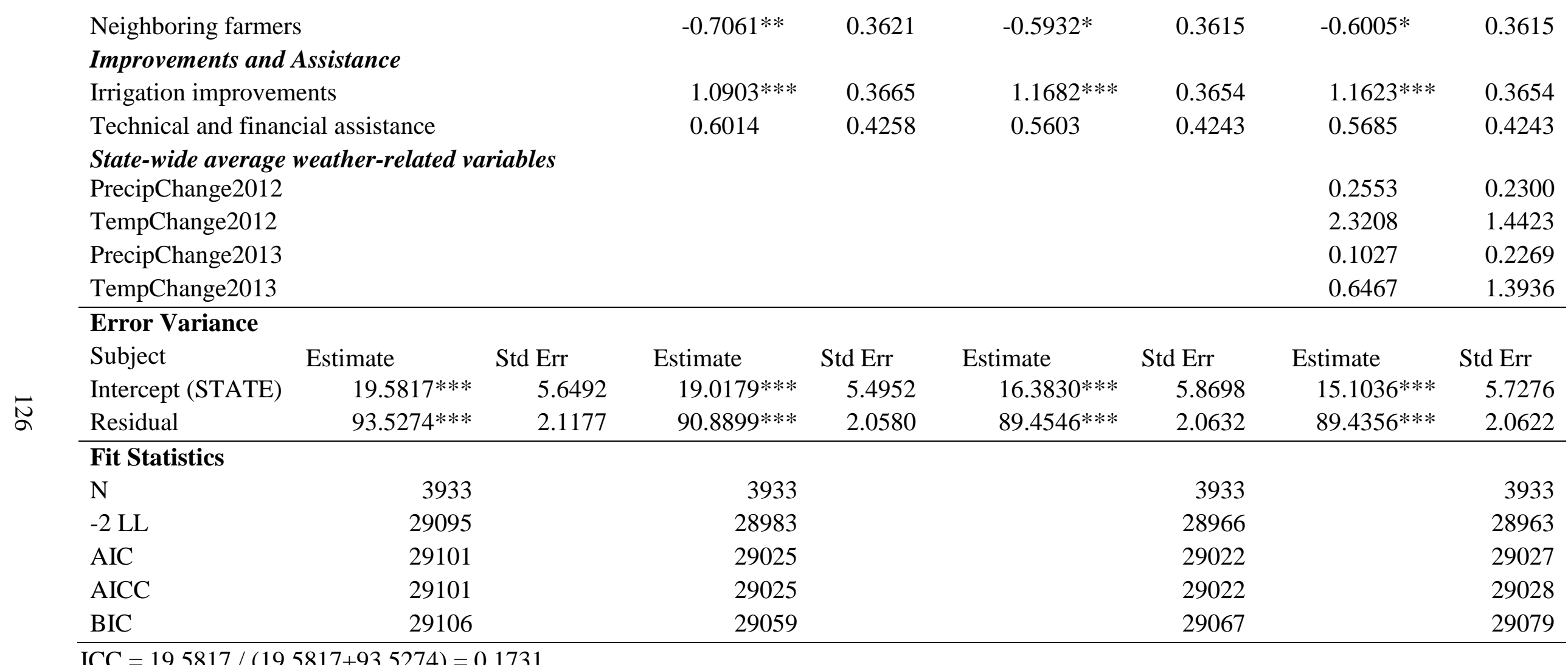

Significance level: * $10 \%$; ** 5\%; *** $1 \%$. 


\subsubsection{Economic irrigation water use efficiency equation}

The parameter estimates for EIWUE equations of corn and soybeans are presented in table 4.8 and table 4.9 , respectively. Both equations have fairly high ICC values indicating about $42 \%$ and $34 \%$ of the variability for irrigation efficiency of corn and soybeans is accounted for by factors at the state level. Water cost has a positive effect on water use efficiency of both corn and soybeans. The higher efficiency can be achieved through reducing water use or/and increasing crop yield. Labor payment shows a negative effect on corn EIWUE. Larger areas of land owned and rented have positive associations with corn EIWUE, and this indicates larger corn farms tend to use water more efficiently. Irrigation using water from on-farm surface only and multiple sources has a negative effect on corn EIWUE, compared to groundwater only. The well variable shows a negative effect on both corn and soybean EIWUE, and this indicates fewer wells available on a farm can encourage an efficient use of irrigation water. Adoption of pressure irrigation increases water use efficiency of soybeans, indicating the effectiveness of achieving higher irrigation water use efficiency with the application of enhanced irrigation systems. Similarly, higher irrigation efficiency on corn farms is related with less financing, and this can be true if water application is limited by poor water distribution systems.

Regarding the state-level variables on climate variability, for soybean farms, compared with the average temperature and precipitation, both temperature change in 2012 and precipitation change in 2013 are positively associated with higher irrigation water use efficiency in 2013. However only precipitation change in 2013 is positively associated with corn water use efficiency. These findings suggest that higher temperatures promote farmers to use water more efficiently. 
Table 4.8. Results of multilevel models for economics irrigation water use efficiency (EIWUE) of CORN farms.

\begin{tabular}{|c|c|c|c|c|c|c|c|c|}
\hline & \multicolumn{2}{|c|}{$\begin{array}{l}\text { Model 1: Random } \\
\text { intercept only }\end{array}$} & \multicolumn{2}{|c|}{$\begin{array}{l}\text { Model 2: M1+fixed } \\
\text { Level 1 }\end{array}$} & \multicolumn{2}{|c|}{$\begin{array}{l}\text { Model 3: M2+random } \\
\text { Level 1 }\end{array}$} & \multicolumn{2}{|c|}{$\begin{array}{l}\text { Model 4: M3+fixed } \\
\text { Level } 2\end{array}$} \\
\hline \multicolumn{9}{|l|}{ Fixed Effects } \\
\hline \multicolumn{9}{|l|}{ Payments } \\
\hline Water cost & & & $0.6300 * * *$ & 0.0652 & $2.9899 * * *$ & 0.5424 & $2.9897 * * *$ & 0.5364 \\
\hline Irrigation equipment expense & & & 0.0098 & 0.1605 & -0.3756 & 0.3345 & -0.3691 & 0.3350 \\
\hline Land owned & & & $9.7304 * * *$ & 3.7363 & $8.9037 * *$ & 3.5589 & $9.0364 *$ & 3.6132 \\
\hline Land leased & & & $9.2858 * *$ & 3.8988 & $9.4687 * *$ & 4.2631 & $9.2924 * *$ & 4.2797 \\
\hline \multicolumn{9}{|c|}{ Water Source (Base: Ground water only) } \\
\hline On-farm surface water only & & & $167.88 * *$ & 81.8657 & $259.85 * *$ & 124.8200 & $272.51 * *$ & 126.0400 \\
\hline Off-farm surface water only & & & -23.4285 & 92.2635 & 219.62 & 197.9900 & 220.89 & 197.9300 \\
\hline Investigating improvement is & not a priority & & $-80.9426^{*}$ & 49.0523 & -90.6568 & 65.2183 & -92.1493 & 66.3538 \\
\hline Cannot finance improvements & & & $-111.27 * *$ & 56.5729 & $-105.39 * *$ & 53.7626 & $-104.51 *$ & 53.7519 \\
\hline \multicolumn{9}{|l|}{ Information Source } \\
\hline Extension agents & & & -64.1159 & 40.2317 & -50.4117 & 38.2765 & -52.7432 & 38.2788 \\
\hline Irrigation equipment dealers & & & -57.6220 & 39.9891 & -40.7684 & 38.0897 & -40.5169 & 38.0892 \\
\hline
\end{tabular}


Local irrigation district employees

$\begin{array}{rrrrrr}-68.5267 & 81.4921 & -75.2484 & 77.9937 & -72.2582 & 78.0137 \\ 35.4471 & 42.9403 & 37.3954 & 46.7352 & 37.9676 & 46.7367 \\ & & & & & \\ 64.0083 & 43.5624 & 80.9328 & 65.0771 & 82.3636 & 67.8658 \\ -66.4820 & 49.8086 & -56.8776 & 49.1306 & -57.0807 & 47.7397 \\ & & & & 46.19 & 33.8161 \\ & & & & 238.96 & 145.2100 \\ & & & & 115.58^{* * *} & 23.4281 \\ & & & & & \\ & & & & & \\ \end{array}$

Neighboring farmers

Improvements and Assistance

Irrigation improvements

State-wide average weather-related variables

PrecipChange2012

TempChange2012

PrecipChange 2013

292.05

178.6100

\begin{tabular}{|c|c|c|c|c|c|c|c|c|}
\hline \multicolumn{9}{|l|}{ Error Variance } \\
\hline Subject & Estimate & Std Err & Estimate & Std Err & Estimate & Std Err & Estimate & Std Err \\
\hline Intercept (STATE) & $1394373 * * *$ & 323491 & $1174646 * * *$ & 276343 & $941825 * * *$ & 237084 & $495307 * * *$ & 141561 \\
\hline Residual & $1956776 * * *$ & 35771 & $1900285^{* * *}$ & 34740 & $1672396^{* * *}$ & 31779 & $1671777 * * *$ & 31926 \\
\hline
\end{tabular}

\section{Fit Statistics}

$\mathrm{N}$

$-2 \mathrm{LL}$

104642

AIC

104648

104460

103952

103930

AICC

104648

104502

104014

104002

BIC

104654

104502

104014

104003

$\mathrm{ICC}=1394373 /(1394373+1956776)=0.4161$

Significance level: * $10 \%$; ** 5\%; *** $1 \%$. 
Table 4.9. Results of multilevel models for economics irrigation water use efficiency (EIWUE) of SOYBEAN farms.

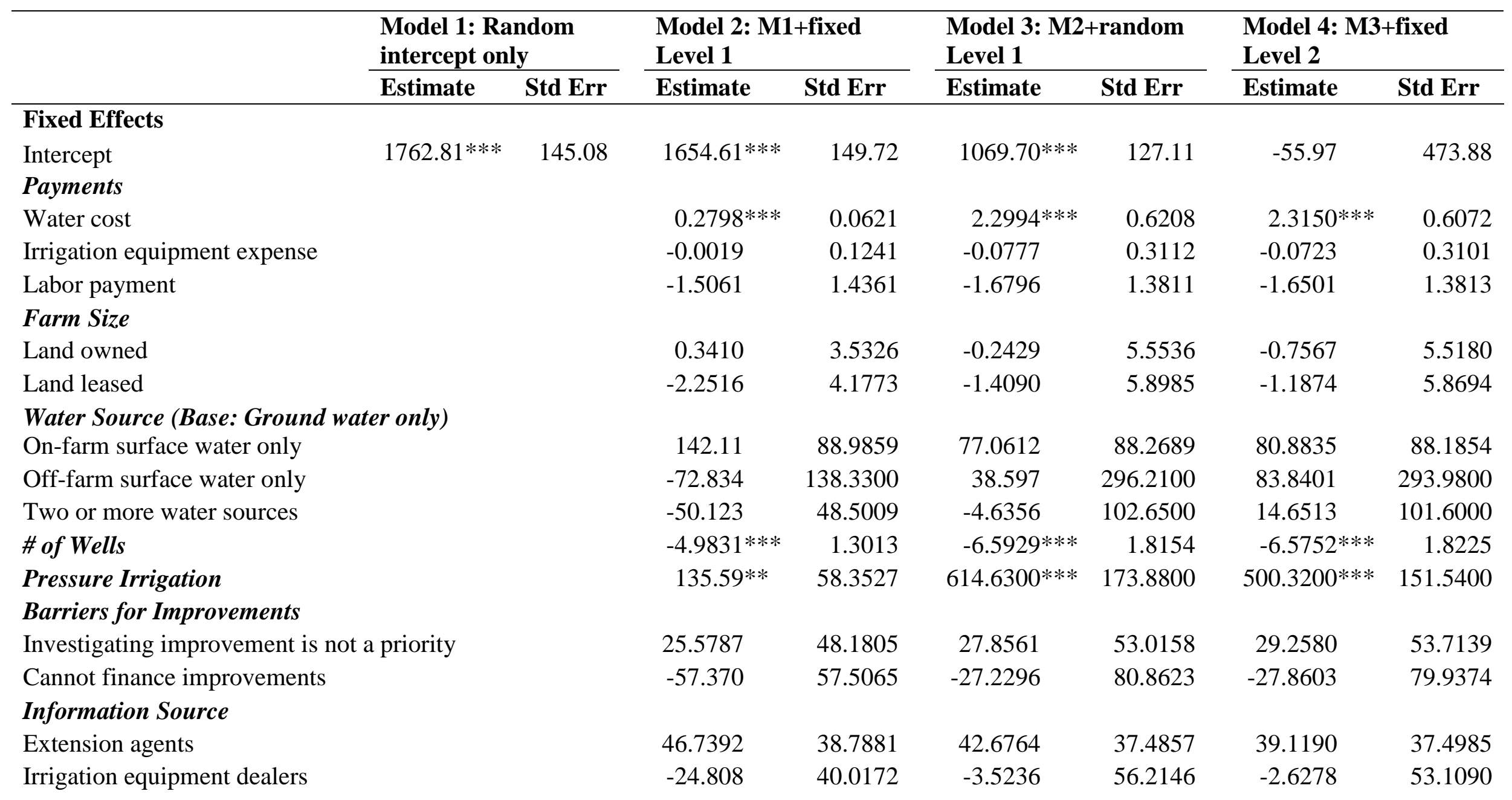


Local irrigation district employees

Neighboring farmers

Improvements and Assistance

Irrigation improvements

Technical and financial assistance

State-wide average weather-related variables

PrecipChange2012

TempChange2012

PrecipChange2013

TempChange2013

\section{Error Variance}

$\begin{array}{ll}\omega & \text { Subject } \\ \omega & \text { Intercept (STATE) }\end{array}$

Residual

\section{Fit Statistics}

$\mathrm{N}$

\begin{tabular}{lllll}
$-2 \mathrm{LL}$ & 66450 & 66388 & 66210 & 66196 \\
AIC & 66456 & 66430 & 66274 & 66268 \\
AICC & 66456 & 66431 & 66275 & 66268 \\
BIC & 66461 & 66464 & 66326 & 66326 \\
\hline
\end{tabular}

$\mathrm{ICC}=648515 /(648515+1238360)=0.3437$.

Significance level: * $10 \%$; ** 5\%; *** $1 \%$.

$\begin{array}{rrrrrr}-109.82 & 99.6656 & -100.28 & 96.4640 & -101.50 & 96.4198 \\ 19.5310 & 41.9710 & 13.9040 & 40.5589 & 14.0965 & 40.5687 \\ & & & & & \\ 45.2484 & 42.4856 & 42.3515 & 41.5565 & 39.7934 & 41.5623 \\ -58.246 & 49.3784 & -50.3658 & 47.6552 & -49.3698 & 47.6601 \\ & & & & & \\ & & & & 30.10 & 23.46 \\ & & & & 421.91^{* * *} & 186.83 \\ & & & & & \\ & & & & & \\ & & & & & \end{array}$

\begin{tabular}{rrrrrrrr} 
Estimate & Std Err & \multicolumn{1}{c}{ Estimate } & Std Err & Estimate & Std Err & Estimate & Std Err \\
$648515 * * *$ & 175695 & $539813 * * *$ & 150000 & 82652 & 76452 & 67711 & 74462 \\
$1238360 * * *$ & 28051 & $1220545^{* * *}$ & 27649 & $1099542 * * *$ & 26318 & $1100615 * * *$ & 26294 \\
\hline
\end{tabular}

66326 


\subsection{Discussion and Conclusions}

Using the USDA 2013 FRIS data, this chapter analyzes farmers' production decisions relating to irrigated agriculture in a multicrop production system. To study the role of water cost, the farm-level water demand is decomposed into crop-specific demands. For each crop, the total effect can be obtained by summing intensive and extensive margins of water use. With the aggregate effect at the farm level, we can quantify the effect of a one unit increase in water price. Furthermore, effects of exogenous variables are analyzed using a multilevel approach. Four equations regarding land allocation, water demand, crop supply, and water use efficiency are formulated using two-level models.

A fundamental finding from the decomposition of farm-level water demand illustrates a higher water cost reduces water demand for both corn and soybeans through both intensive and extensive margins. Similar to the mixed effects of water price found by Moore et al. (1994b), water cost is ineffective in conserving water use once producers have made decisions on crop production.

Results from MLMs allow us to make certain the relative importance of farmand state-level factors, and the estimation outcomes present effects of those exogenous variables at both levels. The econometric results also show higher water price encourages efficient water use. In addition, adoption of pressure irrigation systems could reduce soybean water use or increase corn yield. Higher EIWUE due to enhanced irrigation methods can also be achieved on soybean farms, but not on corn farms. While inconsistent with field experimental findings, more information is needed to understand this effect on corn farms.

The findings from MLMs show the state-level variables on climate variability have fairly consistent effects. High temperature promotes more efficient water use and 
higher yield. High precipitation is correlated with low water application and higher crop yield. Drought increases farmers' awareness of potential production risks not only during drought, but in subsequent years (Peck and Adams, 2010). As a result, farmers can be motivated to change the land allocation for different crops and irrigate more to mitigate adverse effects of climate variability. Contrary to Olen et al. (2016), we find the irrigation water use is more responsive to precipitation than to temperature. Given the nonlinear impacts of climatic factors, farmers' responses in adapting to climate risks depend on the cropping patterns.

This study also has some limitations. Aggregate effect is estimated for a typical farm growing corn and soybeans taking roughly half of the average farming area. Equations on more crops can be estimated to provide a more complete estimate of the effect of water price, and regional equations can be estimated to account for structural differences across regions. Ideally, elasticity with respect to water price can be estimated to quantify price effect from a different and equally important perspective. Though MLMs are supposed to deal with multiple estimation problems, more investigations are needed especially on potential sample selection problems. 


\section{References}

Abd El-Wahed, M.H., Ali, E.A., 2013. Effect of irrigation systems, amounts of irrigation water and mulching on corn yield, water use efficiency and net profit. Agricultural Water Management. 120, 64-71.

Ahmad, B., Hassan, S., Bakhsh, K., 2005. Factors affecting yield and profitability of carrot in two districts of Punjab. International Journal of Agriculture and Biology. 7, 794-798.

Batchelor, C., Lovell, C., Murata, M., 1996. Simple microirrigation techniques for improving irrigation efficiency on vegetable gardens. Agricultural Water Management. 32, 37-48.

Canone, D., Previati, M., Bevilacqua, I., Salvai, L., Ferraris, S., 2015. Field measurements based model for surface irrigation efficiency assessment. Agricultural Water Management. 156, 30-42.

Dahmardeh, N., Asasi, H., 2014. Determined factors on water use efficiency and profitability in agricultural sector. Indian J. Sci. Res. 4, 48-53.

Dalton, P., Raine, S., Broadfoot, K., 2001. Best management practice for maximising whole farm irrigation efficiency in the Australian cotton industry. Final Report for CRDC Project NEC2C, Retrieved from: http://www.insidecotton.com/xmlui/handle/1/3535.

Dolisca, F., McDaniel, J.M., Shannon, D.A., Jolly, C.M., 2009. A multilevel analysis of the determinants of forest conservation behavior among farmers in Haiti. Society and Natural Resources. 22, 433-447.

EPA, 2014. (United States Environmental Protection Agency). Climate Change Indicators in the United States - Weather and Climate, Available online at https://www3.epa.gov/climatechange/pdfs/climateindicators-full-2014.pdf.

George, B.A., Shende, S.A., Raghuwanshi, N.S., 2000. Development and testing of an irrigation scheduling model. Agricultural Water Management. 46, 121-136.

Gheysari, M., Loescher, H.W., Sadeghi, S.H., Mirlatifi, S.M., Zareian, M.J., Hoogenboom, G., 2015. Chapter Three-Water-yield relations and water use efficiency of maize under nitrogen fertigation for semiarid environments: experiment and synthesis. Advances in Agronomy. 130, 175-229.

Guerin, D., Crete, J., Mercier, J., 2001. A multilevel analysis of the determinants of recycling behavior in the European countries. Social Science Research. 30, 195-218. 
Harris, G., 2007. Water use efficiency: What is it, and how to measure, Spotlight on Cotton Research \& Development. Cotton Research \& Development Corporation, p. 7. Retrieved from http://www.crdc.com.au/sites/default/files/pdf/01869\%01820CRDC\%01820Sp otlight\%01820Summer01807_01860.pdf.

Hox, J.J., 1995. Applied multilevel analysis. TT-publikaties Amsterdam.

Ibragimov, N., Evett, S.R., Esanbekov, Y., Kamilov, B.S., Mirzaev, L., Lamers, J.P.A., 2007. Water use efficiency of irrigated cotton in Uzbekistan under drip and furrow irrigation. Agricultural Water Management. 90, 112-120.

Jin, J., Gao, Y., Wang, X., Nam, P.K., 2015. Farmers' risk preferences and their climate change adaptation strategies in the Yongqiao District, China. Land Use Policy. 47, 365-372.

Kang, Y., Wang, R., Wan, S., Hu, W., Jiang, S., Liu, S., 2012. Effects of different water levels on cotton growth and water use through drip irrigation in an arid region with saline ground water of Northwest China. Agricultural Water Management. 109, 117-126.

Kresovic, B., Matovic, G., Gregoric, E., Djuricin, S., Bodroza, D., 2014. Irrigation as a climate change impact mitigation measure: An agronomic and economic assessment of maize production in Serbia. Agricultural Water Management. 139, 7-16.

Moore, M.R., Gollehon, N.R., Carey, M.B., 1994a. Alternative models of input allocation in multicrop systems: Irrigation water in the Central Plains, United States. Agricultural Economics. 11, 143-158.

Moore, M.R., Gollehon, N.R., Carey, M.B., 1994b. Multicrop production decisions in western irrigated agriculture: the role of water price. American Journal of Agricultural Economics. 76, 859-874.

Murray, S.J., Foster, P.N., Prentice, I.C., 2012. Future global water resources with respect to climate change and water withdrawals as estimated by a dynamic global vegetation model. Journal of Hydrology. 448-449, 14-29.

Nair, S., Johnson, J., Wang, C., 2013. Efficiency of irrigation water use: A review from the perspectives of multiple disciplines. Agronomy Journal. 105, 351-363.

Olen, B., Wu, J., Langpap, C., 2016. Irrigation decisions for major west coast crops: Water scarcity and climatic determinants. American Journal of Agricultural Economics. 98, 254-275. 
Peck, D.E., Adams, R.M., 2010. Farm-level impacts of prolonged drought: is a multiyear event more than the sum of its parts? Australian Journal of Agricultural and Resource Economics. 54, 43-60.

Pereira, L.S., 1999. Higher performance through combined improvements in irrigation methods and scheduling: a discussion. Agricultural Water Management. 40, 153-169.

Pereira, L.S., Cordery, I., Iacovides, I., 2012. Improved indicators of water use performance and productivity for sustainable water conservation and saving. Agricultural Water Management. 108, 39-51.

Qin, W., Assinck, F.B.T., Heinen, M., Oenema, O., 2016. Water and nitrogen use efficiencies in citrus production: A meta-analysis. Agriculture, Ecosystems \& Environment. 222, 103-111.

Raudenbush, S.W., Bryk, A.S., 2002. Hierarchical linear models: Applications and data analysis methods. Sage.

Schaible, G., Aillery, M., 2012. Water conservation in irrigated agriculture: Trends and challenges in the face of emerging demands. USDA-ERS Economic Information Bulletin.

Schneider, A.D., Howell, T.A., 2001. Scheduling deficit wheat irrigation with data from an evapotranspiration network. Transactions of the ASAE. 44, $1617-1623$.

Wanders, N., Wada, Y., 2015. Human and climate impacts on the 21 st century hydrological drought. Journal of Hydrology. 526, 208-220.

Zhang, T., Lin, X., 2016. Assessing future drought impacts on yields based on historical irrigation reaction to drought for four major crops in Kansas. Science of The Total Environment. 550, 851-860.

Zhang, T., Lin, X., Sassenrath, G.F., 2015. Current irrigation practices in the central United States reduce drought and extreme heat impacts for maize and soybean, but not for wheat. Science of The Total Environment. 508, 331-342. 


\section{CHAPTER 5. CONCLUSIONS}

Motivated by the influence of climate change on water resources and the 2012 drought in Midwest and West of US, this dissertation examines water management strategies from both residents and farmers' perspectives. To deal with uneven distribution of rainfall and consequent fluctuation in water availability, both residents and farmers need to irrigate and try to mitigate possible adverse effects. Using data from a household survey in Hickson Creek Watershed in Columbia, Missouri, residents' adoption of drought tolerant plants is analyzed focusing on the effects of exogenous variables on trust in information sources, environmental attitudes, and perceptions of climate change. Using data from a national survey conducted by USDA on irrigated farms, this dissertation also analyzes farmers' adoption of pressure irrigation systems and of scientific scheduling practices with irrigation decisions, and irrigation water use efficiency of crops with production decisions in an irrigated multicrop system. The results from these analyses can be helpful for policy design and educational programs that aim to reduce water consumption by residential and farm irrigations and improve the adaptive capacity of stakeholders facing uncertainties.

In both traditional residential landscapes and farm irrigation practices, more water may be applied than necessary, which leads to environmental problems and thwarts sustainable development of water resources. In urban households, a substantial amount of water is used to irrigate lawn and yard to maintain various social and cultural values. In various regions of the US, an irrigation system for a typical residential landscape takes more than half of residential water use volume (Haley et al., 2007). While in agricultural production, traditional irrigation systems result in a large amount of water loss through run-off, and increase economic and 
environmental costs for meeting water demands of crops facing uncertain availability in future. Thus strategies and practices to conserve water are critical and necessary in both sectors. With economic studies on these issues, this dissertation tries to provide some insights on how to achieve sustainability of water resources.

In chapter 2, a univariate probit model is used to analyze DTPs adoption by risk averse households responding to climate risks. In the Midwest, residents typically don't worry about water, but due to the effect of the 2012 drought, residents are facing options of how to reduce water use and avoid paying more on irrigation for their lawns and gardens. DTPs generally don't need regular irrigation to sustain the same landscape once established. The results from this study suggest many factors motivate residential adoption, including owning their home, more yard activities, information from water groups, positive attitudes to water quality, and awareness of water availability issues.

Though residential outdoor water use accounts for a small proportion of the total water consumption for all sectors, its contribution cannot be underestimated. Many Western states including California are trying to reduce residential water use by turf and plants in recent years. In the Midwest, we cannot wait until having a situation like California before taking action. Using an increasing block rate for household water use alone cannot solve the problem. Policy should also encourage the adoption of DTPs not only to reduce water bills, but more emphasis should be given on the environmental contribution of a less water-intensive yard. Developers could be required to plant DTPs for new homes. Social acceptance of water-conserving landscapes including adoption of DTPs can be cultivated with the help of educational programs, along with improved varieties. Given the studies on adopters vs. laggards, 
targeting potential adopters with policies providing incentives and technical assistance is of essential importance.

In chapter 3, a two-stage framework is designed to study farmers' irrigation decisions and adoption of pressure irrigation systems and of scheduling practices. Agricultural production and farmers' livelihoods are affected by water scarcity induced by climate change, which further influences their adoption strategies regarding agricultural irrigation to cope with climatic stresses (Alam, 2015; Alauddin and Sarker, 2014). Given the complex nature of the national dataset, a mixed-method approach is employed to analyze land-related equations, and a multilevel model is used to analyze crop-specific adoption behaviors.

Focusing on the adoption decisions, the results of MLMs show high proportions of variability in adopting pressure systems by corn and soybean farms are accounted for by factors at the state level, while high proportions of variability in adopting scheduling practices are accounted for by the differences at the farm level. This suggests adoption of certain types of practices has similar patterns on different crops, while adoption of other practices needs to consider the heterogeneous characteristics of each individual farm. In previous adoption studies, models usually account for the differences at the same level. This study shows a clear need for MLMs applied primarily to adoption of pressure systems. High ICC values indicate differences at the state level should be considered, and priorities of each state should be emphasized when promoting adoption of pressure systems. On the other hand, low ICC values indicate factors at the farm level account for more variability in adopting scheduling practices. In this case, farm-level heterogeneity should be given an attention when designing programs. 
In chapter 4, analyses focus on production decisions in an irrigated multicrop system and crop irrigation water use efficiency. Through decomposing effects of water price, intensive and extensive margins are calculated to evaluate the possibility of conserving water use through increasing water price. In addition, improving water efficiency in agriculture has great potential as only about one third of the applied water is absorbed by crops to grow food in both rain-fed and irrigated agriculture (Cai et al., 2003). A majority is running off, evaporating or infiltrating deep into the soil, and the inefficient water use is mainly because of ineffective irrigation water management (Cai et al., 2003). Advanced pressure irrigation systems could be particularly effective in reducing water use, and improving yield and water use efficiency through slowing down soil evaporation and minimizing losses due to seepage (Dağdelen et al., 2009; Kang et al., 2012; Liu et al., 2010).

Higher water prices not only reduce water consumption, but also promote higher efficiency of water use. Compared with gravity systems, adopting pressure irrigation systems reduces water use. Depending on the location of farms, the incentive to adopt enhanced irrigation systems may vary, and thus different influences on crop WUE can be expected. More region-specific studies are needed to provide a better understanding of the adoption patterns and effects of climate change.

Climate change is occurring, which poses a threat to households and farmers through intensifying water scarcity. To some extent, adapting to climate change means taking actions to stay viable with limited and decreasing water availability. From both residents and farmers' point of view, broader benefits in the long term should be expected as a result of adopting drought tolerant plants and pressure irrigation systems. In the residents' case, environmental benefits to the community and even society can be possible outcomes. More research is needed to investigate the compatibility of 
adopting multiple practices in addition to the DTPs, and the economic feasibility across different social groups. Evaluation of governmental and non-governmental programs can help better design future policies and educational programs. In the farmers' case, sustainability of water resources is always a goal but hard to realize due to farmers' maximization of short-term profits. Though evidence has been found in this dissertation on the effects of water price, pressure irrigation, and perceptions of climate risks, better measures can be constructed with specific questions on perceptions of increased price, better irrigation systems, and climate change. With survey questions, better understanding can be obtained regarding socioeconomic factors, environmental preferences, and effects of related institutions. 


\section{References}

Alam, K., 2015. Farmers' adaptation to water scarcity in drought-prone environments: A case study of Rajshahi District, Bangladesh. Agricultural Water Management. 148, 196-206.

Alauddin, M., Sarker, M.A.R., 2014. Climate change and farm-level adaptation decisions and strategies in drought-prone and groundwater-depleted areas of Bangladesh: an empirical investigation. Ecological Economics. 106, 204-213.

Cai, X., Rosegrant, M.W., Ringler, C., 2003. Physical and economic efficiency of water use in the river basin: Implications for efficient water management. Water Resources Research. 39.

Dağdelen, N., Başal, H., Yılmaz, E., Gürbüz, T., Akçay, S., 2009. Different drip irrigation regimes affect cotton yield, water use efficiency and fiber quality in western Turkey. Agricultural Water Management. 96, 111-120.

Haley, M.B., Dukes, M.D., Miller, G.L., 2007. Residential irrigation water use in Central Florida. Journal of Irrigation and Drainage Engineering. 133, 427-434.

Kang, Y., Wang, R., Wan, S., Hu, W., Jiang, S., Liu, S., 2012. Effects of different water levels on cotton growth and water use through drip irrigation in an arid region with saline ground water of Northwest China. Agricultural Water Management. 109, 117-126.

Liu, Y., Li, S., Chen, F., Yang, S., Chen, X., 2010. Soil water dynamics and water use efficiency in spring maize (Zea mays L.) fields subjected to different water management practices on the Loess Plateau, China. Agricultural Water Management. 97, 769-775. 
APPENDIX

\section{A. Additional tables on summary statistics and results for chapter 3 and 4 .}

Table A3.1 Summary statistics of independent variables for CORN and SOYBEANS.

\begin{tabular}{|c|c|c|c|c|c|c|}
\hline \multirow[b]{2}{*}{ Variable } & \multicolumn{3}{|c|}{ Corn $(\mathrm{N}=6030)$} & \multicolumn{3}{|c|}{ Soybeans $(\mathrm{N}=3933)$} \\
\hline & Mean & SD & $\mathbf{C V}$ & Mean & SD & $\mathbf{C V}$ \\
\hline \multicolumn{7}{|l|}{ Payments } \\
\hline Water cost & 77 & 277 & 3.61 & 72 & 289 & 4.01 \\
\hline Irrigation equipment expense & 30 & 113 & 3.80 & 29 & 144 & 4.95 \\
\hline Labor payment & 4 & 56 & 12.92 & 2 & 12 & 7.30 \\
\hline \multicolumn{7}{|l|}{ Farm Size } \\
\hline Land owned & 1368 & 8154 & 5.96 & 809 & 1867 & 2.31 \\
\hline Land leased & 1732 & 3749 & 2.16 & 1666 & 2351 & 1.41 \\
\hline \multicolumn{7}{|l|}{ Water Source } \\
\hline Ground water only (Base) & 0.69 & 0.46 & 0.67 & 0.74 & 0.44 & 0.59 \\
\hline On farm surface water only & 0.06 & 0.24 & 3.92 & 0.05 & 0.22 & 4.33 \\
\hline Off farm surface water only & 0.07 & 0.25 & 3.77 & 0.02 & 0.14 & 7.22 \\
\hline Two or more water sources & 0.18 & 0.38 & 2.14 & 0.19 & 0.39 & 2.08 \\
\hline \# of Wells & 10 & 16 & 1.60 & 12 & 16 & 1.34 \\
\hline \multicolumn{7}{|l|}{ Barriers for Improvements } \\
\hline Investigating improvement is not a priority & 0.16 & 0.37 & 2.25 & 0.17 & 0.38 & 2.21 \\
\hline Risk of reduced yield or poorer quality crop & 0.09 & 0.29 & 3.10 & 0.09 & 0.28 & 3.26 \\
\hline $\begin{array}{l}\text { Limitation of physical field or crop } \\
\text { conditions }\end{array}$ & 0.12 & 0.32 & 2.77 & 0.11 & 0.32 & 2.78 \\
\hline $\begin{array}{l}\text { Not enough to recover implementation } \\
\text { costs }\end{array}$ & 0.17 & 0.38 & 2.19 & 0.17 & 0.38 & 2.22 \\
\hline Cannot finance improvements & 0.12 & 0.32 & 2.74 & 0.11 & 0.32 & 2.82 \\
\hline $\begin{array}{l}\text { Landlords will not share improvements } \\
\text { costs }\end{array}$ & 0.13 & 0.34 & 2.56 & 0.14 & 0.35 & 2.46 \\
\hline Uncertainty about future water availability & 0.09 & 0.28 & 3.25 & 0.07 & 0.25 & 3.71 \\
\hline Will not be farming long enough & 0.07 & 0.25 & 3.74 & 0.07 & 0.25 & 3.68 \\
\hline Will increase management time or cost & 0.07 & 0.26 & 3.64 & 0.07 & 0.26 & 3.65 \\
\hline \multicolumn{7}{|l|}{ Information Source } \\
\hline Extension agents & 0.37 & 0.48 & 1.31 & 0.41 & 0.49 & 1.19 \\
\hline Private irrigation specialists & 0.32 & 0.47 & 1.45 & 0.31 & 0.46 & 1.49 \\
\hline Irrigation equipment dealers & 0.41 & 0.49 & 1.20 & 0.40 & 0.49 & 1.22 \\
\hline Local irrigation district employees & 0.06 & 0.23 & 4.12 & 0.03 & 0.18 & 5.33 \\
\hline Government specialists & 0.14 & 0.35 & 2.44 & 0.15 & 0.36 & 2.38 \\
\hline Media reports & 0.12 & 0.33 & 2.69 & 0.12 & 0.32 & 2.73 \\
\hline Neighboring farmers & 0.27 & 0.44 & 1.66 & 0.27 & 0.44 & 1.64 \\
\hline E-information services & 0.20 & 0.40 & 1.99 & 0.20 & 0.40 & 2.03 \\
\hline
\end{tabular}




\section{Improvements and Assistance}

Irrigation improvements

Technical and financial assistance

Value of Sales

$\$ 0-9,999$

\$10,000-24,999

$\$ 25,000-49,999$

$\$ 50,000-99,999$

\$100,000-249,999 (Base)

$\$ 250,000-499,999$

$\$ 500,000-999,999$

$\$ 1,000,000$ and above

Regions

West

Plains (Base)

Midwest

South

Atlantic

SD: Standard deviation.

$\mathrm{CV}$ : Coefficient of variation.

$\begin{array}{rrrrrr}0.53 & 0.50 & 0.94 & 0.54 & 0.50 & 0.92 \\ 0.24 & 0.43 & 1.79 & 0.23 & 0.42 & 1.82 \\ & & & & & \\ 0.01 & 0.10 & 9.73 & 0.01 & 0.08 & 12.50 \\ 0.01 & 0.08 & 12.09 & 0.00 & 0.07 & 14.35 \\ 0.01 & 0.11 & 9.16 & 0.01 & 0.11 & 9.30 \\ 0.03 & 0.18 & 5.51 & 0.03 & 0.17 & 5.59 \\ 0.10 & 0.30 & 3.06 & 0.11 & 0.31 & 2.91 \\ 0.14 & 0.34 & 2.50 & 0.15 & 0.35 & 2.42 \\ 0.23 & 0.42 & 1.85 & 0.23 & 0.42 & 1.85 \\ 0.48 & 0.50 & 1.04 & 0.47 & 0.50 & 1.07 \\ & & & & & \\ 0.11 & 0.32 & 2.78 & 0.00 & 0.06 & 16.16 \\ 0.20 & 0.40 & 1.98 & 0.16 & 0.36 & 2.32 \\ 0.38 & 0.49 & 1.27 & 0.40 & 0.49 & 1.21 \\ 0.20 & 0.40 & 1.98 & 0.33 & 0.47 & 1.43 \\ 0.10 & 0.29 & 3.07 & 0.11 & 0.31 & 2.87\end{array}$

\section{2}

2.50

4.35

30

42

1.85

.07

6.16

32

.87 


\section{Harvest share (Chapter 3)}

The results for the share of harvested cropland in 2013 are presented in table A3.2. Similar to the IS equation, three models are estimated for the HS equation. Consistent results are obtained across the three models as the signs of the estimates for significant variables are the same and the significance levels are also the same except for some variables related with water sources and values of sales. The R-squared for OLS log odds model is 0.2440 . The AIC values from Tobit and fractional logit models indicate the Tobit model has a better fit. Thus the interpretation focuses on the results from the Tobit model.

Water application rate and water cost. A higher share of irrigation increases the harvest share of cropland, indicating larger area irrigated increases the percentage of cropland being harvested. Higher water cost has a negative effect on harvest share, suggesting higher water cost decreases the percentage of cropland being harvested.

Farm size. Leased land has a positive effect on the harvest share, implying farms with larger areas have a relatively larger percent of harvest as producers may farm more intensively and provide better management if they have leased the land.

Water source. Compared with groundwater, water from on-farm surface decreases harvest share, while water from off-farm surface and multiple sources increases harvest share. More wells used on a farm also show a negative association with harvest share.

Irrigation system. The results show both sprinkler and drip irrigation systems increase the harvest share. This implies pressure irrigation systems not only save water, but increase the probability of the farmer harvesting a crop. Alternatively, the high costs of these systems would only be incurred by farmers that planned to use the water effectively. 
Barriers for improvement. Mixed effects are found for the barrier variables, that is, not a priority and improvements costs not shared by landlords have positive effects on the harvest share, while lack of financing and uncertainty about future water availability have negative effects.

Information source. The results show irrigation information from private irrigation specialists and government specialists has consistent, negative effects on harvest share.

Improvements and assistance. The results show technical and financial assistance show a negative effect. This result is very interesting, and more information on what type of assistance is needed to understand the effect.

Value of sales. The results show low values have a negative association with harvest share, while higher values show a positive effect.

Regions. Compared with the Plains, the West has a smaller harvest share, while Midwest, South and Atlantic states have larger harvest shares.

Crop diversity. The results show more crops planted on a farm increase the harvest share, indicating co-planting of multiple crops or crop rotation may be beneficial. 
Table A3.2 Results for harvest share equation.

\begin{tabular}{|c|c|c|c|c|c|c|}
\hline \multirow[b]{2}{*}{ Variable } & \multicolumn{2}{|c|}{ OLS_LogOdds } & \multicolumn{2}{|c|}{ Fraction logit } & \multicolumn{2}{|l|}{ Tobit } \\
\hline & Estimate & Std Err & Estimate & Std Err & Estimate & Std Err \\
\hline Water application share & $4.3908^{* * *}$ & 0.0598 & $4.0823 * * *$ & 0.0543 & $0.3392 * * *$ & 0.0042 \\
\hline Water cost & $-1.5 \mathrm{E}-05$ & $1.43 \mathrm{E}-05$ & $-2 \mathrm{E}-05^{*}$ & $1 \mathrm{E}-05$ & $-2 \mathrm{E}-06^{*}$ & $1.01 \mathrm{E}-06$ \\
\hline Irrigation equipment expense & $3.4 \mathrm{E}-05$ & $2.78 \mathrm{E}-05$ & $2.9 \mathrm{E}-05$ & $4 \mathrm{E}-05$ & $2.1 \mathrm{E}-06$ & $1.97 \mathrm{E}-06$ \\
\hline Labor payment & $1.6 \mathrm{E}-05^{*}$ & $9.69 \mathrm{E}-06$ & $7.5 \mathrm{E}-05^{*}$ & $3 \mathrm{E}-05$ & $8.5 \mathrm{E}-07$ & 0 \\
\hline Land owned & $-0.0102 * *$ & 0.0041 & -0.0048 & 0.0039 & $1.8 \mathrm{E}-06$ & 0.0003 \\
\hline Land leased & $0.0192 * * *$ & 0.0037 & $0.0243 * * *$ & 0.0030 & $0.0023 * * *$ & 0.0003 \\
\hline \multicolumn{7}{|l|}{ Water Source (Base: Ground water only) } \\
\hline On farm surface water only & $0.1673^{* * *}$ & 0.0608 & $0.0826^{*}$ & 0.0492 & $0.0098 * *$ & 0.0043 \\
\hline Off farm surface water only & -0.0330 & 0.0547 & $-0.1016^{* *}$ & 0.0442 & $-0.0090 * *$ & 0.0039 \\
\hline Two or more water sources & $-0.2096^{* * *}$ & 0.0525 & $-0.2302 * * *$ & 0.0464 & $-0.0130 * * *$ & 0.0037 \\
\hline Two or more systems & 0.0481 & 0.0569 & -0.0433 & 0.0496 & 0.0061 & 0.0040 \\
\hline \multicolumn{7}{|l|}{ Barriers for Improvements } \\
\hline Investigating improvement is not a priority & $0.1276^{* * *}$ & 0.0460 & $0.0817 * *$ & 0.0387 & $0.0094 * * *$ & 0.0033 \\
\hline Limitation of physical field or crop conditions & 0.0865 & 0.0644 & 0.0632 & 0.0564 & 0.0064 & 0.0046 \\
\hline Not enough to recover implementation costs & -0.0732 & 0.0542 & -0.0227 & 0.0461 & -0.0032 & 0.0038 \\
\hline Cannot finance improvements & $-0.1589 * * *$ & 0.0520 & $-0.1537 * * *$ & 0.0425 & $-0.0116^{* * *}$ & 0.0037 \\
\hline Landlords will not share improvements costs & $0.1575 * *$ & 0.0710 & $0.1565^{* *}$ & 0.0663 & $0.0093 *$ & 0.0050 \\
\hline
\end{tabular}


Uncertainty about future water availability

\section{Information Source}

Extension agents

Private irrigation specialists

Irrigation equipment dealers

Local irrigation district employees

Government specialists

Neighboring farmers

\section{Improvements and Assistance}

Irrigation improvements

Technical and financial assistance

Value of Sales (Base: \$100,000-249,999)

\$0-9,999

\$10,000-24,999

$\$ 25,000-49,999$

$\$ 50,000-99,999$

$\$ 250,000-499,999$

\$500,000-999,999

$\$ 1,000,000$ and above

\section{Regions (Base: Plains)}

West

Midwest

South

Atlantic

Crop Diversity

\begin{tabular}{llllll}
$-0.3232 * * *$ & 0.0656 & $-0.2682 * * *$ & 0.0514 & $-0.0234 * * *$ & 0.0047 \\
-0.0569 & 0.0410 & 0.0027 & 0.0350 & $2.13 \mathrm{E}-05$ & 0.0029 \\
$-0.1427 * * *$ & 0.0467 & $-0.1326 * * *$ & 0.0404 & $-0.0061 *$ & 0.0033 \\
-0.0542 & 0.0430 & -0.0360 & 0.0369 & -0.0016 & 0.0031 \\
0.0731 & 0.0761 & 0.0079 & 0.0667 & 0.0034 & 0.0054 \\
$-0.2388 * * *$ & 0.0569 & $-0.2210^{* * *}$ & 0.0483 & $-0.0173 * * *$ & 0.0040 \\
0.0143 & 0.0447 & 0.0282 & 0.0386 & 0.0028 & 0.0032 \\
& & & & & \\
-0.0401 & 0.0442 & -0.0109 & 0.0380 & 0.0002 & 0.0031 \\
$-0.1689 * * *$ & 0.0568 & $-0.1076 * *$ & 0.0497 & $-0.0076 *$ & 0.0040 \\
& & & & & \\
0.0106 & 0.0728 & $-0.1295^{* *}$ & 0.0573 & $-0.0180^{* * *}$ & 0.0052 \\
0.0550 & 0.0907 & -0.0758 & 0.0692 & $-0.0115 *$ & 0.0064 \\
0.0435 & 0.0922 & -0.0452 & 0.0714 & -0.0039 & 0.0065 \\
-0.0377 & 0.0834 & -0.0647 & 0.0660 & -0.0053 & 0.0059 \\
-0.0334 & 0.0718 & -0.0087 & 0.0596 & 0.0020 & 0.0051 \\
0.0489 & 0.0703 & 0.0958 & 0.0606 & $0.0113 * *$ & 0.0050 \\
0.0369 & 0.0655 & $0.1368 * *$ & 0.0561 & $0.0118 * *$ & 0.0046 \\
& & & & & \\
-0.0712 & 0.0668 & $-0.3034 * * *$ & 0.0516 & $-0.0221 * * *$ & 0.0047 \\
$1.3304 * * *$ & 0.0661 & $1.1840 * * *$ & 0.0533 & $0.0914 * * *$ & 0.0047 \\
$0.7318 * * *$ & 0.0692 & $0.4222 * * *$ & 0.0553 & $0.0360 * * *$ & 0.0049 \\
$1.0907 * * *$ & 0.0712 & $0.8564 * * *$ & 0.0539 & $0.0648 * * *$ & 0.0051 \\
$0.2340 * * *$ & 0.0147 & $0.3463 * * *$ & 0.0138 & $0.0265 * * *$ & 0.0010 \\
\hline & & & & &
\end{tabular}




\begin{tabular}{|c|c|c|c|c|}
\hline \multicolumn{5}{|l|}{ Model Fit } \\
\hline $\mathrm{N}$ & 19272 & $\mathrm{~N}$ & 19272 & 19272 \\
\hline F Value & 159 & $-2 \mathrm{LL}$ & 9252 & -13085 \\
\hline $\operatorname{Pr}>\mathrm{F}$ & $<.0001$ & AIC & 9332 & -13003 \\
\hline Adj R-Sq & 0.2424 & & & \\
\hline
\end{tabular}

Significance level: * 10\%; ** 5\%; *** $1 \%$. 
Table A4.1 Summary statistics of irrigated farms, mean farming area, mean water use, mean yield, and irrigation water use efficiency, additional crops.

\begin{tabular}{|c|c|c|c|c|c|c|c|}
\hline & \multirow[b]{2}{*}{ Units } & \multirow[b]{2}{*}{ National } & \multicolumn{5}{|c|}{ Regions } \\
\hline & & & West & Plains & Midwest & South & Atlantic \\
\hline \multicolumn{8}{|c|}{ Number of irrigated farms } \\
\hline All farms & Farms & 19272 & 5737 & 2237 & 4251 & 3563 & 3484 \\
\hline Corn for silage & Farms & 1086 & 655 & 192 & 165 & 40 & 34 \\
\hline Wheat & Farms & 2012 & 1092 & 556 & 138 & 114 & 112 \\
\hline Rice & Farms & 943 & 104 & 13 & 114 & 711 & 1 \\
\hline Small grain & Farms & 858 & 710 & 79 & 36 & 13 & 20 \\
\hline Alfalfa & Farms & 3104 & 2549 & 309 & 212 & 5 & 29 \\
\hline Other hay & Farms & 1896 & 1439 & 244 & 43 & 96 & 74 \\
\hline Cotton & Farms & 1226 & 218 & 319 & 101 & 539 & 49 \\
\hline Vegetables & Farms & 3215 & 874 & 121 & 810 & 311 & 1099 \\
\hline Berries & Farms & 1113 & 167 & 22 & 290 & 142 & 492 \\
\hline Orchards & Farms & 1642 & 854 & 59 & 111 & 383 & 235 \\
\hline Other crops & Farms & 4199 & 1453 & 351 & 617 & 796 & 982 \\
\hline Pasture & Farms & 1675 & 1365 & 119 & 39 & 99 & 53 \\
\hline \multicolumn{8}{|l|}{ Mean Acres } \\
\hline Corn for silage & Acres/farm & 420 & 464 & 517 & 220 & 295 & 125 \\
\hline Wheat & Acres/farm & 554 & 661 & 548 & 241 & 326 & 168 \\
\hline Rice & Acres/farm & 803 & 753 & 427 & 720 & 831 & 65 \\
\hline Small grain & Acres/farm & 410 & 443 & 393 & 65 & 100 & 108 \\
\hline Alfalfa & Acres/farm & 457 & 499 & 380 & 116 & 24 & 120 \\
\hline Hay & Acres/farm & 410 & 467 & 322 & 134 & 159 & 70 \\
\hline Cotton & Acres/farm & 733 & 1079 & 697 & 1003 & 599 & 346 \\
\hline Vegetables & Acres/farm & 463 & 1077 & 417 & 336 & 480 & 70 \\
\hline Berries & Acres/farm & 54 & 78 & 1 & 56 & 46 & 49 \\
\hline Orchards & Acres/farm & 623 & 813 & 170 & 56 & 798 & 30 \\
\hline Other & Acres/farm & 276 & 309 & 362 & 129 & 572 & 48 \\
\hline Pasture & Acres/farm & 407 & 439 & 324 & 88 & 371 & 68 \\
\hline \multicolumn{8}{|c|}{ Mean water applied } \\
\hline Corn for silage & Acre-feet/acre & 1.72 & 2.31 & 1.22 & 0.54 & 0.57 & 0.39 \\
\hline Wheat & Acre-feet/acre & 1.31 & 1.78 & 0.93 & 0.49 & 0.46 & 0.48 \\
\hline Rice & Acre-feet/acre & 2.31 & 4.20 & 2.06 & 2.01 & 2.09 & 0.30 \\
\hline Small grain & Acre-feet/acre & 1.49 & 1.65 & 0.94 & 0.36 & 0.75 & 0.72 \\
\hline Alfalfa & Acre-feet/acre & 2.14 & 2.40 & 1.21 & 0.56 & 1.14 & 0.50 \\
\hline Hay & Acre-feet/acre & 1.71 & 1.99 & 1.02 & 0.71 & 0.62 & 0.56 \\
\hline Cotton & Acre-feet/acre & 1.26 & 3.53 & 1.06 & 0.90 & 0.60 & 0.43 \\
\hline Vegetables & Acre-feet/acre & 0.96 & 2.00 & 0.88 & 0.51 & 0.72 & 0.55 \\
\hline Berries & Acre-feet/acre & 0.93 & 1.42 & 1.10 & 0.86 & 0.74 & 0.86 \\
\hline Orchards & Acre-feet/acre & 1.54 & 2.26 & 1.24 & 0.47 & 0.84 & 0.61 \\
\hline Other & Acre-feet/acre & 1.21 & 1.77 & 1.22 & 0.79 & 0.96 & 0.86 \\
\hline
\end{tabular}




\begin{tabular}{|c|c|c|c|c|c|c|c|}
\hline Pasture & Acre-feet/acre & 1.59 & 1.78 & 0.98 & 0.75 & 0.60 & 0.62 \\
\hline \multicolumn{8}{|l|}{ Mean yield } \\
\hline Corn for silage & Tons/acre & 24 & 25 & 22 & 23 & 21 & 24 \\
\hline Wheat & Bu/acre & 80 & 99 & 47 & 73 & 68 & 72 \\
\hline Rice & Cwt/acre & 76 & 88 & 64 & 72 & 75 & 78 \\
\hline Small grain & & NA & & & & & \\
\hline Alfalfa & Tons/acre & 5.13 & 5.12 & 5.12 & 5.43 & 5.00 & 4.34 \\
\hline Hay & Tons/acre & 3.82 & 3.51 & 5.04 & 4.74 & 4.78 & 4.08 \\
\hline Cotton & Lbs lint/acre & 1177 & 1580 & 1045 & 1005 & 1134 & 1057 \\
\hline Vegetables & & NA & & & & & \\
\hline Berries & & NA & & & & & \\
\hline Orchards & & NA & & & & & \\
\hline Other & & NA & & & & & \\
\hline Pasture & & NA & & & & & \\
\hline \multicolumn{8}{|c|}{ Irrigation water use efficiency } \\
\hline Corn for silage & Tons/acre-foot & 30 & 19 & 22 & 60 & 62 & 107 \\
\hline Wheat & Bu/acre-foot & 115 & 85 & 78 & 235 & 239 & 314 \\
\hline Rice & Cwt/acre-foot & 41 & 26 & 63 & 54 & 41 & 260 \\
\hline Small grain & & NA & & & & & \\
\hline Alfalfa & Tons/acre-foot & 5 & 3 & 7 & 13 & 10 & 20 \\
\hline Hay & Tons/acre-foot & 5 & 3 & 8 & 10 & 19 & 17 \\
\hline $\begin{array}{l}\text { Cotton } \\
\text { Vegetables }\end{array}$ & Lbs lint/acre-foot & $\begin{array}{r}2013 \\
\text { NA }\end{array}$ & 633 & 1185 & 1705 & 2957 & 3804 \\
\hline Berries & & NA & & & & & \\
\hline Orchards & & NA & & & & & \\
\hline Other & & NA & & & & & \\
\hline Pasture & & NA & & & & & \\
\hline
\end{tabular}

IWUE = Yield / irrigation water applied. Due to lack of data on crop prices, EIWUE of these additional corps is not calculated.

NA: Not calculated due to lack of data. 
Table A4.2 Mean irrigated acres of CORN farms in each state.

\begin{tabular}{|c|c|c|c|c|c|}
\hline State & $\mathbf{N}$ & Mean & Std Dev & $\begin{array}{c}\text { Lower } 95 \% \\
\text { CL for Mean }\end{array}$ & $\begin{array}{c}\text { Upper } 95 \% \\
\text { CL for Mean }\end{array}$ \\
\hline Alabama & 72 & 347 & 419 & 248 & 445 \\
\hline Arizona & 25 & 825 & 749 & 516 & 1135 \\
\hline Arkansas & 291 & 707 & 717 & 624 & 790 \\
\hline California & 81 & 541 & 854 & 352 & 730 \\
\hline Colorado & 140 & 992 & 1417 & 756 & 1229 \\
\hline Delaware & 117 & 334 & 339 & 272 & 396 \\
\hline Florida & 25 & 509 & 541 & 286 & 732 \\
\hline Georgia & 228 & 350 & 399 & 298 & 402 \\
\hline Idaho & 105 & 376 & 515 & 277 & 476 \\
\hline Illinois & 423 & 532 & 878 & 448 & 616 \\
\hline Indiana & 382 & 475 & 548 & 420 & 530 \\
\hline Iowa & 241 & 331 & 409 & 279 & 383 \\
\hline Kansas & 270 & 1056 & 1265 & 904 & 1208 \\
\hline Kentucky & 47 & 401 & 587 & 229 & 574 \\
\hline Louisiana & 180 & 864 & 769 & 751 & 977 \\
\hline Maryland & 145 & 198 & 194 & 166 & 230 \\
\hline Massachusetts & 1 & (D) & & & \\
\hline Michigan & 300 & 572 & 873 & 473 & 672 \\
\hline Minnesota & 344 & 394 & 703 & 319 & 468 \\
\hline Mississippi & 352 & 901 & 936 & 803 & 999 \\
\hline Missouri & 333 & 546 & 696 & 471 & 621 \\
\hline Montana & 46 & 242 & 391 & 126 & 358 \\
\hline Nebraska & 379 & 1493 & 1729 & 1318 & 1668 \\
\hline Nevada & 5 & 268 & 387 & 213 & 748 \\
\hline New Jersey & 37 & 157 & 185 & 96 & 219 \\
\hline New Mexico & 29 & 1086 & 3075 & 84 & 2255 \\
\hline New York & 12 & 147 & 162 & 44 & 250 \\
\hline North Carolina & 46 & 241 & 307 & 150 & 332 \\
\hline North Dakota & 88 & 560 & 891 & 371 & 748 \\
\hline Ohio & 26 & 203 & 198 & 123 & 282 \\
\hline Oklahoma & 94 & 692 & 1144 & 458 & 927 \\
\hline Oregon & 51 & 352 & 488 & 215 & 489 \\
\hline Pennsylvania & 16 & 62 & 108 & 5 & 120 \\
\hline South Carolina & 75 & 275 & 314 & 203 & 347 \\
\hline South Dakota & 196 & 436 & 624 & 348 & 524 \\
\hline Tennessee & 123 & 420 & 624 & 308 & 531 \\
\hline Texas & 203 & 1415 & 2407 & 1082 & 1748 \\
\hline Utah & 54 & 237 & 263 & 165 & 309 \\
\hline Virginia & 31 & 271 & 283 & 167 & 375 \\
\hline
\end{tabular}




\begin{tabular}{lccccc} 
Washington & 111 & 442 & 672 & 315 & 568 \\
West Virginia & 2 & (D) & & & \\
Wisconsin & 259 & 359 & 538 & 293 & 424 \\
Wyoming & 45 & 241 & 198 & 181 & 300 \\
\hline
\end{tabular}

(D) Withheld to avoid disclosing data for individual farms. 
Table A4.3 Mean irrigated acres of SOYBEAN farms in each state.

\begin{tabular}{|c|c|c|c|c|c|}
\hline State & $\mathbf{N}$ & Mean & Std Dev & $\begin{array}{l}\text { Lower } 95 \% \mathrm{CL} \\
\text { for Mean }\end{array}$ & $\begin{array}{c}\text { Upper } 95 \% \\
\text { CL for Mean }\end{array}$ \\
\hline Alabama & 36 & 288 & 328 & 177 & 399 \\
\hline Arkansas & 528 & 1258 & 1217 & 1154 & 1362 \\
\hline Colorado & 6 & 120 & 43 & 74 & 166 \\
\hline Connecticut & 1 & (D) & & & \\
\hline Delaware & 101 & 200 & 223 & 156 & 244 \\
\hline Florida & 4 & 334 & 220 & -17 & 684 \\
\hline Georgia & 67 & 283 & 268 & 218 & 349 \\
\hline Idaho & 1 & (D) & & & \\
\hline Illinois & 273 & 242 & 322 & 204 & 281 \\
\hline Indiana & 248 & 214 & 212 & 188 & 241 \\
\hline Iowa & 141 & 236 & 283 & 188 & 283 \\
\hline Kansas & 114 & 364 & 382 & 293 & 435 \\
\hline Kentucky & 35 & 300 & 325 & 189 & 412 \\
\hline Louisiana & 183 & 730 & 841 & 607 & 852 \\
\hline Maine & 1 & (D) & & & \\
\hline Maryland & 112 & 155 & 143 & 128 & 181 \\
\hline Michigan & 190 & 234 & 324 & 188 & 280 \\
\hline Minnesota & 216 & 214 & 390 & 161 & 266 \\
\hline Mississippi & 442 & 1204 & 1132 & 1099 & 1310 \\
\hline Missouri & 391 & 661 & 622 & 599 & 723 \\
\hline Montana & 6 & 171 & 132 & 33 & 309 \\
\hline Nebraska & 274 & 541 & 557 & 475 & 607 \\
\hline New Jersey & 31 & 137 & 115 & 94 & 179 \\
\hline New York & 1 & (D) & & & \\
\hline North Carolina & 22 & 151 & 180 & 71 & 231 \\
\hline North Dakota & 56 & 222 & 232 & 160 & 284 \\
\hline Ohio & 16 & 103 & 113 & 43 & 163 \\
\hline Oklahoma & 43 & 267 & 203 & 204 & 329 \\
\hline Pennsylvania & 2 & (D) & & & \\
\hline South Carolina & 26 & 155 & 100 & 115 & 195 \\
\hline South Dakota & 120 & 307 & 362 & 242 & 373 \\
\hline Tennessee & 94 & 342 & 538 & 232 & 452 \\
\hline Texas & 8 & 534 & 505 & 112 & 956 \\
\hline Virginia & 27 & 237 & 274 & 129 & 346 \\
\hline Washington & 1 & (D) & & & \\
\hline Wisconsin & 115 & 194 & 236 & 150 & 237 \\
\hline Wyoming & 1 & (D) & & & \\
\hline
\end{tabular}

(D) Withheld to avoid disclosing data for individual farms. 
Table A4.4 Intraclass correlation coefficients (ICC) for null models of each crop-specific multilevel model, additional crops.

\begin{tabular}{lccccc}
\hline \multicolumn{1}{c}{ State level } & $\begin{array}{c}\text { Crop } \\
\text { choice }\end{array}$ & $\begin{array}{c}\text { Land } \\
\text { allocation }\end{array}$ & $\begin{array}{c}\text { Water } \\
\text { demand }\end{array}$ & $\begin{array}{c}\text { Crop } \\
\text { supply }\end{array}$ & EIWUE \\
\hline Corn for silage & 0.3824 & 0.0548 & 0.5237 & 0.1690 & NA \\
Wheat & 0.5075 & 0.0310 & 0.4656 & 0.4640 & NA \\
Rice & 0.9635 & 0.0061 & 0.4878 & 0.5582 & NA \\
Small grain & 0.5577 & 0.0409 & 0.3370 & NA & NA \\
Alfalfa & 0.6848 & 0.0696 & 0.4756 & 0.2669 & NA \\
Hay & 0.5032 & 0.0393 & 0.3291 & 0.2269 & NA \\
Cotton & 0.9499 & 0.0287 & 0.7520 & 0.4151 & NA \\
Vegetables & 0.2456 & 0.0890 & 0.4554 & NA & NA \\
Berries & 0.3674 & 0.0682 & 0.2279 & NA & NA \\
Orchards & 0.2792 & 0.0256 & 0.3097 & NA & NA \\
Other crop & 0.1348 & 0.0022 & 0.2111 & NA & NA \\
Pasture & 0.4499 & 0.0433 & 0.2735 & NA & NA \\
\hline Nites:
\end{tabular}

Notes: Higher level models for crop choice are not presented in the dissertation.

EIWUE: Economics irrigation water use efficiency.

NA: Not available due to lack of data. 


\section{Land allocation equation (Chapter 4)}

The estimated coefficients from MLMs for land allocation of corn and soybeans are presented in table A4.5 and table A4.6. Both land allocation equations have low ICC values indicating only about $10 \%$ and $14 \%$ of the variability for land allocation of corn and soybeans is accounted for by the state-level differences. For both crops, the models show consistency in terms of the signs and significance levels of farm-level independent variables.

Water cost doesn't affect land allocation, which is consistent with expectation as the decision on how much land allocated to grow a crop is made mainly depending on the expected crop price and input costs with little consideration of water cost. Larger areas of land owned and leased increase the land allocation to corn, while owned land shows a negative effect on the planting of soybeans. Compared with groundwater use, water from on-, off-farm surface and more sources shows a positive effect on land allocation to soybean planting. More wells on a farm increase the planting of both crops.

Adoption of pressure irrigation systems has a positive effect on corn land allocation, while it shows a negative effect in soybean equation (model 2). This indicates farmers may plant more of one crop and less of other crops ( in this case, more corn and less soybeans) in a multicrop system. Investigating improvement is not a priority and lack of finance are major barriers for corn land allocation, while for soybeans, lack of finance is a barrier.

Information from extension agents and neighboring farmers decreases the planting of both crops, while information from local irrigation district employees increases the plantin of corn. These findings indicate the effectiveness of extension programs in promoting the growing of water-conserving crops. Irrigation 
improvements show a negative effect on the planting of corn, indicating farms with better irrigation and drainage conditions tend to growing less corn.

At the state-level, the precipitation change in 2013 is negatively associated with corn planting, and the precipitation change in 2012 is also negatively associated the acreage of soybean. These findings suggest that given their perception of climate variability, less water available for crop production probably promotes farmers growing more water-conserving crops. 
Table A4.5 Results of multilevel models for land allocation for CORN farms.

\begin{tabular}{|c|c|c|c|c|c|c|c|c|}
\hline & \multicolumn{2}{|c|}{$\begin{array}{l}\text { Model 1: Random } \\
\text { intercept only }\end{array}$} & \multicolumn{2}{|c|}{$\begin{array}{l}\text { Model 2: M1+fixed } \\
\text { Level } 1\end{array}$} & \multicolumn{2}{|c|}{$\begin{array}{l}\text { Model 3: M2+random } \\
\text { Level 1 }\end{array}$} & \multicolumn{2}{|c|}{$\begin{array}{l}\text { Model 4: M3+fixed } \\
\text { Level } 2\end{array}$} \\
\hline & Estimate & Std Err & Estimate & Std Err & Estimate & Std Err & Estimate & Std Err \\
\hline \multicolumn{9}{|l|}{ Fixed Effects } \\
\hline Intercept & $523.0600 * * *$ & 52.3083 & 48.6772 & 49.8099 & $134.6500 * * *$ & 39.3103 & $262.3400 * * *$ & 62.4647 \\
\hline \multicolumn{9}{|l|}{ Payments } \\
\hline Water cost & & & -0.0564 & 0.0354 & -0.0493 & 0.0320 & -0.0465 & 0.0320 \\
\hline Irrigation equipment expens & & & 0.0022 & 0.0872 & -0.0071 & 0.0793 & -0.0102 & 0.0793 \\
\hline Labor payment & & & 0.0549 & 0.1754 & 0.0294 & 0.1597 & -0.0244 & 0.1598 \\
\hline \multicolumn{9}{|l|}{ Farm Size } \\
\hline Land owned & & & 3.2598 & 2.0226 & $3.2013 *$ & 1.8446 & $3.3463^{*}$ & 1.8441 \\
\hline Land leased & & & $9.0154 * * *$ & 2.1125 & $7.2427 * *$ & 3.1734 & $7.6934 * *$ & 3.2635 \\
\hline \multicolumn{9}{|c|}{ Water Source (Base: Ground water only) } \\
\hline On-farm surface water only & & & 53.8955 & 43.7460 & 63.4483 & 39.8373 & 50.4216 & 40.0743 \\
\hline Off-farm surface water only & & & $183.8300 * * *$ & 48.4714 & $192.4200 *$ & 103.3700 & 162.1200 & 102.4700 \\
\hline Two or more water sources & & & 3.1452 & 27.9549 & 38.7330 & 35.9997 & 14.3942 & 35.0044 \\
\hline \# of Wells & & & $41.9454 * * *$ & 0.7043 & $42.7816^{* * *}$ & 4.3042 & $41.8462 * * *$ & 4.4080 \\
\hline Pressure Irrigation & & & $175.7700 * * *$ & 35.2087 & 57.2680 & 35.2057 & $75.0058 * *$ & 33.9543 \\
\hline \multicolumn{9}{|l|}{ Barriers for Improvements } \\
\hline Investigating improvement & is not a priority & & $-69.3060 * * *$ & 26.6238 & $-56.7504 * *$ & 24.1388 & $-55.3781 * *$ & 24.1328 \\
\hline Cannot finance improvemer & & & $-84.0000 * * *$ & 30.7082 & $-76.2691 * * *$ & 27.8028 & $-76.6857 * * *$ & 27.7973 \\
\hline \multicolumn{9}{|l|}{ Information Source } \\
\hline Extension agents & & & -46.2402 & 21.8106 & $-39.1188 * *$ & 19.7220 & $-37.2925^{*}$ & 19.7193 \\
\hline Irrigation equipment dealers & & & 22.0092 & 21.6763 & 18.3831 & 19.8903 & 19.6321 & 20.2926 \\
\hline
\end{tabular}


Local irrigation district employees

Neighboring farmers

Improvements and Assistance

Irrigation improvements

Technical and financial assistance

State-wide average weather-related variables

PrecipChange2012

TempChange2012

PrecipChange2013

TempChange2013

\section{Error Variance}

जु Subject

Intercept (STATE)

Residual

\section{Fit Statistics}

$\mathrm{N}$

$-2 \mathrm{LL}$

AIC

AICC

BIC

$\mathrm{ICC}=98162 /(98162+925803)=0.0959$.

\begin{tabular}{rrrrrrrr} 
Estimate & Std Err & Estimate & Std Err & Estimate & Std Err & Estimate & Std Err \\
$98162^{* * *}$ & 23921 & $33664 * * *$ & 8627 & $3400^{* * *}$ & 4069 & $2.89 \mathrm{E}-13$ & \\
$925803^{* * *}$ & 16914 & $561132^{* * *}$ & 10250 & $451203 * * *$ & 8443 & $451364 * * *$ & 8443 \\
\hline
\end{tabular}

Significance level: * $10 \%$; ** 5\%; *** $1 \%$.

\begin{tabular}{lccccc}
$84.2843 *$ & 44.1363 & $88.1099 * *$ & 43.5836 & $77.8230 *$ & 44.5826 \\
$-60.1631 * * *$ & 23.3148 & $-61.5933 * * *$ & 21.1371 & $-60.6633 * * *$ & 21.1297 \\
& & & & & \\
$-41.1309 *$ & 23.6501 & $-48.2666 * *$ & 21.4793 & $-46.8191 * *$ & 21.4675 \\
-33.5958 & 27.0373 & 40.6864 & 61.4639 & 29.4382 & 57.4074 \\
& & & & & \\
& & & & -4.3507 & 4.6131 \\
& & & & -37.8763 & 24.2198 \\
& & & & $-11.0494 * *$ & 3.7839 \\
& & & & 36.2270 & 28.9459 \\
\hline
\end{tabular}

\begin{tabular}{|c|c|c|c|}
\hline 6030 & 6030 & 6030 & 6030 \\
\hline 100056 & 97017 & 95952 & 95938 \\
\hline 100062 & 97059 & 96010 & 96002 \\
\hline 100062 & 97059 & 96010 & 96003 \\
\hline 100067 & 97096 & 96061 & 96059 \\
\hline
\end{tabular}


Table A4.6 Results of multilevel models for land allocation for SOYBEAN farms.

\begin{tabular}{|c|c|c|c|c|c|c|c|c|}
\hline & \multicolumn{2}{|c|}{$\begin{array}{l}\text { Model 1: Random } \\
\text { intercept only }\end{array}$} & \multicolumn{2}{|c|}{$\begin{array}{l}\text { Model 2: M1+fixed } \\
\text { Level 1 }\end{array}$} & \multicolumn{2}{|c|}{$\begin{array}{l}\text { Model 3: M2+random } \\
\text { Level 1 }\end{array}$} & \multicolumn{2}{|c|}{$\begin{array}{l}\text { Model 4: M3+fixed } \\
\text { Level } 2\end{array}$} \\
\hline & Estimate & Std Err & Estimate & Std Err & Estimate & Std Err & Estimate & Std Err \\
\hline \multicolumn{9}{|l|}{ Fixed Effects } \\
\hline \multicolumn{9}{|l|}{ Payments } \\
\hline Water cost & & & -0.0002 & 0.0291 & -0.0172 & 0.0267 & -0.0151 & 0.0268 \\
\hline \multicolumn{9}{|l|}{ Farm Size } \\
\hline Land owned & & & $-5.5665 * * *$ & 1.6502 & $-3.5641 *$ & 1.9700 & $-3.6000^{*}$ & 1.9090 \\
\hline Land leased & & & $6.6888^{* * *}$ & 1.9508 & 4.6603 & 2.8538 & 4.2928 & 2.9216 \\
\hline \multicolumn{9}{|c|}{ Water Source (Base: Ground water only) } \\
\hline On-farm surface water onl & & & $141.6800 * * *$ & 40.9968 & $108.7500 * *$ & 42.2582 & $106.2000 * *$ & 42.7506 \\
\hline \multicolumn{9}{|l|}{ Barriers for Improvements } \\
\hline Investigating improvement & is not a priority & & $38.2816^{*}$ & 22.5368 & 10.0841 & 20.6810 & 11.0373 & 20.6786 \\
\hline Cannot finance improveme & & & $-78.5614 * * *$ & 26.8967 & $-62.3015 * *$ & 24.6555 & $-61.9041 * *$ & 24.6608 \\
\hline \multicolumn{9}{|l|}{ Information Source } \\
\hline Extension agents & & & $-40.7945 * *$ & 18.1260 & $-40.9305 * *$ & 16.5634 & $-41.1229 * *$ & 16.5706 \\
\hline
\end{tabular}




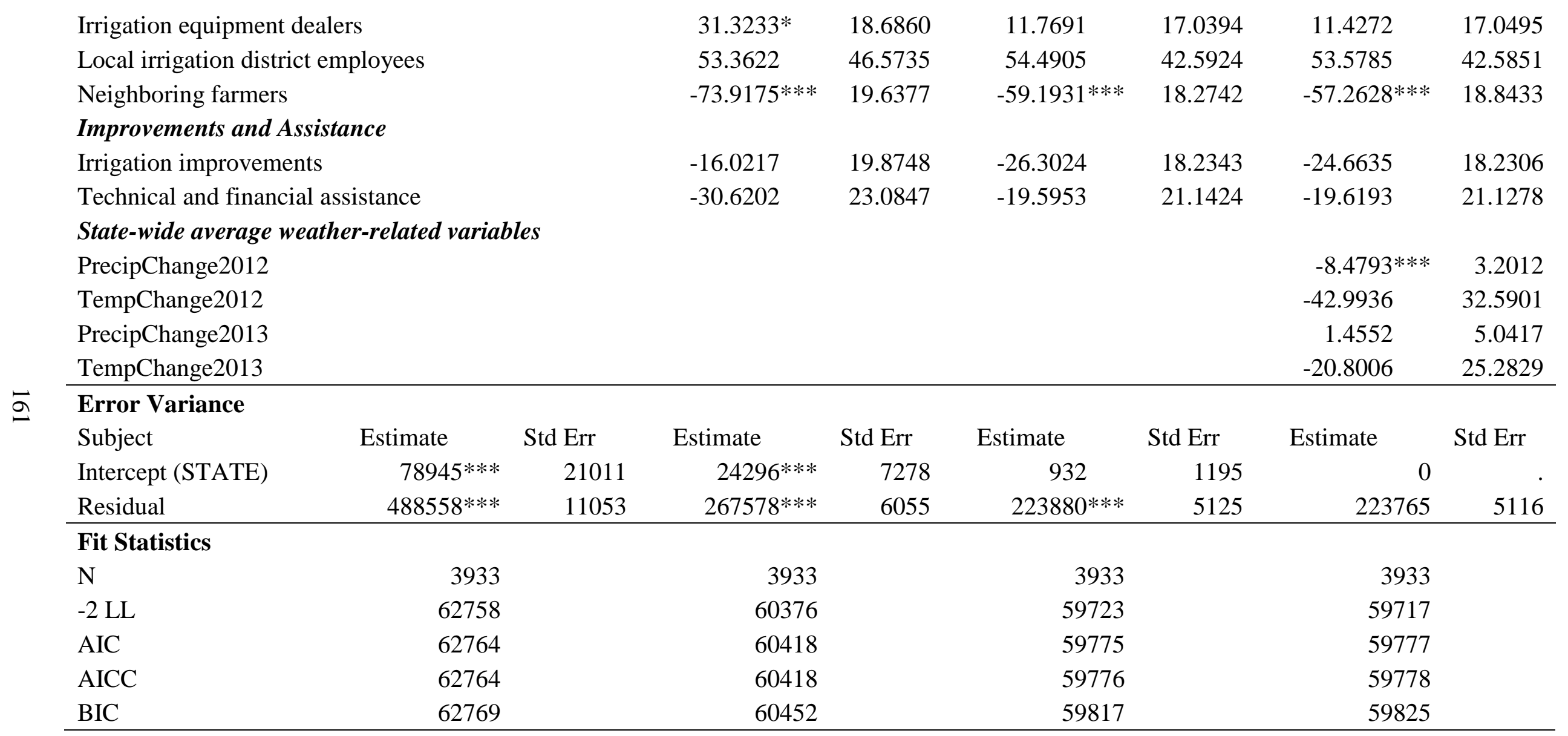

ICC $=78945 /(78945+488558)=0.1391$.

Significance level: $* 10 \%$; ** 5\%; *** $1 \%$. 


\section{B. Additional data and sources.}

Data related with state-level variables.

\begin{tabular}{|c|c|c|c|c|c|c|c|c|c|c|c|c|}
\hline \multirow[t]{2}{*}{ State } & \multirow{2}{*}{$\begin{array}{l}\text { Total acre } \\
\text { in } 2012\end{array}$} & \multirow{2}{*}{$\begin{array}{l}\text { Federal aid due to } \\
\text { crop losses (\$) in } \\
2012\end{array}$} & \multicolumn{5}{|c|}{ Precipitation (inches) } & \multicolumn{5}{|c|}{ Temperature $(F)$} \\
\hline & & & $\begin{array}{r}\text { 1981-2010 } \\
\text { Average }\end{array}$ & 2012 & 2013 & A2012 & A2013 & $\begin{array}{r}\text { 1981-2010 } \\
\text { Average }\end{array}$ & 2012 & 2013 & A2012 & A2013 \\
\hline Alabama & $1,145,662$ & $30,174,082$ & 55.66 & 53.38 & 64.7 & -2.28 & 9.04 & 63.1 & 64.9 & 62.6 & 1.8 & -0.5 \\
\hline Alaska & 833,861 & 12,399 & 37.28 & 37.28 & 40.81 & 0 & 3.53 & 27.2 & 24.3 & 27.8 & -2.9 & 0.6 \\
\hline Arizona & 369,588 & $22,900,276$ & 12.58 & 9.56 & 12.13 & -3.02 & -0.45 & 60.5 & 62.1 & 60.5 & 1.6 & 0 \\
\hline Arkansas & $5,825,275$ & $73,372,186$ & 51.2 & 39.8 & 54.23 & -11.4 & 3.03 & 60.6 & 63.6 & 59.6 & 3 & -1 \\
\hline California & $7,010,669$ & $106,931,668$ & 23.12 & 23.45 & 7.93 & 0.33 & -15.19 & 58.4 & 59.5 & 59.3 & 1.1 & 0.9 \\
\hline Colorado & $6,814,950$ & $221,804,172$ & 18.67 & 12.31 & 18.79 & -6.36 & 0.12 & 45.7 & 48.3 & 45.1 & 2.6 & -0.6 \\
\hline Connecticut & 15,293 & $4,498,519$ & 49.57 & 39.39 & 43.39 & -10.18 & -6.18 & 49.3 & 52.5 & 49.8 & 3.2 & 0.5 \\
\hline Delaware & 390,155 & $14,399,288$ & 44.33 & 39.33 & 50.73 & -5 & 6.4 & 55.4 & 58.5 & 55.8 & 3.1 & 0.4 \\
\hline Florida & $1,718,667$ & $70,082,547$ & 53.35 & 55.09 & 56.87 & 1.74 & 3.52 & 70.8 & 71.9 & 71.7 & 1.1 & 0.9 \\
\hline Georgia & $2,793,796$ & $59,255,018$ & 49.23 & 42.02 & 63.49 & -7.21 & 14.26 & 63.7 & 65.5 & 63.4 & 1.8 & -0.3 \\
\hline Hawaii & 56,543 & 796,124 & 49.86 & 36.47 & 42.80 & -13.40 & -7.06 & 75.9 & 75.525 & 75.775 & -0.375 & -0.125 \\
\hline Idaho & $4,458,572$ & $31,813,425$ & 23.87 & 25.72 & 17.64 & 1.85 & -6.23 & 45.1 & 43.4 & 43.7 & -1.7 & -1.4 \\
\hline Illinois & $21,884,061$ & $3,013,676,723$ & 39.96 & 30.11 & 42.49 & -9.85 & 2.53 & 52.3 & 55.8 & 51.1 & 3.5 & -1.2 \\
\hline Indiana & $11,142,705$ & $1,153,559,349$ & 42.38 & 33.83 & 45.14 & -8.55 & 2.76 & 52 & 55.1 & 51.2 & 3.1 & -0.8 \\
\hline Iowa & $23,608,469$ & $1,982,810,673$ & 34.76 & 25.61 & 34.44 & -9.15 & -0.32 & 48.1 & 52.1 & 46.7 & 4 & -1.4 \\
\hline
\end{tabular}




\begin{tabular}{|c|c|c|c|c|c|c|c|c|c|c|c|c|}
\hline Kansas & $19,436,263$ & $1,367,207,249$ & 29.02 & 19.29 & 29.03 & -9.73 & 0.01 & 54.7 & 58.2 & 53.7 & 3.5 & -1 \\
\hline Kentucky & $3,536,951$ & $414,181,139$ & 47.9 & 43.21 & 55.78 & -4.69 & 7.88 & 55.9 & 58.4 & 55 & 2.5 & -0.9 \\
\hline Louisiana & $2,899,197$ & $32,105,077$ & 58.88 & 62.88 & 61.43 & 4 & 2.55 & 66.6 & 68.7 & 66.3 & 2.1 & -0.3 \\
\hline Maine & 160,920 & $5,328,987$ & 44.66 & 47.38 & 45.61 & 2.72 & 0.95 & 41.3 & 43.9 & 42 & 2.6 & 0.7 \\
\hline Maryland & $1,282,883$ & $22,221,105$ & 43.62 & 40.38 & 46.01 & -3.24 & 2.39 & 54.8 & 57.5 & 54.7 & 2.7 & -0.1 \\
\hline Massachusetts & 49,500 & $3,619,202$ & 48.48 & 41.78 & 46.39 & -6.7 & -2.09 & 48.1 & 51.4 & 48.8 & 3.3 & 0.7 \\
\hline Michigan & $5,653,212$ & $213,231,634$ & 32.94 & 31 & 38.23 & -1.94 & 5.29 & 44.9 & 48.4 & 44.1 & 3.5 & -0.8 \\
\hline Minnesota & $17,182,255$ & $244,790,176$ & 27.92 & 26.17 & 29.01 & -1.75 & 1.09 & 41.5 & 45.2 & 39.3 & 3.7 & -2.2 \\
\hline Mississippi & $3,625,115$ & $52,444,757$ & 57.21 & 59.16 & 62.93 & 1.95 & 5.72 & 63.7 & 65.7 & 63.1 & 2 & -0.6 \\
\hline Missouri & $9,639,962$ & $1,095,628,163$ & 43.24 & 31.03 & 45.71 & -12.21 & 2.47 & 54.9 & 58.6 & 53.6 & 3.7 & -1.3 \\
\hline Montana & $6,831,334$ & $102,066,956$ & 18.48 & 16.81 & 20.02 & -1.67 & 1.54 & 42.3 & 44.5 & 42.4 & 2.2 & 0.1 \\
\hline Nebraska & $16,509,351$ & $1,529,365,226$ & 23.89 & 13.36 & 23.44 & -10.53 & -0.45 & 49.2 & 52.7 & 48.5 & 3.5 & -0.7 \\
\hline Nevada & 10,033 & 62,567 & 10.62 & 8.88 & 7.46 & -1.74 & -3.16 & 50.5 & 52.4 & 50.5 & 1.9 & 0 \\
\hline New Hampshire & 7,223 & 342,730 & 47.48 & 45.18 & 45.75 & -2.3 & -1.73 & 43.5 & 46.6 & 44.2 & 3.1 & 0.7 \\
\hline New Jersey & 291,745 & $2,776,764$ & 46.36 & 42 & 46.38 & -4.36 & 0.02 & 52.9 & 55.9 & 53.2 & 3 & 0.3 \\
\hline New Mexico & 564,704 & $38,910,626$ & 14.8 & 8.41 & 13.67 & -6.39 & -1.13 & 53.7 & 56 & 53.7 & 2.3 & 0 \\
\hline New York & $3,471,235$ & $67,451,436$ & 42.64 & 39.56 & 43.99 & -3.08 & 1.35 & 45.5 & 48.9 & 45.7 & 3.4 & 0.2 \\
\hline North Carolina & $3,840,628$ & $77,754,113$ & 48.69 & 46.61 & 56.44 & -2.08 & 7.75 & 59 & 60.7 & 58.6 & 1.7 & -0.4 \\
\hline North Dakota & $17,314,459$ & $239,452,764$ & 18.18 & 15.09 & 23.28 & -3.09 & 5.1 & 41 & 44.1 & 38.8 & 3.1 & -2.2 \\
\hline Ohio & $8,744,648$ & $360,247,569$ & 39.45 & 37.28 & 41.69 & -2.17 & 2.24 & 51.2 & 54 & 50.9 & 2.8 & -0.3 \\
\hline Oklahoma & $6,424,307$ & $198,529,011$ & 36.49 & 25.7 & 36.7 & -10.79 & 0.21 & 59.8 & 63.2 & 58.8 & 3.4 & -1 \\
\hline
\end{tabular}




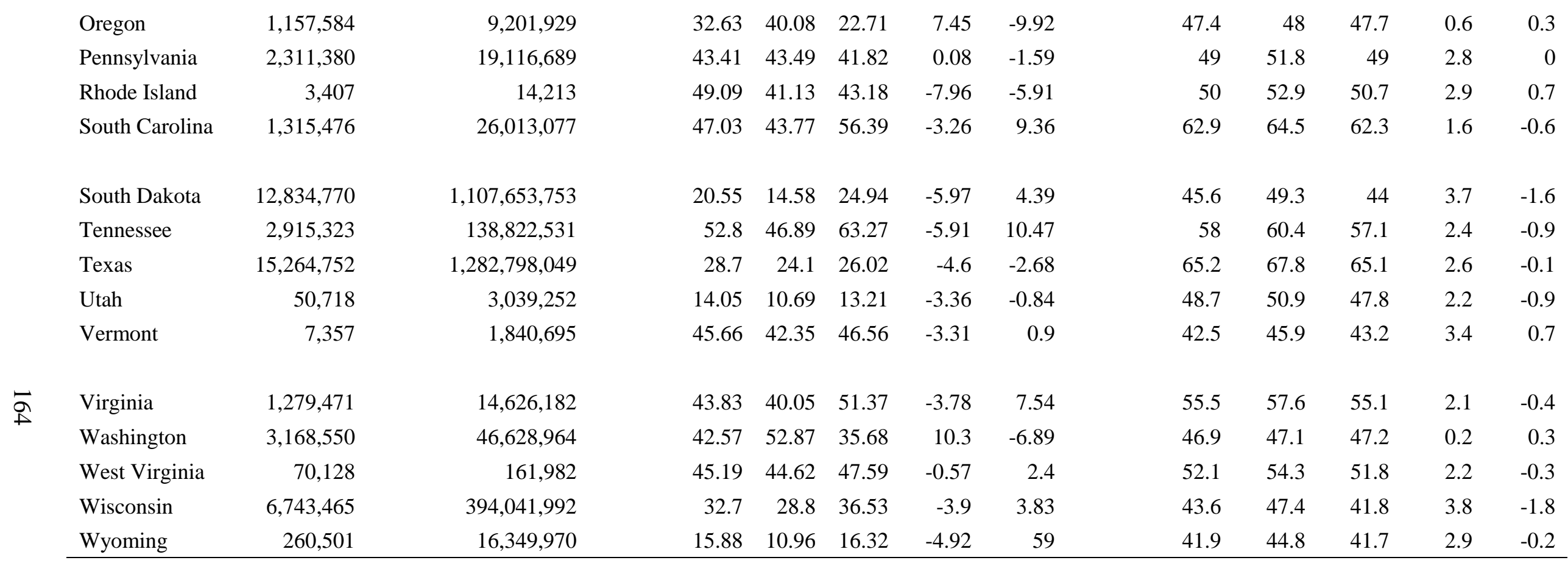

Sources: NOAA and NRDC.

A2012 $=2012-1981-2010$ Average

A2013 $=2013-1981-2010$ Average 
State-average prices for corn and soybeans in 2013 (Dollars per bushel).

\begin{tabular}{|c|c|c|c|}
\hline \multicolumn{2}{|l|}{ Corn for grain } & \multicolumn{2}{|c|}{ Soybeans for beans } \\
\hline State & Price & State & Price \\
\hline Alabama & 4.50 & Alabama & 13.10 \\
\hline Arizona & 6.30 & Arkansas & 13.10 \\
\hline Arkansas & 5.20 & Colorado & $12.50^{\mathrm{a}}$ \\
\hline California & 5.55 & Connecticut & $12.50^{\mathrm{a}}$ \\
\hline Colorado & 4.65 & Delaware & 12.40 \\
\hline Delaware & 4.70 & Florida & 11.90 \\
\hline Florida & 4.55 & Georgia & 13.50 \\
\hline Georgia & 5.35 & Idaho & $12.40^{\mathrm{a}}$ \\
\hline Idaho & 5.70 & Illinois & 12.90 \\
\hline Illinois & 4.50 & Indiana & 12.80 \\
\hline Indiana & 4.25 & Iowa & 12.80 \\
\hline Iowa & 4.60 & Kansas & 12.50 \\
\hline Kansas & 4.55 & Kentucky & 12.90 \\
\hline Kentucky & 4.55 & Louisiana & 13.30 \\
\hline Louisiana & 5.10 & Maine & $12.30^{\mathrm{a}}$ \\
\hline Maryland & 4.70 & Maryland & 12.40 \\
\hline Massachusetts & $4.35^{\mathrm{a}}$ & Michigan & 12.50 \\
\hline Michigan & 4.05 & Minnesota & 12.60 \\
\hline Minnesota & 4.60 & Mississippi & 13.10 \\
\hline Mississippi & 5.35 & Missouri & 12.80 \\
\hline Missouri & 4.55 & Montana & $12.40^{\mathrm{a}}$ \\
\hline Montana & 4.50 & Nebraska & 12.50 \\
\hline Nebraska & 4.55 & New Jersey & 12.40 \\
\hline Nevada & $5.00^{\mathrm{a}}$ & New York & 12.50 \\
\hline New Jersey & 4.65 & North Carolina & 12.90 \\
\hline New Mexico & 5.10 & North Dakota & 12.40 \\
\hline New York & 4.35 & Ohio & 12.60 \\
\hline North Carolina & 4.90 & Oklahoma & 12.60 \\
\hline North Dakota & 4.00 & Pennsylvania & 12.30 \\
\hline Ohio & 4.30 & South Carolina & 12.90 \\
\hline Oklahoma & 5.20 & South Dakota & 12.40 \\
\hline Oregon & 5.60 & Tennessee & 12.80 \\
\hline Pennsylvania & 4.15 & Texas & 12.50 \\
\hline South Carolina & 4.70 & Virginia & 12.80 \\
\hline South Dakota & 4.10 & Washington & $12.40^{\mathrm{a}}$ \\
\hline Tennessee & 4.70 & West Virginia & 12.80 \\
\hline Texas & 5.15 & Wisconsin & 12.30 \\
\hline Utah & 5.35 & Wyoming & $12.40^{\mathrm{a}}$ \\
\hline Virginia & 4.70 & & \\
\hline
\end{tabular}




\begin{tabular}{ll} 
Washington & 5.50 \\
West Virginia & 4.70 \\
Wisconsin & 4.20 \\
Wyoming & 4.15 \\
\hline
\end{tabular}

Notes: Data obtained from the report: Crop Values 2013 Summary by USDA, National Agricultural Statistics Service.

${ }^{a}$ Indicates estimates using prices in neighbor states. 
Links related with USDA 2013 Farm and Ranch Irrigation Survey:

\section{The survey:}

https://www.agcensus.usda.gov/Publications/2012/Online_Resources/Farm_an d_Ranch_Irrigation_Survey/appendix_b.pdf

\section{Online summary:}

https://www.agcensus.usda.gov/Publications/2012/Online_Resources/Farm_an d_Ranch_Irrigation_Survey/

\section{More information:}

https://www.agcensus.usda.gov/Publications/Irrigation_Survey/ 


\section{VITA}

Yubing Fan, son of Jinping Fan and Hongjun Chen, husband of Lin Du, and father of Jasmine Meiya Fan, was born in Dezhou, Shandong Province, China on May 30, 1986. He received his Bachelor of Arts in English from Xi'an Shiyou University, China. Yubing then attended Lanzhou University, China, where he received his Master of Agricultural Extension in Rural and Regional Development. During his master period, he studied as an exchange student at Texas Tech University. Yubing continued his graduate study at the University of Missouri - Columbia, where he worked on his Doctor of Philosophy degree. His general research interests concern production economics, and environmental and resource economics. Yubing is currently working on agricultural water management, adoption of irrigation systems and related farm management practices, and water policy. 